2017

\title{
Studies of Aqueous Hydrogen Sulfide Corrosion in Producing SAGD Wells
}

\author{
Pehlke, Trent
}

Pehlke, T. (2017). Studies of Aqueous Hydrogen Sulfide Corrosion in Producing SAGD Wells (Unpublished master's thesis). University of Calgary, Calgary, AB. doi:10.11575/PRISM/27911 http://hdl.handle.net/11023/3904

Downloaded from PRISM Repository, University of Calgary 


\title{
UNIVERSITY OF CALGARY
}

Studies of Aqueous Hydrogen Sulfide Corrosion in Producing SAGD Wells

by

Trent Pehlke

\begin{abstract}
A THESIS
SUBMITTED TO THE FACULTY OF GRADUATE STUDIES

IN PARTIAL FULFILMENT OF THE REQUIREMENTS FOR THE

DEGREE OF MASTER OF SCIENCE
\end{abstract}

GRADUATE PROGRAM OF MECHANICAL ENGINEERING

CALGARY, ALBERTA

June, 2017

(C) Trent Pehlke 2017 


\begin{abstract}
In this research lab and field corrosion coupon testing was completed to determine corrosion rates on relevant Steam Assisted Gravity Drainage (SAGD) metals. Evaluating how rates varied with well depth, environment, and a dominating corrosion mechanism.

Materials tested in the lab were 1018 carbon steel, Deloro-40 and Stellite-6, TN55TH, galvanized (GLV) J-55 and K-55. Field coupon materials included L-80, J-55, and a GLV-J55+J-55 couple.

Corrosion rates decreased from $0.0178 \mathrm{~mm} / \mathrm{y}$ at the wells bottom to $0.0145 \mathrm{~mm} / \mathrm{y}$ at higher elevations. This corresponded to a decrease in iron sulfide (FeS) scale content from the well bottom upwards formed through a solid-state reaction between aqueous $\mathrm{H}_{2} \mathrm{~S}$ and the metal. High average corrosion rates of $0.263 \mathrm{~mm} / \mathrm{y}$ were measured in the lab, compared to the low $0.0183 \mathrm{~mm} / \mathrm{y}$ in field studies. This difference is due to the inhibiting effects of oil in the field which inhibits corrosion rates and the longer test duration.
\end{abstract}




\section{Acknowledgements}

I would like to express my sincere gratitude to my respected supervisor, Dr. Frank Cheng, for his instruction, encouragement and support throughout my whole research career here at the University of Calgary. His enthusiasm, diligence, perception and professional attitude to science and research have been inspiring and guiding me to move forwards in my future life and career. This work was also supported by Suncor Energy, Cormetrics Ltd, Corr Science, and the University of Calgary. Their support and cooperation has been greatly appreciated through the research process.

Appreciations are also worth extending to the members in my group, Dr. Qiang Li, Yuanchao Feng, Yuan Li, Shan Qian, and Yao Yang for their unforgettable support and generous help in this work. 


\section{Dedication}

This work is dedicated to my parents, as well as Leon Fedenczuk, Kristina Hoffmann, and Hugo Acosta-Ramirez for pushing me to pursue graduate studies and their support throughout. 


\section{Table of Contents}

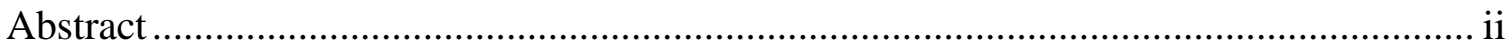

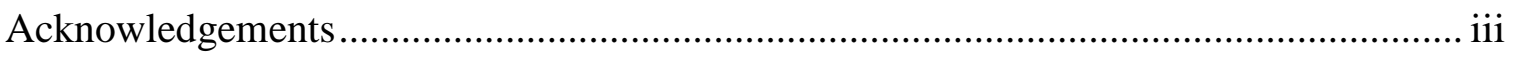

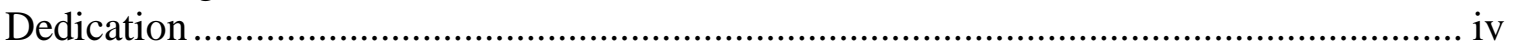

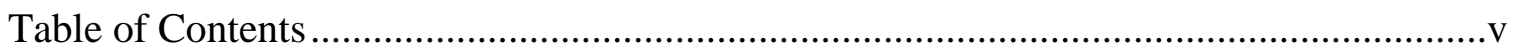

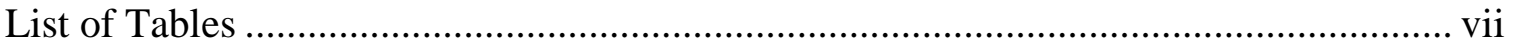

List of Figures and Illustrations .......................................................................... ix

List of Symbols, Abbreviations and Nomenclature................................................... xii

CHAPTER ONE: INTRODUCTION ..................................................................

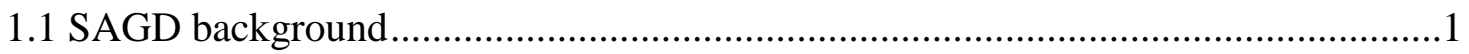

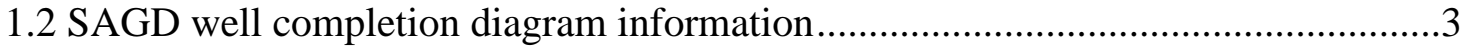

1.3 SAGD produced fluid and gas information ........................................................

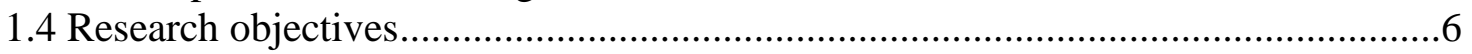

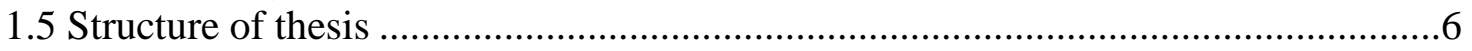

CHAPTER TWO: LITERATURE REVIEW ..............................................................8

2.1 A brief introduction to corrosion during oil production .......................................8

2.1.1 Corrosion as a key mechanism resulting in well failures during oil

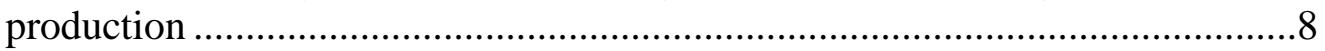

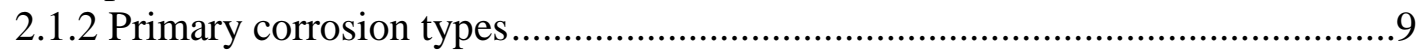

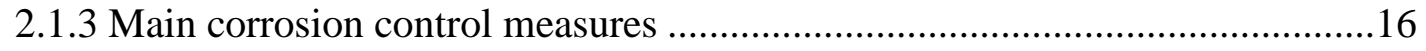

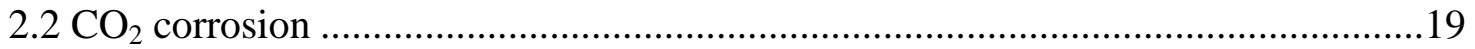

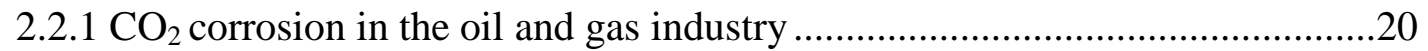

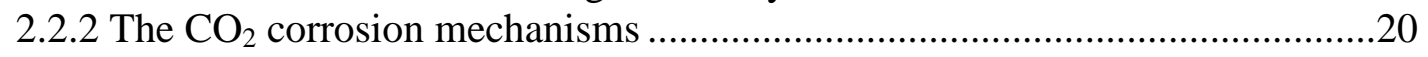

2.2.3 Factors which affect $\mathrm{CO}_{2}$ corrosion .........................................................22

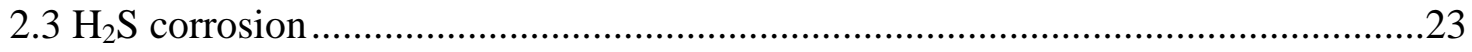

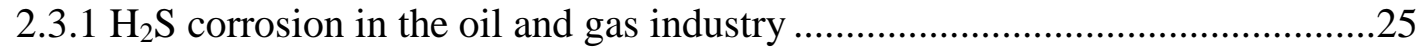

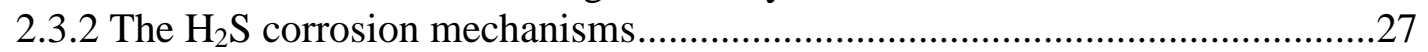

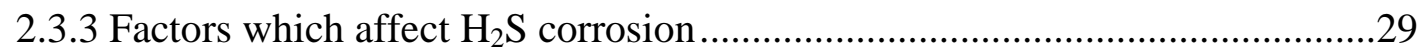

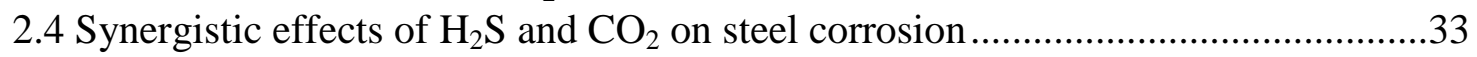

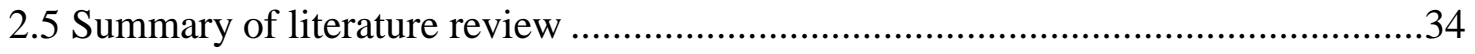

CHAPTER THREE: EXPERIMENTAL TESTING .....................................................36

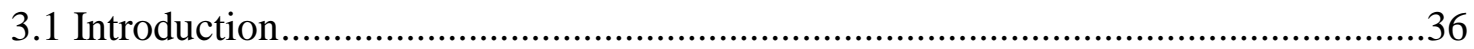

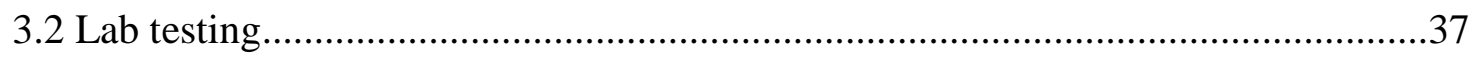

3.2.1 Wellhead material autoclave testing....................................................... 41

3.2.1.1 Autoclave Setup and Measurements...................................................41

3.2.1.2 Coupon materials and autoclave setup..............................................43

3.2.1.3 Solution and testing conditions.....................................................44

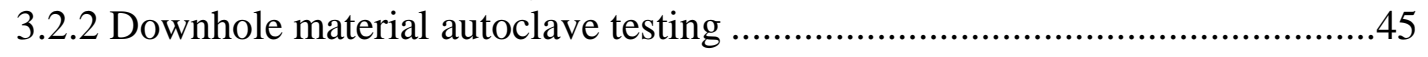

3.2.2.1 Autoclave setup and measurements .................................................46

3.2.2.2 Coupon materials and testing setup ...............................................48

3.2.2.3 Solution and testing conditions .....................................................49 


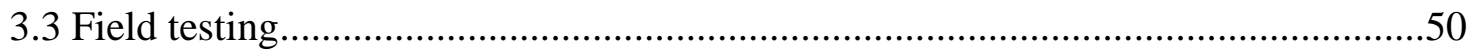

3.3.1 Coupon materials, clamp design, and installation design.................................53

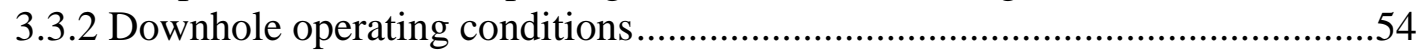

3.3.3 Field testing analysis ......................................................................................5

CHAPTER FOUR: TESTING RESULTS AND ANALYSIS .......................................59

4.1 Lab testing results and analysis .......................................................................59

4.1.1 Wellhead material testing results..................................................................60

4.1.2 Downhole material testing results ................................................................67

4.1.3 Lab testing discussion and summary ............................................................76

4.2 Field testing results and analysis ..........................................................................79

4.2.1 Downhole material pre and post-test acid washing images...............................79

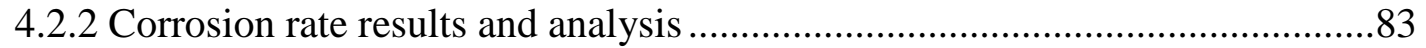

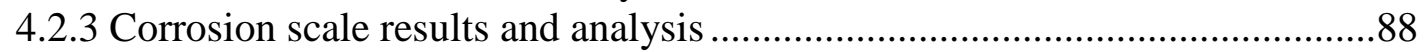

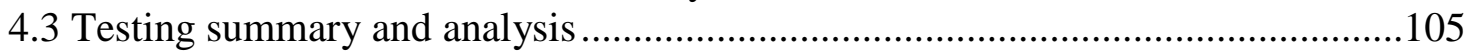

4.3.1 Autoclave testing .......................................................................................106

4.3.1.1 Autoclave wellhead material testing...................................................106

4.3.1.2 Autoclave downhole completion material testing ................................107

4.3.2 Field corrosion coupon testing …………………..........................................110

4.3.3 Combined testing analysis and summary ......................................................112

CHAPTER FIVE: MECHANISTIC ASPECTS OF METAL CORROSION IN $\mathrm{H}_{2} \mathrm{~S}$ AND CO ${ }_{2}$ SAGD ENVIRONMENTS............................................................115

5.1 Mechanism of hydrogen sulfide corrosion ………………..................................116

5.2 Factors which affect the $\mathrm{H}_{2} \mathrm{~S}$ corrosion mechanism ............................................119

5.2.1 The effect of flow rate and fluid composition ................................................119

5.2.2 The effect of $\mathrm{H}_{2} \mathrm{~S}$ concentration ..............................................................120

5.2.3 The effect of temperature …………………….........................................120

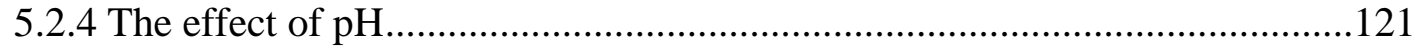

5.3 Implications of mechanistic research..................................................................122

CHAPTER SIX: CONCLUSIONS AND RECOMMENDATIONS …………………....125

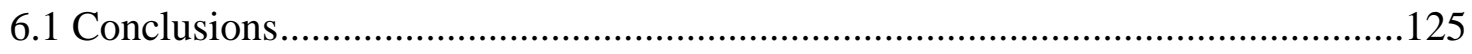

6.2 Recommendations for industry and future work .................................................126

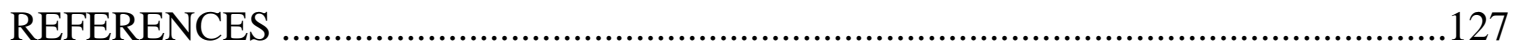

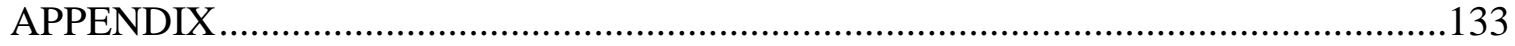




\section{List of Tables}

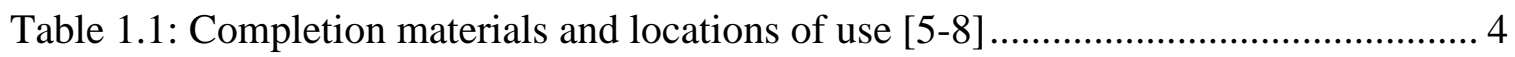

Table 1.2: Average Firebag emulsion composition ...................................................... 4

Table 1.3: Average Firebag produced gas composition................................................... 5

Table 2.1: Common corrosive environments and corrosion resistant material ................ 18

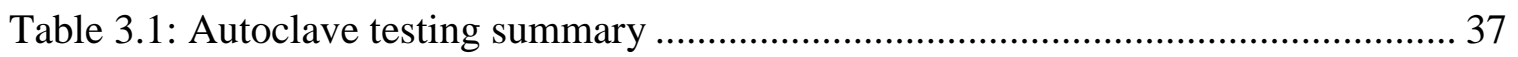

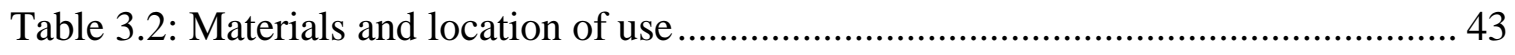

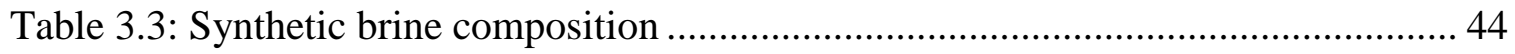

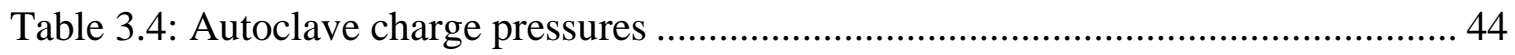

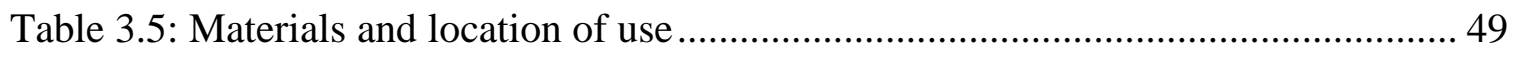

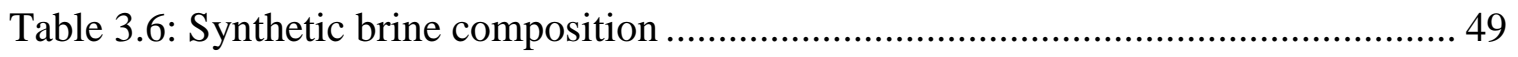

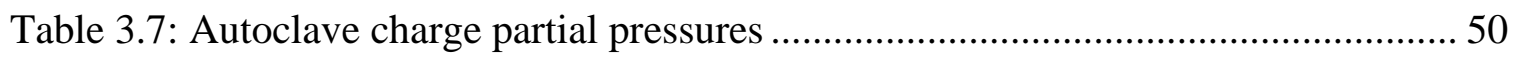

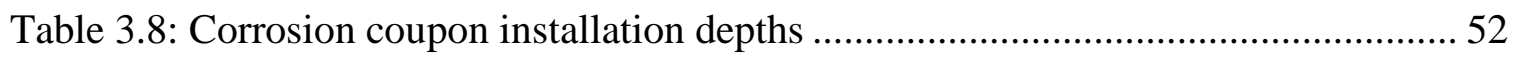

Table 3.9: Field coupon testing summary ............................................................... 53

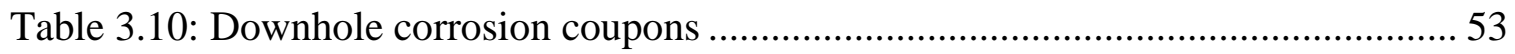

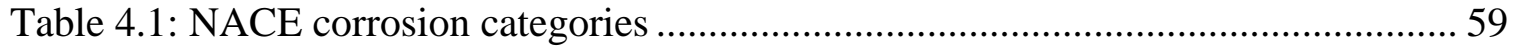

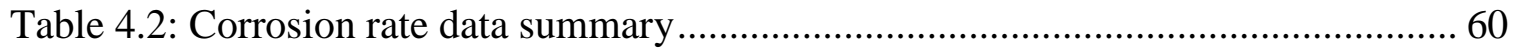

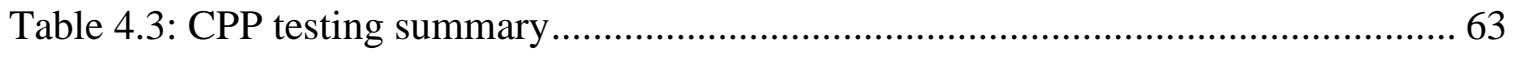

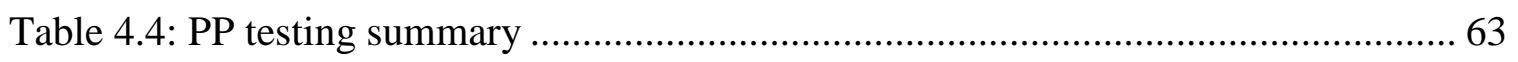

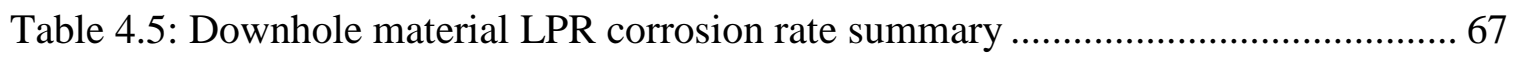

Table 4.6: Downhole material crevice corrosion rate testing summary ........................ 69

Table 4.7: Downhole material galvanic testing corrosion rate summary ….................... 72

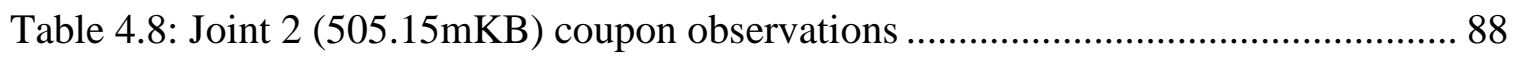

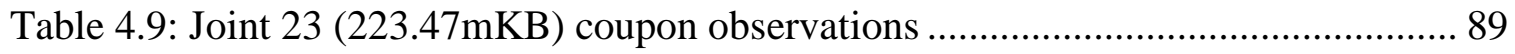




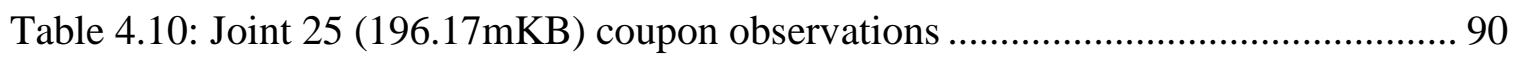

Table 4.11: Joint 2, coupon \#8, J-55, position \#1, deposit analysis.............................. 97

Table 4.12: Joint 12, coupon \#9, L-80, position \#2 deposit analysis.............................. 98

Table 4.13: Joint 12, coupon \#20, J-55, position \#1 deposit analysis............................. 98

Table 4.14: Joint 12, coupon \#47, GLV J-55, position \#3 deposit analysis .................... 99

Table 4.15: Joint 12, coupon \#49, J-55, position \#3 deposit analysis........................... 100

Table 4.16: Joint 23, coupon \#9, J-55, position \#1 deposit analysis............................. 100

Table 4.17: Joint 24, coupon \#18, L-80, position \#2 deposit analysis........................... 100

Table 4.18: Joint 24, coupon \#16, J-55, position \#1 deposit analysis............................ 101

Table 4.19: Joint 24, coupon \#35, GLV J-55, position \#3 deposit analysis ................... 102

Table 4.20: Joint 24, coupon \#33, J-55, position \#3 deposit analysis........................... 102

Table 4.21: Joint 25, coupon \#22, J-55, position \#1 deposit analysis............................ 103

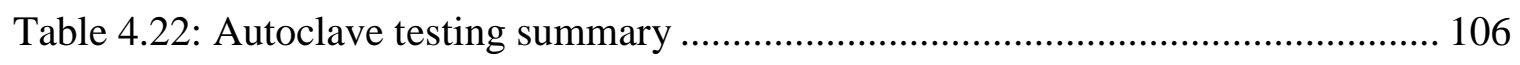




\section{List of Figures and Illustrations}

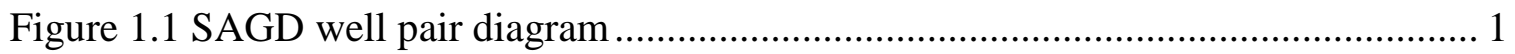

Figure 1.2: Typical Firebag production well completion diagram ................................. 3

Figure 2.1: Magnified cable pitting corrosion example (10X magnification) [17] .......... 12

Figure 2.2: Intergranular SCC (500X magnification) (left) and trans-granular SCC

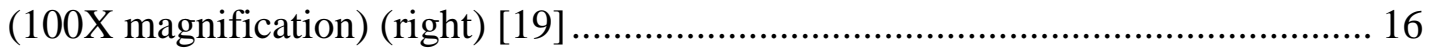

Figure 2.3: NACE MR0175/ISO 15156 - Materials for use in $\mathrm{H}_{2} \mathrm{~S}$ containing

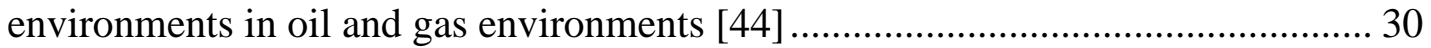

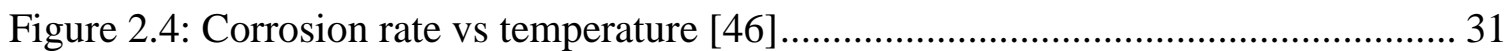

Figure 2.5: Corrosion scale depending on temperature vs $\mathrm{H}_{2} \mathrm{~S}$ activity [46].................. 32

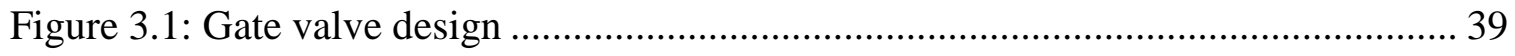

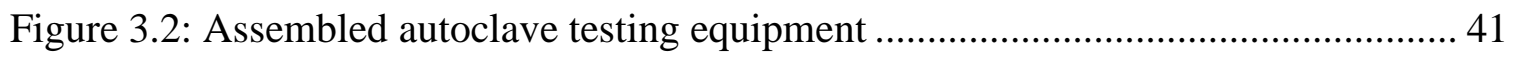

Figure 3.3: Crevice washer and electrode assembly ................................................ 42

Figure 3.4: Autoclave lid for general LPR testing .................................................... 46

Figure 3.5: Galvanized J-55 \& K-55 coupon pair tied at the base................................. 47

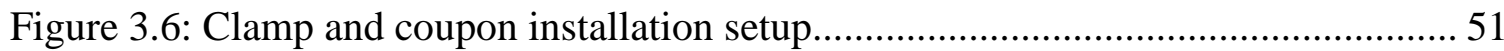

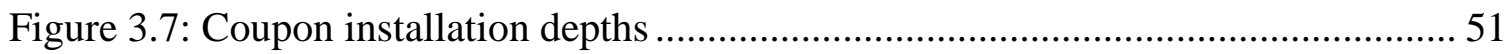

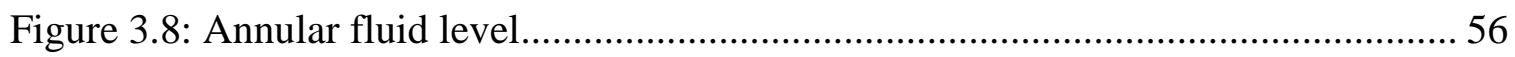

Figure 3.9: Bottom hole and casing surface pressures............................................ 57

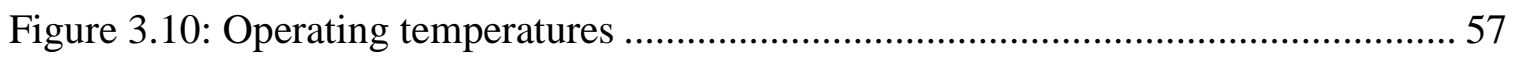

Figure 4.1: Wellhead material LPR autoclave crevice corrosion testing........................ 60

Figure 4.2: Magnified LPR autoclave crevice corrosion testing trend ........................... 61

Figure 4.3: Post-test weight loss data and electrode photographs ............................... 61

Figure 4.4: Deloro-40 HF CPP data (Solid - Anodic, Dashed - Cathodic Sweeps) ........ 64

Figure 4.5: Stellite-6 HF CPP data (Solid - Anodic, Dashed - Cathodic Sweeps) .......... 64 
Figure 4.6: Deloro-40 HF and Stellite-6 HF potentiostatic test data ............................. 66

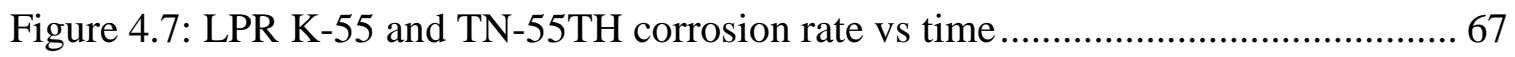

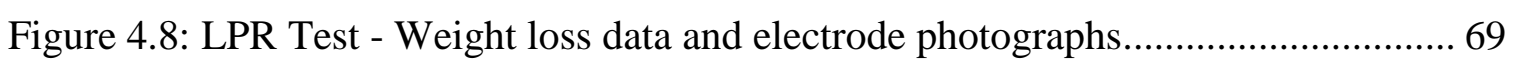

Figure 4.9: Crevice test - Weight loss data and electrode photographs ......................... 70

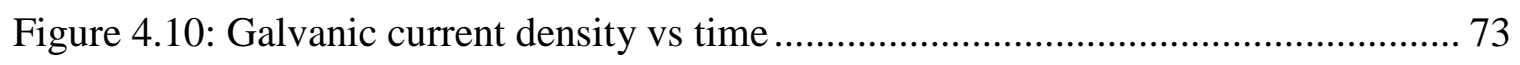

Figure 4.11: Galvanic coupled open circuit potential vs time .................................... 73

Figure 4.12: Galvanic test - Weight loss data and electrode photographs...................... 74

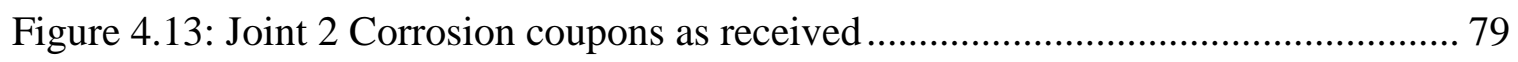

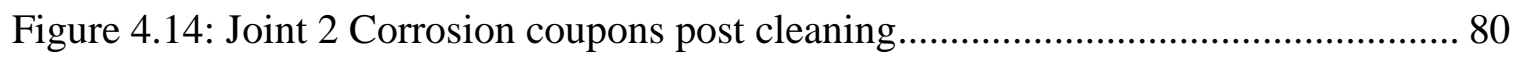

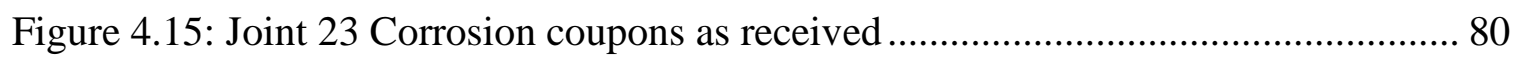

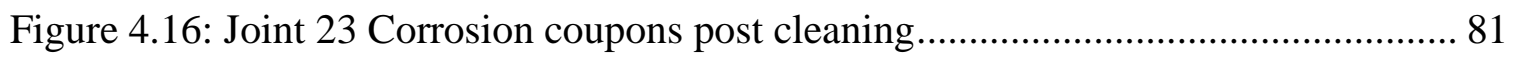

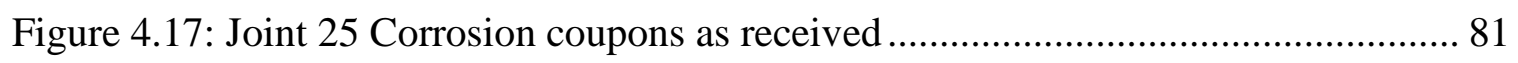

Figure 4.18: Joint 25 Corrosion coupons post cleaning ........................................... 82

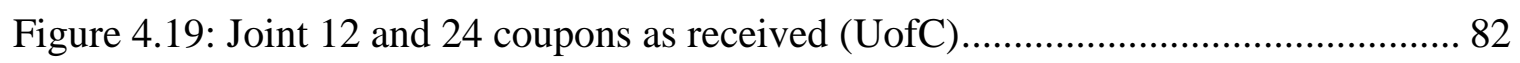

Figure 4.20: Weight loss by depth and varying material ......................................... 84

Figure 4.21: Corrosion rate by depth and varying material ........................................ 85

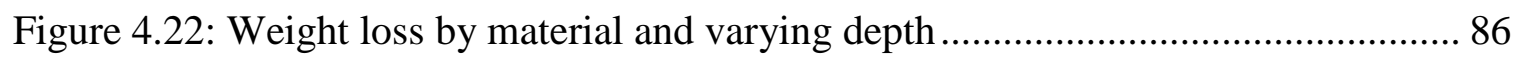

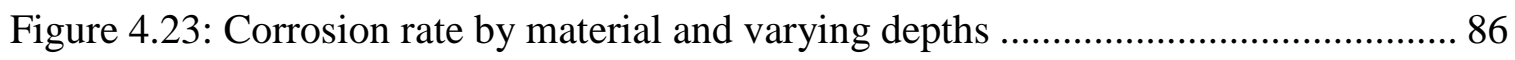

Figure 4.24: Joint 12, J-55 at 372.47 mKB SEM; (Coupon 20) .................................... 92

Figure 4.25: Joint 24, J-55 at 209.76 mKB SEM; (Coupon 16) ................................... 92

Figure 4.26: Joint 12, L-80 at 372.47 mKB SEM; (Coupon 9) ..................................... 93

Figure 4.27: Joint 24, L-80 at 209.76 mKB SEM; (Coupon 18) .................................. 94

Figure 4.28: Joint 12, J-55 at 372.47 mKB SEM; (Coupon 49) .................................... 95

Figure 4.29: Joint 24, J-55 at 209.76 mKB SEM; (Coupon 33) .................................... 95 
Figure 4.30: Joint 12, GLV-J55 at 372.47 mKB SEM; (Coupon 47)............................. 96

Figure 4.31: Joint 24, GLV-J55 at 209.76 mKB SEM; (Coupon 35) ............................. 97

Figure 4.32: Joint 12, coupon \#9, L-80, position \#2 deposit analysis ............................. 98

Figure 4.33: Joint 12, coupon \#20, J-55, position \#1 deposit analysis ........................... 99

Figure 4.34: Joint 12, coupon \#47, GLV J-55, position \#3 deposit analysis ................... 99

Figure 4.35: Joint 12, coupon \#49, J-55, position \#3 deposit analysis ......................... 100

Figure 4.36: Joint 24, coupon \#18, L-80, position \#2 deposit analysis ......................... 101

Figure 4.37: Joint 24, coupon \#16, J-55, position \#1 deposit analysis .......................... 101

Figure 4.38: Joint 24, coupon \#35, GLV J-55, position \#3 deposit analysis .................. 102

Figure 4.39: Joint 24, coupon \#33, J-55, position \#3 deposit analysis ......................... 103 


\section{List of Symbols, Abbreviations and Nomenclature}

\begin{tabular}{|c|c|}
\hline Symbol & Definition \\
\hline AP & Anodic Protection \\
\hline BHP & Bottom Hole Pressure \\
\hline$c_{b, H_{2} S}, c_{s, H_{2} S}$ & $\begin{array}{l}\mathrm{H}_{2} \mathrm{~S} \text { concentrations in the bulk solution and } \\
\text { locally at the steels surface respectively, } \\
\mathrm{mol} / \mathrm{m}^{3}\end{array}$ \\
\hline $\mathrm{CP}$ & Cathodic Protection \\
\hline СРP & Cyclic Potentiodynamic Polarization \\
\hline CRA & Corrosion Resistant Alloy \\
\hline$C R_{\mathrm{H}_{2} \mathrm{~S}}$ & Corrosion rate as $\mathrm{mol} / \mathrm{m}^{2} \mathrm{~s}$ \\
\hline CS & Carbon Steel \\
\hline$D_{\left(H_{s} S\right)}$ & Diffusion transfer coefficient of $\mathrm{H}_{2} \mathrm{~S}$ in water \\
\hline$\overline{E_{\text {prot }}}$ & Re-Passivation Potential \\
\hline $\mathrm{E}_{\text {Pit }}$ & Pitting Potential \\
\hline ESP & Electric Submersible Pump \\
\hline GLV & Galvanized Coating \\
\hline HE & Hydrogen Embrittlement \\
\hline HIC & Hydrogen Induced Cracking \\
\hline HTHP & High Temperature High Pressure \\
\hline$k_{m\left(H_{s} S\right)}$ & $\begin{array}{l}\text { Mass transfer coefficient of } \mathrm{H}_{2} \mathrm{~S} \text { in liquid } \\
\text { boundary layer in } \mathrm{m} / \mathrm{s}\end{array}$ \\
\hline LPR & Linear Polarization Resistance \\
\hline $\mathrm{mKB}$ & Meters Kelly Bushing \\
\hline $\mathrm{mm} / \mathrm{y}$ & Millimeter per year \\
\hline MPY & Mils per year \\
\hline OCP (E $\left.E_{O C}\right)$ & Open Circuit Potential \\
\hline$P_{\mathrm{CO}_{2}}$ & $\mathrm{CO}_{2}$ Partial Pressure \\
\hline$P_{\mathrm{H}_{2} \mathrm{~S}}$ & $\mathrm{H}_{2} \mathrm{~S}$ Partial Pressure \\
\hline $\mathrm{PP}$ & Potentiostatic Polarization \\
\hline ppmv & parts per million by volume \\
\hline PTFE & Polytetrafluoroethylene \\
\hline SAGD & Steam Assisted Gravity Drainage \\
\hline SCC & Stress Corrosion Cracking \\
\hline TSR & Thermochemical Sulphate Reduction \\
\hline VCI & Volatile Corrosion Inhibitors \\
\hline $\mathrm{WL}$ & Weight Loss \\
\hline ZRA & Zero Resistance Ammeter \\
\hline$\varphi$ & Tortuosity of outer film \\
\hline$\varepsilon^{\prime}$ & Porosity of outer film \\
\hline$\delta_{O S}$ & Outer film thickness, $\mathrm{m}$ \\
\hline
\end{tabular}




\section{Chapter One: Introduction}

\subsection{SAGD background}

SAGD is a high temperature oil recovery technique used to produce bitumen from relatively deep, usually greater than $200 \mathrm{~m}$ [1], heavy oil sands deposits. SAGD is a relatively new and advanced form of oil recovery, where a pair of horizontal wells are drilled into the reservoir with a steam injection well drilled only a few meters above a second production well [2]. Steam is injected into the upper well at temperatures at or above $240^{\circ} \mathrm{C}$ to heat the bitumen and reduce its viscosity from approximately being close to that of a solid ( $>1,000,000 \mathrm{cp})$ down to $\sim 20 \mathrm{cp}$ so that it can drain and be produced economically using one of a variety of artificial lift methods. Figure 1.1 shows a typical SAGD drilling and production description diagram.

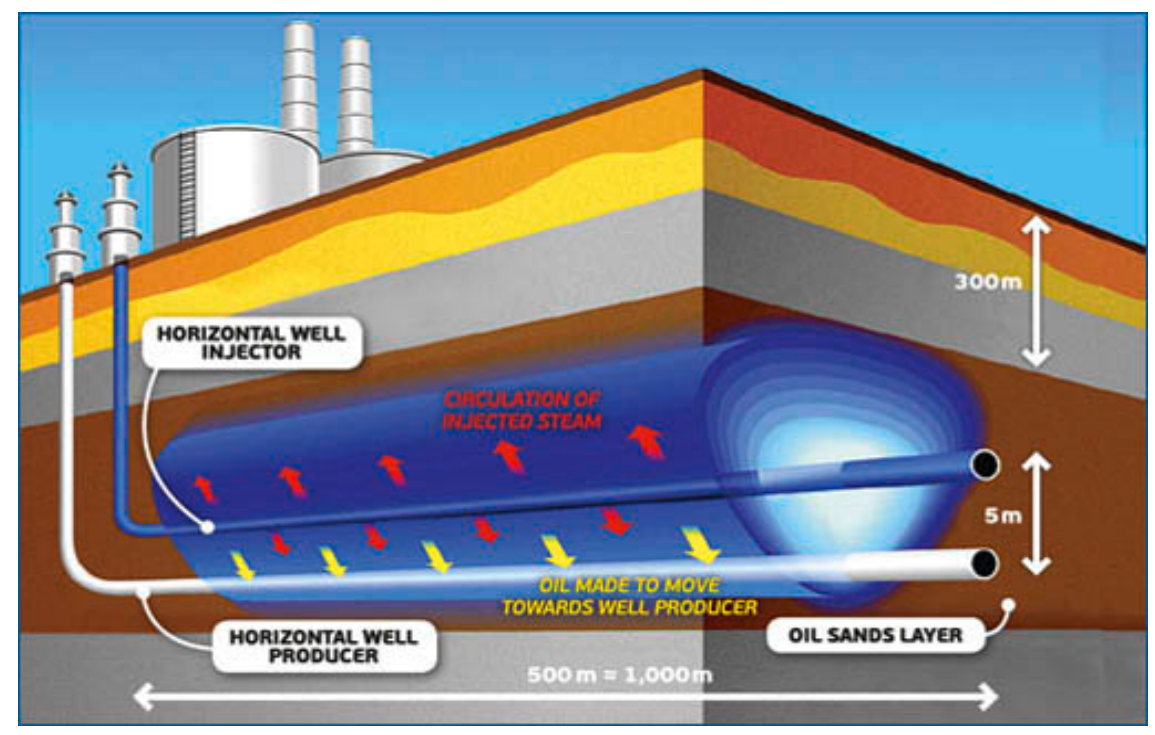

Figure 1.1 SAGD well pair diagram 
With the first full scale SAGD asset having now produced for only 10-15 years, this is a relatively new method of producing oil compared to conventional oil and gas assets which have been producing for 60+ years. As SAGD assets begin to age, downhole well corrosion, well integrity concerns, and other issues are being found and discussed. Well integrity and corrosion concerns can be an issue at several locations within a well, including internally and externally on tubing and casing strings as well as on wellhead components. Downhole completion and tubular materials used in SAGD are similar to those used in conventional oil and gas assets. Materials used include a variety of carbon steels, metal alloys, and corrosion resistant alloy’s (CRA's). The advantage and reason many operations use carbon steel is due to their lower costs. The disadvantage of using standard carbon steel tubulars is that they are susceptible to corrosion, specifically corrosion caused by aqueous acidic gases.

In SAGD, a process known as aquathermolysis [3, 4] takes place and leads to the formation of aqueous acidic gases, including $\mathrm{H}_{2} \mathrm{~S}$ and $\mathrm{CO}_{2}$, both of which are known to be highly corrosive when dissolved in water. Such conditions can be present in SAGD wells, specifically in the annulus of production wells where these gases are able to concentrate in a low flowing or stale environment.

The combination of exposures to aqueous acidic gases, elevated temperatures $\left(>200^{\circ} \mathrm{C}\right)$, and relatively high pressures $(>2000 \mathrm{kPa})$ are known to accelerate localized and general corrosion. Corrosion is likely initiated and accelerated by the presence of galvanic and crevice corrosion cells formed between components. Corrosion control measures commonly used in the oil and gas industry include promoting the formation of passive scales, corrosion inhibitors, upgraded CRA materials, and altering environmental 
conditions. Given the relatively new application and use of SAGD, corrosion in this type of producing environment is not a well understood issue, and limited research has been completed to date to understand the main corrosion mechanisms, corrosion rates, and how to prevent it. The results presented in this thesis are based on the completion types and operating conditions present at Suncor Energy's Firebag SAGD asset.

\subsection{SAGD well completion diagram information}

Figure 1.2 shows an image of a typical SAGD well completion at Firebag. Red indicates the production tubing where the emulsion is produced to surface. The green area is the annulus between the production tubing and production casing. The blue line is the instrumentation (pressure measurement and electrical power lines)

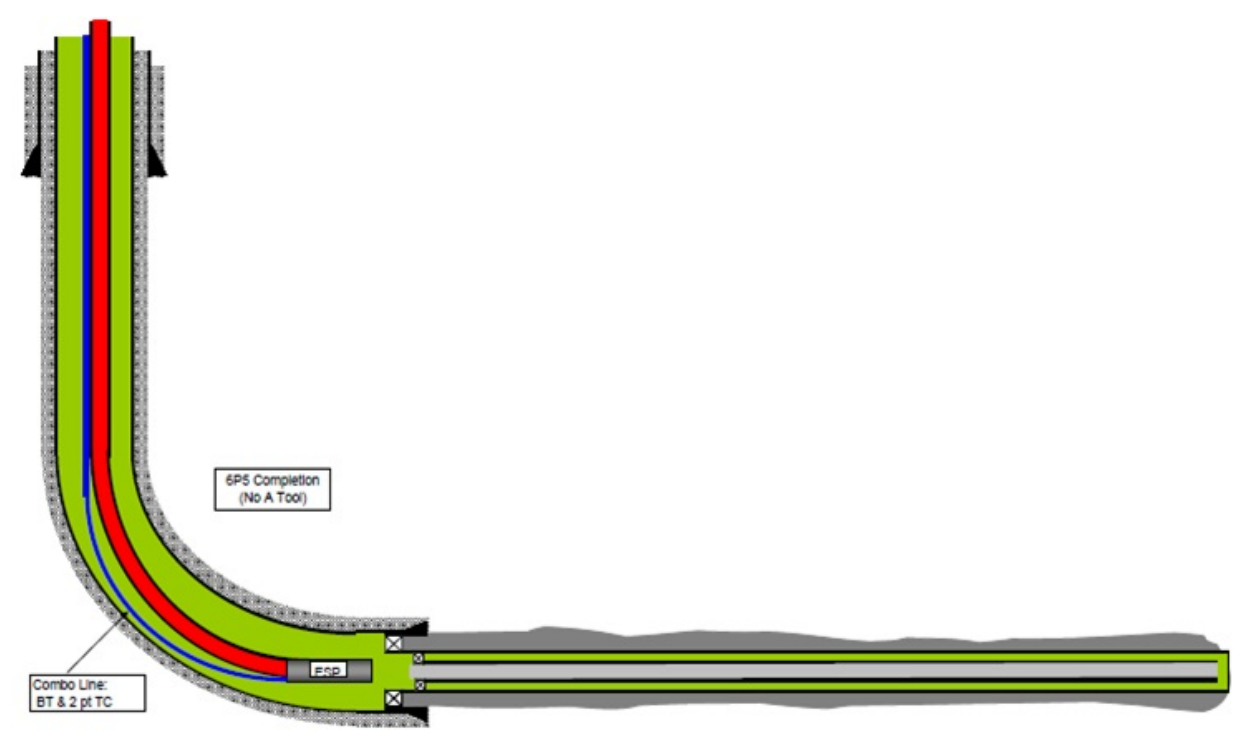

Figure 1.2: Typical Firebag production well completion diagram

In this completion, an electric submersible pump (ESP) is used to artificially lift fluids from the reservoir to surface for further processing in the central plant. Alternative 
artificial lift methods include a process known as gas lift which utilizes injecting an inert gas to lift fluids to the surface by reducing the downhole fluid density and the pressure required to lift the fluid to surface. Inert gases commonly used are methane or natural gas.

Tubular and completion components and materials commonly used in SAGD are shown in Table 1.1:

Table 1.1: Completion materials and locations of use [5-8]

\begin{tabular}{|l|l|}
\hline Material & Location of Use \\
\hline J-55/K-55/TN-55TH/L-80 & Casing and Tubing \\
\hline Galvanized J-55 and/or Galvanized K-55 & Clamps and Cables \\
\hline Deloro-40 HF & Gate Valve Gate Face \\
\hline Stellite-6HF & Gate Valve Gate Seat \\
\hline 1018 Carbon Steel & General use \\
\hline
\end{tabular}

\subsection{SAGD produced fluid and gas information}

Table 1.2 and Table 1.3 list the typical produced fluid and gas compositions from a SAGD well during oil production $[9,10]$.

Table 1.2: Average Firebag emulsion composition

\begin{tabular}{|l|r|}
\hline Component & Relative Concentration (mass \%) \\
\hline Water & $50-95$ \\
\hline Oil & $5-30$ \\
\hline Gas & $1-15$ \\
\hline Solids & $<5$ \\
\hline
\end{tabular}




\section{Table 1.3: Average Firebag produced gas composition}

\begin{tabular}{|l|r|}
\hline Compound & Concentration (mol fraction \%) \\
\hline $\mathrm{CH}_{4}$ & $40-70$ \\
\hline $\mathrm{CO}_{2}$ & $35-55$ \\
\hline $\mathrm{H}_{2} \mathrm{~S}$ & $1-15$ \\
\hline $\mathrm{N}$ & $<1.5$ \\
\hline $\mathrm{H}$ & $<1$ \\
\hline
\end{tabular}

As can be seen, the emulsion consists mostly of water with lesser amounts of oil, gas, and solids, which are typically sands produced from the reservoir. The produced water is a combination of condensed water from the re-produced steam as well as formation (connate) water already in place. Produced water samples have shown to be non-saline, salt free, with limited amount of chlorides present. Both salt and chlorides are known to accelerate corrosion of metals. Produced gases from the reservoir consist mostly of methane $\left(\mathrm{CH}_{4}\right)$, relatively high concentrations of $\mathrm{CO}_{2}$, and in the case of Suncor's Firebag Asset, higher concentrations of $\mathrm{H}_{2} \mathrm{~S}$. Lesser amount of nitrogen $\left(\mathrm{N}_{2}\right)$ and hydrogen $\left(\mathrm{H}_{2}\right)$ are also produced. The ratio and quantities of these gases can vary from site to site depending on reservoir properties, production conditions, and asset age [4].

Aqueous $\mathrm{CO}_{2}$ and $\mathrm{H}_{2} \mathrm{~S}$ are produced from oil and gas fields around the world and are known to cause corrosion related completion, facility, and reliability issues. This type of corrosion has been well studied in conventional oil and gas assets and has led to numerous material, corrosion inhibitor, and production operation advancements to prevent and mitigate the corrosion process.

The corrosive environment in producing SAGD assets is different and unique from most conventional assets. This is due to the combination of high temperatures, relatively 
high pressures, the relative quantities of $\mathrm{CO}_{2}$ and $\mathrm{H}_{2} \mathrm{~S}$, and the completion designs used.

For this reason, further studies are required to understand the potential for corrosion.

\subsection{Research objectives}

The objective of this research is to better understand the corrosion rates present in the annulus of producing SAGD wells through lab and field tests, and to determine the likely corrosion mechanisms in order to evaluate the severity of corrosion in SAGD wells. Progress has been made in the following areas:

- The potential corrosion rates in the annulus of producing SAGD wells on common completion materials. Materials include carbon steel, J-55, K-55, TH-55TH, and galvanized materials, and different hard facing overlay finishes

- A better understanding of the corrosion product characteristics and composition

- Changes in corrosion product composition with well depth

- Changes in corrosion rates at different well depths

- Relating findings and results to known corrosion mechanisms to recommend mitigating strategies and measures

\subsection{Structure of thesis}

The thesis contains seven chapters, with Chapter 1 giving an introduction of the research background and objectives.

Chapter 2 is a comprehensive review of literature relevant to this research. This includes a discussion on aqueous $\mathrm{CO}_{2}$ and $\mathrm{H}_{2} \mathrm{~S}$ corrosion mechanisms, corrosion rates, 
scale products, and a review of relevant High Temperature High Pressure (HTHP) literature in combined $\mathrm{CO}_{2}$ and $\mathrm{H}_{2} \mathrm{~S}$ gaseous systems.

Chapter 3 outlines the lab and field experimental setups, including material specimens used and the preparation of the material samples and solutions. This includes the autoclave testing parameters, field production conditions, measurement techniques and analysis methods used.

Chapter 4 presents the lab and field testing results on materials commonly used in SAGD production wells, including the corrosion rates and scale products in varied corrosion scenarios.

Chapter 5 outlines the possible corrosion mechanism present to better understand how to possibly predict and prevent corrosion.

Chapter 6 presents conclusions and recommendations based on the research completed. 


\section{Chapter Two: Literature review}

\subsection{A brief introduction to corrosion during oil production}

In 2016 a NACE Impact study was completed, which estimated the annual global cost of corrosion to be US $\$ 2.5$ trillion, of which approximately $\$ 5.6 \mathrm{~B}$ can be attributed to the oil and gas industry [11]. Corrosion is present throughout the production, processing, and consumption cycles of hydrocarbon products. This includes corrosion in downhole wells, processing facilities, refineries, pipelines, and shipping/distribution assets throughout their life cycles from initial construction to final asset abandonment and many years afterwards. While preventing and eliminating corrosion can be very difficult and costly, controlling the corrosion rate through improved products, facility design, and chemicals are the common and economical options to delay the process to a manageable level compared to eliminating it. Corrosion engineers are therefore increasingly involved in designing corrosion prevention systems to estimate their costs and the useful life of equipment. [11].

\subsubsection{Corrosion as a key mechanism resulting in well failures during oil production}

It is integral that producing oil and gas companies take the steps and prevention measures to ensure that well integrity is maintained to prevent well failures throughout the lifecycle of an asset. One of the most common definitions of well integrity is given by NORSOK D-010 as the "application of technical, operational and organizational solutions to reduce risk of uncontrolled release of formation fluids throughout the life cycle of a well” [12]. Uncontrolled releases of a fluid from a well can occur for several 
reasons and happen below or above ground level. Well failure mechanisms leading to uncontrolled releases can be initiated and occur due to operating or maintenance procedures not being followed, improper well design and construction, and corrosion. Historical rates of well "failures" in oil and gas fields can vary from a few percent of wells to $>40 \%$ depending on the wells operating conditions and procedures followed [13, $14]$.

Corrosion is a leading cause of failure as it can attack every component in a well at all stages of its life cycle. This includes all downhole completion components and tubulars from the time a well is initially drilled through to its final abandonment. Corrosion is a common cause of well failures due to the number of initiating and propagation mechanisms that exist and the extreme conditions present. These include the presence of oxygen, acidic gases, water, solids, microbes, varied materials and stresses, chemicals, and elevated temperatures and pressures. All of which are known to initiate and accelerate corrosion.

\subsubsection{Primary corrosion types}

There are 8 known general forms of corrosion. In the oil and gas industry all forms can be found throughout the production to consumption process of oil products [15]. These main forms of corrosion are discussed next along with a brief description of the mechanism and their effects in oil wells and assets. The 8 forms are uniform, galvanic, crevice, pitting, intergrannular, de-alloying, erosion, and stress corrosion cracking. 
Uniform corrosion, or general corrosion, is defined as a type of corrosion that is uniformly distributed over the entire exposed surface of a metal. Uniform corrosion also refers to the corrosion that proceeds at approximately the same rate over the exposed metal surface without appreciable localization. It is recognized by a roughening of the surface and usually by the presence of corrosion products. The mechanism of the attack typically is an electrochemical process that takes place on the surface of the material. Differences in composition or orientation between small areas on the metal surface create local anodes and cathodes that facilitate the corrosion process. The anodic reaction in the corrosion process is always the oxidation reaction (M - "Metal”):

$$
M \leftrightarrow M^{+}+e^{-}
$$

In acidic environments, i.e., $\mathrm{pH}<7$, the cathodic process is mainly the reduction of hydrogen ions:

$$
2 H^{+}+2 e \leftrightarrow H_{2}
$$

In alkaline and neutral, environments with a $\mathrm{pH} \geq 7$, the reduction of dissolved oxygen is the predominant cathodic process:

$$
\mathrm{O}_{2}+2 \mathrm{H}_{2} \mathrm{O}+4 e \leftrightarrow 4 \mathrm{OH}^{-}
$$

With uniform distribution of cathodic reactants over the entire exposed metal surface, reactions (2-2) and/or (2-3) take place in a "uniform" manner and there is no preferential site or location for cathodic or anodic reaction. The cathodes and anodes are located randomly and alternating with time. This results in a relatively uniform loss of thickness of the metals [16]. Uniform corrosion is most often caused by an inappropriate material selected for use in a corrosive environment. General corrosion can be tolerated because the effect of metal loss is relatively easy to assess and allowances can be made in 
the initial design. Protective coatings and/or cathodic protection (CP) are particularly effective in controlling uniform corrosion. Such protection methods, individually or in combination, are commonly used to protect above and below ground oil and gas pipelines from uniform corrosion.

Galvanic corrosion occurs due to the electrical potential difference that exists when dissimilar metals come into contact in a conductive medium, i.e., electrolyte. One metal acts as the anode and the other as the cathode. The electrolyte provides a means for ion migration whereby metallic ions move from the anode to the cathode. The anode metal dissolves into the electrolyte, and deposit collects on the cathodic metal.

Crevice corrosion refers to the localized attack on a metal surface at, or immediately adjacent to, the gap or crevice between two joining surfaces. The gap or crevice can be formed between two metals or a metal and non-metallic material. Outside the gap or without the gap, both metals are resistant to corrosion. The damage caused by crevice corrosion is normally confined to one metal at a localized area within or close to the joining surfaces.

Crevice corrosion is initiated by a difference in concentration of chemical constituents, often oxygen, which set up an electrochemical concentration cell. In the case of oxygen this is a differential aeration cell. Outside of the crevice, at the cathode, the oxygen content and the $\mathrm{pH}$ are higher, but chlorides are lower. Chlorides are also able to concentrate inside the crevice, at the anode, worsening the situation. Ferrous ions form ferric chloride and attack stainless steels rapidly. The $\mathrm{pH}$ and the oxygen content are lower in the crevice than in the bulk water solution, just as they are inside a pit. The $\mathrm{pH}$ inside the crevice may be as low as 2 when the bulk solution is neutral. Once a crevice 
has formed, the propagation mechanism for crevice corrosion is the same as for pitting corrosion. The major factors influencing crevice corrosion are:

- Crevice type: metal-to-metal, metal-to-non-metal

- Crevice geometry: gap size, depth, surface roughness

- Material: alloy composition (e.g. Cr, Mo), structure

- Environment: pH, temperature, halide ions, oxygen

Pitting corrosion is a form of extremely localized corrosion attack that results in holes in the metal which are commonly found in oil and gas operations. A pitting corrosion example is in Figure 2.1 from a field failure inspection on a section of galvanized power cable.

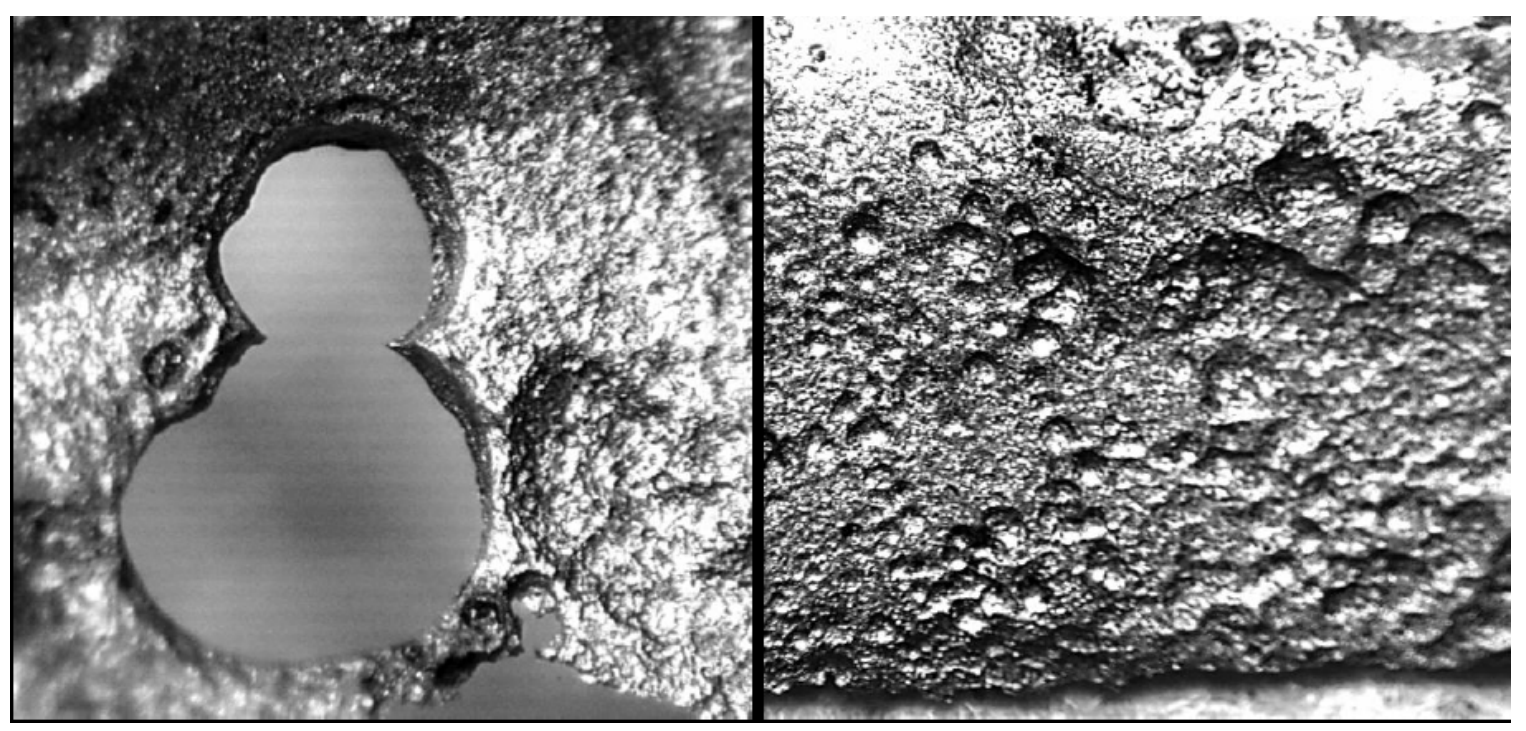

Figure 2.1: Magnified cable pitting corrosion example (10X magnification) [17]

These holes may be small or large in diameter but in most cases, they are relatively small. Pits are sometimes isolated or so close together that they look like a rough surface. 
Generally, a pit may be described as a cavity or hole with the surface diameter about the same as or less than the depth. Pitting is one of the most destructive and insidious forms of corrosion. It is often difficult to detect pits because of their small size and because the pits are often covered with corrosion products. Pitting is particularly aggressive because it is a localized and intensive form of corrosion, and failures often occur with extreme suddenness. Pitting corrosion can be initiated several ways including:

- Localized chemical or mechanical damage to a protective passive film

- Water chemistry factors which can cause breakdown of a passive film are acidity, low dissolved oxygen concentrations (which reduce the protectiveness of oxide films) and high concentrations of chloride [18]

- Localized damage to, or poor application of, a protective coating

- The presence of non-uniformities in the metal structure of the component, e.g. non-metallic inclusions

Intergranular corrosion is localized attack along grain boundaries, or immediately adjacent to grain boundaries, while the bulk of the grains remain largely unaffected. The microstructure of metals and alloys is made up of grains, separated by grain boundaries.

Grain boundary effects are of little or no consequence in most applications or uses of metals. If a metal corrodes, uniform attack occurs since grain boundaries are usually only slightly more reactive than the matrix. However, under certain conditions, grain interfaces are very reactive and intergranular corrosion is caused. Intergranular corrosion attack is usually related to the segregation of specific elements or the formation of a 
compound in the boundary. Corrosion then occurs by preferential attack on the grainboundary phase, or in a zone adjacent to it that has lost an element necessary for adequate corrosion resistance - thus making the grain boundary zone anodic relative to the remainder of the surface. The attack usually progresses along the narrow grain boundary and, in a severe case of grain-boundary corrosion, entire grains may be dislodged due to complete deterioration of their boundaries.

Selective leaching is the removal of one element from a solid alloy by corrosion processes. The most common example is the selective removal of zinc in brass alloys (dezincification). Similar processes occur in other alloy systems in which aluminum, iron, cobalt, chromium, and other elements are removed. Selective leaching is the general term to describe these processes $[19,20]$.

Erosion-corrosion is the acceleration or increase in rate of deterioration or attack on a metal because of relative movement between a corrosive fluid and the metal surface. Generally, this movement is quite rapid, and mechanical wear effects or abrasion are involved. Metal is removed from the surface as dissolved ions, or it forms solid corrosion products which are mechanically swept from the metal surface. The increased turbulence caused by pitting on the internal surfaces of a tube can result in rapidly increasing erosion rates and eventually a leak.

Materials selection plays an important role in minimizing erosion corrosion damage. Caution is in order when predicting erosion corrosion behavior based on hardness. High hardness in a material does not necessarily guarantee a high degree of resistance to erosion corrosion. 
Erosion corrosion is characterized in appearance by grooves, gullies, waves, rounded holes, and valleys, and usually exhibits a directional pattern. In many cases, failures caused by erosion corrosion occur in a relatively short time, and they are unexpected largely because corrosion evaluation testing is completed under static conditions or because the erosion effects were not considered. Prevention methods include increasing material thickness in areas prone to erosion, improved materials, removing particles and solids, and improving system design to reduce fluid velocity as well as preventing turbulent flow.

Stress-corrosion cracking (SCC) refers to material cracking caused by the simultaneous presence of a tensile stress, a specific corrosive medium, and a susceptible material. The stresses that cause SCC can be produced as a result from externally applied stresses or from residual stresses introduced during manufacturing. The stresses required to cause SCC are typically small and well below the materials yield strength in an aggressive aqueous environment. Cracks often initiate at pre-existing surface flaws/discontinuities, corrosion pits, or dislocation slip lines and steps. Crack propagation is typically intergranular or trans-granular in nature but it can also be a combination of the two. Examples of each are shown in Figure 2.2 [19]. 


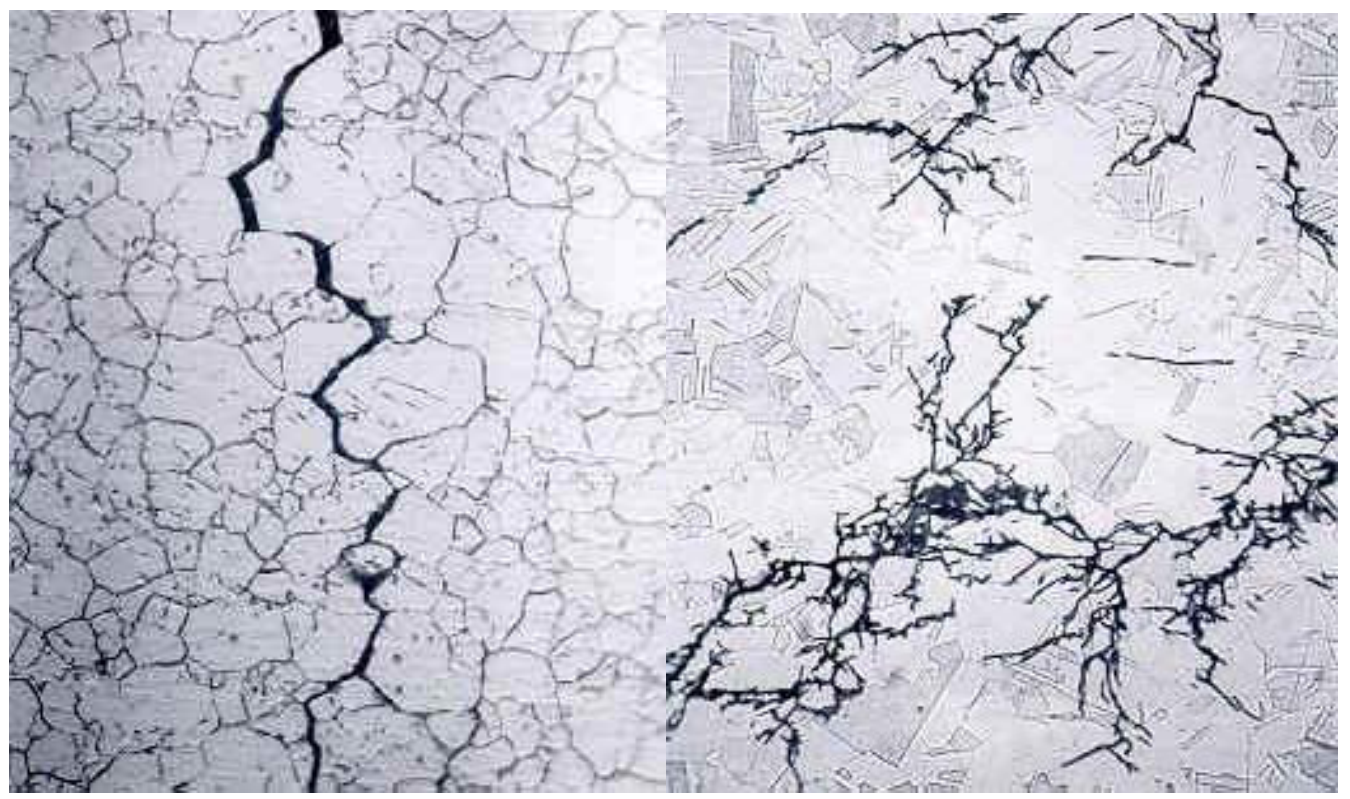

Figure 2.2: Intergranular SCC (500X magnification) (left) and trans-granular SCC (100X magnification) (right) [19]

During SCC, the metal or alloy is virtually unattacked over most of its surface while fine cracks progress through it. This cracking phenomenon has serious consequences since it can occur at stresses within the range of typical design stress.

\subsubsection{Main corrosion control measures}

Significant measures are taken to prevent, limit, and delay corrosion. These include: corrosion inhibition, coating applications, improving or altering materials, cathodic and anodic protection system implementation, and by altering and improving the environment and conditions present.

A corrosion inhibitor is a substance which, when added in a small concentration to an environment, reduces the corrosion rate of a metal exposed to that environment. Inhibitors often play an important role in the oil and gas industries throughout extraction 
and processing. Here, and in many other industries, they have been considered to be the first line of defence against corrosion due to the extreme environments and processes required as well as material limitations. Inhibitors often work by adsorbing themselves on the metallic surface and protecting the metallic surface by forming a film. Inhibitors are normally distributed and dispersed from a solution but they can also be included during a protective coatings formulation. Inhibitors slow corrosion processes in one of three ways:

- Increasing the anodic or cathodic polarization behavior

- Reducing the movement or diffusion of ions to the metallic surface

- Increasing the electrical resistance of the metallic surface

Anti-corrosion coatings are primarily applied for the protection of solid metal surfaces, and occasionally some non-metals. The main functions of surface coatings are to act as an insulating barrier that eliminates the likelihood of contact between a substrate and electrolytes in the working environment, thus preventing the likely electrochemical reaction that can cause corrosion. When selecting a suitable corrosion protection system one must consider the nature of the corrosive environment faced by the assets to be protected, such as pipelines, structures, vehicles, ships, bridges, plant equipment, and buildings as well as the environment in which it is located. Desirable coating characteristics include: effective electrical insulator and moisture barrier, its ability to resist holiday development, good adhesion to pipe and resistance to dis-bonding, ease of repair, good hardness/abrasion, soil stressing, and penetration resistance.

In selecting an appropriate material for corrosion control, the material's corrosion resistance is an important property to consider. The materials most resistant to 
corrosion are those for which corrosion is thermodynamically unfavorable. An optimum material is the least expensive material that can provide the performance which is safe to install and operate, suitable to the application, and economic. To select a material, it is best to review past materials, specific test and material data, and industry experiences. It is also important to consider passive metals, non-metallic metals, and materials close together in the galvanic series when designing a system. Commonly used materials in specific environments are shown in Table 2.1.

Table 2.1: Common corrosive environments and corrosion resistant material

\begin{tabular}{|c|c|c|}
\hline Number & Environment & Material \\
\hline 1 & Nitric Acid & Stainless Steels \\
\hline 2 & Caustic (high pH) & Nickel and Nickel Alloys \\
\hline 3 & Hydrofluoric Acid & Monel (Ni-Cu) \\
\hline 4 & Hot Hydrochloric Acid & Hastelloys (Ni-Cr-Mo) \\
\hline 5 & Dilute Sulfuric Acid & Lead \\
\hline 6 & Non-staining Atm Exposure & Aluminum \\
\hline 7 & Distilled Water & Tin \\
\hline 8 & Hot Strong Oxidizing Solution & Titanium \\
\hline 9 & Ultimate Resistance & Titanium \\
\hline 10 & Concentrated Sulfuric Acid & Steel \\
\hline
\end{tabular}

Cathodic protection (CP) has become a widely used and cost effective method for controlling the corrosion of metallic structures in electrically conducting environments. Such environments contain enough ions to conduct electricity such as soils, seawater and basically all natural waters. Cathodic protection reduces the corrosion rate of a metallic structure by supplying electrical current (or free electrons) from an alternate source. This reduces the structures corrosion potential, bringing the metal closer to an immune state. This converts all the anodic (active) sites on the metal surface to cathodic (passive) sites. 
From thermodynamics point of view, the application of a CP current basically reduces the corrosion rate of a metallic structure by reducing its corrosion potential towards its immune state.

Anodic protection (AP) is a technique to reduce the corrosion of a metal surface by passing an external current to it to cause its electrical potential to become passive and therefore preventing corrosive attack. AP is used to protect metals that exhibit passivation in environments whereby the current density in the freely corroding state is significantly higher than the current density in the passive state over a wide range of potentials. AP is often used to protect mild steel storage vessels containing concentrated acidic or alkaline fluids such as concentrated sulfuric acid [21-23]. AP is only applicable to metals which show active-passive behaviour and can handle more aggressive environments as compared to CP.

Preventing corrosion in the design phase is the best method and required an understanding of its potential and to plan for it by involving a corrosion engineer for a complete project review and analysis.

\section{$2.2 \mathrm{CO}_{2}$ corrosion}

Metals, including steels, do not corrode in dry $\mathrm{CO}_{2}$ gas. However, corrosion can occur in the presence of water where aqueous $\mathrm{CO}_{2}$ forms into carbonic acid which can be highly corrosive, which is often present in oil and gas production systems. 


\subsection{1 $\mathrm{CO}_{2}$ corrosion in the oil and gas industry}

$\mathrm{CO}_{2}$ corrosion is by far the most prevalent form of corrosion attack encountered in upstream oil and gas production [24]. It has been studied extensively in a variety of conditions and environments, both in surface facilities and downhole, due to its prevalence and the severe consequences of a failure [25]. $\mathrm{CO}_{2}$ is produced from, and at times re-injected into [26], oil and gas reservoirs in corrosion promoting conditions. This has led to corrosion studies being completed in many different environmental conditions.

$\mathrm{CO}_{2}$ on its own is a gas, but in the presence of free water can form carbonic acid. Water and water condensates are present in oil and gas production and injection operations leading to the formation of carbonic acid.

A variety of methods are used to prevent and reduce $\mathrm{CO}_{2}$ corrosion. Facilities and operations often rely on the formation of a passive scale, siderite or magnetite, to form. These are known to be stable, adhesive, and non-conductive and prevent corrosion under the right conditions. As long as the film remains intact it is highly protective. In the presence of high velocity turbulent fluids, solids, or other scale impurities the film breaks off and leads to highly accelerate corrosion rates. Other methods include using inhibitors and scavengers, increasing $\mathrm{pH}$ to buffer the carbonic acid, elevated temperatures and flow path design to reduce turbulence. Pitting and mesa corrosion are commonly used terms to describe the morphology and appearance of $\mathrm{CO}_{2}$ corrosion [27].

\subsubsection{The $\mathrm{CO}_{2}$ corrosion mechanisms}

Due to the prevalence in $\mathrm{CO}_{2}$ corrosion occurrence, numerous $\mathrm{CO}_{2}$ corrosion models have been developed and proposed to predict it. An original and one of the most 
widely accepted models for $\mathrm{CO}_{2}$ corrosion was presented in 1975 by DeWaard and Milliams [28]. It outlined a direct reduction of carbonic acid and was based on the dependence of temperature and partial pressure of $\mathrm{CO}_{2}$. Since its original development in 1975, multiple revisions have been made. Alternative models available include Norsok M-506 Model, Hydrocor, Corplus, Cassandra, KSC Model, Multicorp, and several others [29]. These utilize different approaches to account for oil welling factors, protective film formation and adhesion, and the effects of impurities. The fundamental mechanism and reactions for $\mathrm{CO}_{2}$ corrosion are as follows [30].

$$
\begin{gathered}
\mathrm{CO}_{2(g)} \leftrightarrow \mathrm{CO}_{2(a q)} \\
\mathrm{CO}_{2(a q)}+\mathrm{H}_{2} \mathrm{O} \leftrightarrow \mathrm{H}_{2} \mathrm{CO}_{3} \\
\mathrm{H}_{2} \mathrm{CO}_{3} \leftrightarrow \mathrm{H}^{+}+\mathrm{HCO}_{3}^{-} \\
\mathrm{HCO}_{3} \leftrightarrow \mathrm{H}^{+}+\mathrm{CO}_{3}^{2-}
\end{gathered}
$$

Iron carbonate scales can form chemically as above, as well as electrochemically during the corrosion of the steels. The anodic reaction is primarily the oxidation of iron:

$$
\mathrm{Fe} \leftrightarrow \mathrm{Fe}^{2+}+2 e
$$

Cathodic reactions depend on the solutions $\mathrm{pH}$. These are:

$$
\begin{gathered}
\mathrm{H}^{+}+e \rightarrow 0.5 \mathrm{H}_{2}(\mathrm{pH}<4) \\
\mathrm{H}_{2} \mathrm{CO}_{3}+e \rightarrow \mathrm{HCO}_{3}+0.5 \mathrm{H}_{2}(4<\mathrm{pH}<6)
\end{gathered}
$$


For $\mathrm{pH}>6$ the direct reduction of bicarbonate ions and water can be important at low $\mathrm{CO}_{2}$ partial pressures, $\mathrm{P}_{\mathrm{CO} 2}$.

$$
\begin{aligned}
& 2 \mathrm{HCO}_{3}^{-}+2 e \rightarrow 2 \mathrm{CO}_{3}^{2-}+\mathrm{H}_{2} \\
& 2 \mathrm{H}_{2} \mathrm{O}+2 e \rightarrow 2 \mathrm{OH}^{-}+\mathrm{H}_{2}
\end{aligned}
$$

The formation of an iron carbonate scale $\left(\mathrm{FeCO}_{3}\right)$ occurs either chemically or electrochemically when the bicarbonate and carbonate ions $\left[\mathrm{HCO}_{3}{ }^{-}\right]$and $\left[\mathrm{CO}_{3}{ }^{2-}\right]$ exceed the solubility limit. This progresses as follow:

$$
\begin{gathered}
\text { Chemical: } \mathrm{Fe}^{2+}+\mathrm{CO}_{3}{ }^{2-} \leftrightarrow \mathrm{FeCO}_{3} \\
\text { Electrochemical: } \mathrm{Fe}+\mathrm{HCO}_{3}{ }^{-} \leftrightarrow \mathrm{FeCO}_{3}+\mathrm{H}^{+}+e
\end{gathered}
$$

\subsubsection{Factors which affect $\mathrm{CO}_{2}$ corrosion}

The main factor which affects corrosion caused by $\mathrm{CO}_{2}$ is its ability to form an iron carbonate scale. Depending on the type and quality of the scale, it can become very protective and reduce the rate of underlying steel corrosion by blocking the surface and preventing corrosive species from reaching it. The protectiveness of the iron carbonate scale depends on a number of factors. Factors include fluid flow rates, temperature, pressure, $\mathrm{pH}$, as well as the presence of condensates, chlorides, salts and other impurities present in a system.

One of the main factors is the local system temperature. Generally, at ambient temperatures below $60^{\circ} \mathrm{C}$ a non-passive scale can form. This scale is relatively light, thin, non-adhesive, and therefore not protective. When the temperatures are increased to above 
$60^{\circ} \mathrm{C}$ the formed iron carbonate scale is adhesive and dense, providing an effective passive film to protect the underlying steel. At more extreme temperatures, above $150^{\circ} \mathrm{C}$, the scales formed remain protective.

The formation of iron carbonate scale and its structure is also dependent on solution $\mathrm{pH}$. In acidic solutions $(\mathrm{pH}<5)$ a scale is usually not formed. A compact and protective scale is generally formed in near-neutral or alkaline solutions with a $\mathrm{pH}>7$ [31].

The scales formation and protectiveness also depend on the partial pressure of $\mathrm{CO}_{2}$, $P_{\mathrm{CO}_{2}}$. A general rule of thumb used for predicting $\mathrm{CO}_{2}$ corrosion is based on the partial pressure of $\mathrm{CO}_{2}\left(P_{\mathrm{CO}_{2}}=\right.$ fractional mole $\%$ of $\mathrm{CO}_{2} \times$ system pressure $)$ when [31]:

- $P_{\mathrm{CO}_{2}}$ 'is greater than $30 \mathrm{kPa}$, corrosion is very likely

- $P_{\mathrm{CO}_{2}}$ is between 7-30 $\mathrm{kPa}$, corrosion is possible

- $P_{\mathrm{CO}_{2}}$ is less than $7 \mathrm{kPa}$, corrosion is not likely

It is interesting to note that in SAGD steam injection systems with elevated temperatures, between $80^{\circ} \mathrm{C}$ to $250^{\circ} \mathrm{C}$, that $\mathrm{Fe}_{3} \mathrm{O}_{4}$ could also be formed due to reaction of $\mathrm{FeCO}_{3}$ with water, rather than with $\mathrm{O}_{2}$, because the oxygen content is negligibly low in the steam [32].

\section{$2.3 \mathrm{H}_{2} \mathrm{~S}$ corrosion}

Extensive studies have shown that the kinetics of $\mathrm{H}_{2} \mathrm{~S}$ corrosion are controlled by the presence of an iron sulfide, $\mathrm{FeS}$, corrosion product film. $\mathrm{H}_{2} \mathrm{~S}$ corrosion is more 
localized than $\mathrm{CO}_{2}$ corrosion and increasing $\mathrm{H}_{2} \mathrm{~S}$ would not necessarily cause an increase in general corrosion rates, but rather acceleration in localized corrosion rates leaving a material susceptible to catastrophic failure. Forms of $\mathrm{H}_{2} \mathrm{~S}$ corrosion include aqueous $\mathrm{H}_{2} \mathrm{~S}$ corrosion, Hydrogen Induced Cracking (HIC), Hydrogen Embrittlement (HE), and Sulfide Stress Corrosion Cracking (SSCC). $\mathrm{H}_{2} \mathrm{~S}$ corrosion appears to be of major concern in SAGD operations, specifically at Suncors Firebag operation.

HIC can occur in the presence of $\mathrm{H}_{2} \mathrm{~S}$ corrosion due to the formation of the $\mathrm{FeS}$ scale and release of hydrogen atoms into the materials matrix. HIC is caused by the blistering of a metal due to a high concentration of hydrogen atoms diffused into the steels matrix. When a critical amount of hydrogen is accumulated, HIC cracks initiate and propagate [33].

HE occurs when hydrogen gas is absorbed, and diffuses into the metal at local defects. This creates local increases in internal stress causing the material to fail at stresses much less than the materials yield stress [34].

SSCC is generally encountered in high strength steels with Rockwell hardness above 22 and occurs in $\mathrm{H}_{2} \mathrm{~S}$ containing environments. It is similar to $\mathrm{HE}$ with the exception of having $\mathrm{H}_{2} \mathrm{~S}$ being present as the source of Hydrogen. HE and SSCC can be differentiated through applying current. If the specimen becomes anodic, the attack is SSCC. If cracking accelerates in the opposite direction and hydrogen gas forms, the attack is HE [34].

Depending on the environment, different corrosion films can form. Each film having distinct properties and morphology [35]. Environmental conditions which can affect these include $\mathrm{H}_{2} \mathrm{~S}$ concentration, temperature, pressure, $\mathrm{H}_{2} \mathrm{~S}$ activity, $\mathrm{pH}$, fluid flow 
rate and composition. Forms of scales include mackinawite, pyrrhotite, pyrite, troilite, and cubic $\mathrm{FeS}$. The morphology of $\mathrm{FeS}$ will vary depending on the environmental conditions present.

\subsection{1 $\mathrm{H}_{2} \mathrm{~S}$ corrosion in the oil and gas industry}

It is well known that sour oil and gas reservoirs can produce hydrogen sulfide and lead to the corrosion of downhole tubulars and surface facility infrastructure. Given the prevalence of $\mathrm{H}_{2} \mathrm{~S}$ corrosion and its severe failure consequences extensive reviews and laboratory research [36] has been completed to understand and prevent corrosion in sour oil and gas operations [37]. Sour oil and gas fields have now been operating for more than 50 years and are classified as ones in which gas phase concentrations of $\mathrm{H}_{2} \mathrm{~S}$ are greater than 3 parts per million by volume (ppmv) [38].

Several mechanisms exist which can lead to the release and production of $\mathrm{H}_{2} \mathrm{~S}$ from oil and gas reservoirs. As noted in section 1.3 one common mechanism which can release $\mathrm{H}_{2} \mathrm{~S}$ when high temperature processes are used, such as SAGD and Cyclic Steam Stimulation (CSS), is through a process known as aquathermolysis. Elevated temperatures decompose the organic sulfur compounds found in oil sands bitumen to release a variety of organic and inorganic compounds including sulfur and the autocatalytic reduction of $\mathrm{H}_{2} \mathrm{~S}$. Hydrogen sulfide can also form and be produced through the introduction of foreign microbes to a reservoir, specifically Sulfur Reducing Bacteria (SRB). SRB's consume sulfur in the reservoir to produce $\mathrm{H}_{2} \mathrm{~S}$. This is also known as reservoir souring. Foreign bacteria can be introduced to a reservoir through the injection of water back into the reservoir. Water is often injected during well workover operations, 
for reservoir pressure maintenance, and for the purposes of disposing of produced waters. Other non-microbiological souring mechanisms include Thermochemical Sulphate Reduction (TSR), dissolution of pyritic materials, and redox reactions involving bisulphite oxygen scavengers [36, 38, 39].

Materials used in sour oil and gas operations continue to be dominated by carbon steels, although more recently through the advancement of CRA's and improved CRA material economics, their use is becoming more common for major pieces of equipment [36]. Commonly used CRA's include:

- Martensitic Stainless Steels

- Austenitic Stainless Steels

- Duplex and Super Duplex Stainless Steels

- Nickel Alloys

- Super Austenitic Stainless Steels

- Non-metallics

It is important to note that CRA's should be carefully selected for use as some may cause extra, unforeseen material failure mechanisms. In some situations, it may be appropriate to use a combination of CS and CRA's where high corrosion rates can be expected. The can include downhole liners and tubular components, as well as on aging assets after reservoir souring or higher water cuts are noticed. 


\subsubsection{The $\mathrm{H}_{2} \mathrm{~S}$ corrosion mechanisms}

Many studies have been done to understand the mechanism for $\mathrm{H}_{2} \mathrm{~S}$ Corrosion [40-42]. It is generally accepted that the corrosion of steels in aqueous $\mathrm{H}_{2} \mathrm{~S}$ environments proceeds initially by a very fast direct heterogeneous chemical reaction at the steel surface to form a solid adherent corrosion layer. The type of layer can depend on many factors, temperature being a main one. At lower temperatures mackinawite often forms, but at elevated temperature pyrrhotite, pyrite, or cubic FeS can form [41]. The overall reaction is a solid-state reaction and can be written as:

$$
\mathrm{Fe}+2 \mathrm{H}_{2} \mathrm{~S} \leftrightarrow \mathrm{FeS}_{(s)}+\mathrm{H}_{2}
$$

Under standard conditions, $\mathrm{H}_{2} \mathrm{~S}$ absorbs onto steel surface and reacts very fast to form a thin protective mackinawite film. The mackinawite's scale formation is known to be a "Solid State Reaction" as both the initial and final states of Fe are solid. This initial mackinawite formed is a very thin $(<<1 \mu \mathrm{m})$ [43], but dense scale acts as a solid state diffusion barrier for the sulfide species involved in the corrosion reaction.

The thin mackinawite film continuously goes through a cyclic process of growth, cracking and delamination. This generates the outer sulfide layer which thickens over time (typically $>1 \mu \mathrm{m}$ ), presenting a diffusion barrier. This outer sulfide layer is more porous and rather loosely attached. Over time it may crack, peel and spall when aggravated by flow. The form of iron sulfide scale may change, depending on a variety of production parameters including temperature and $\mathrm{H}_{2} \mathrm{~S}$ activity. Variations of FeS scale that can form include mackinawite, pyrite, pyrrhotite, triolite, and cubic FeS. 
Due to the presence of the thin passive inner mackinawite film and the outer sulfide layer, it is assumed that the corrosion rate of steels in $\mathrm{H}_{2} \mathrm{~S}$ solutions is always under mass, flux, transfer control [41]. The total flux of $\mathrm{H}_{2} \mathrm{~S}$ through the scale is a combination of:

- Convective diffusion through the mass transfer boundary layer

- Molecular diffusion through the liquid in the porous outer layer

- Solid state diffusion through the inner mackinawite film

The morphology of corrosion scales on carbon steels in sour environments can take many shapes and forms. The most common of which is that of a pit, which could be a single large wide pit, or a cluster of smaller pits. Failures often initiate in these areas. Corrosion pit morphology variations in carbon steels can be due to several factors which include the microstructure of the steel, variations in the materials surface finish, and local variations in water chemistry. Mechanisms for pit development on ferritic-pearlitic steel surfaces are due to big differences in ferrite grain size and the distribution of pearlite between different carbon steels with similar elemental composition. During exposure in the field, differences in service history can be an important factor, e.g., production shutdowns and stagnant conditions, as they have been found to enhance and accelerate the pitting initiation process.

Lab morphology testing usually finds that edge and crevice corrosion near test coupon holders are sometimes observed in sour corrosion tests. These attacks can be so severe that the corrosion on the rest of the surface is overshadowed. While it may be impossible to completely avoid artificial corrosion attacks, the possibility of such attacks 
should be considered when designing the experimental setup, evaluating of the results, and in making field comparisons [35].

\subsubsection{Factors which affect $\mathrm{H}_{2} \mathrm{~S}$ corrosion}

A variety of factors can affect the occurrence and rate of $\mathrm{H}_{2} \mathrm{~S}$ corrosion. In most environments and solutions, a very thin and protective iron sulfide film, often mackinawite, is able to form. The rate of corrosion is highly dependent on the formation of this passive film. Alternate forms of FeS scales commonly found include pyrrhotite, pyrite, and cubic iron sulfide. These scales are more porous and have a higher porosity, permeability, and are less adhesive than mackinawite. A variety of factors contribute to the ability for an adhesive scale to form and protect the steel. Contributing factors include material and electrolyte properties, fluid flow rates, as well as the solution $\mathrm{pH}$, and partial pressure of $\mathrm{H}_{2} \mathrm{~S}\left(P_{H_{s} S}\right)$.

The material being used has a large effect on the occurrence and rate of corrosion. Proper material selection plays a large role in preventing $\mathrm{H}_{2} \mathrm{~S}$ corrosion from initiating, giving rise to the development of the NACE standard: NACE MR0175/ISO 15156 [44]. This standard was developed to determine the severity of an environment to corrosion, specifically SCC, depending on solution $\mathrm{pH}$ and $P_{\mathrm{H}_{2} \mathrm{~S}}$. Four regions are outlined, which describe the severity of the corrosion environment and recommends material and design specifications, as shown in Figure 2.3 [44]. 


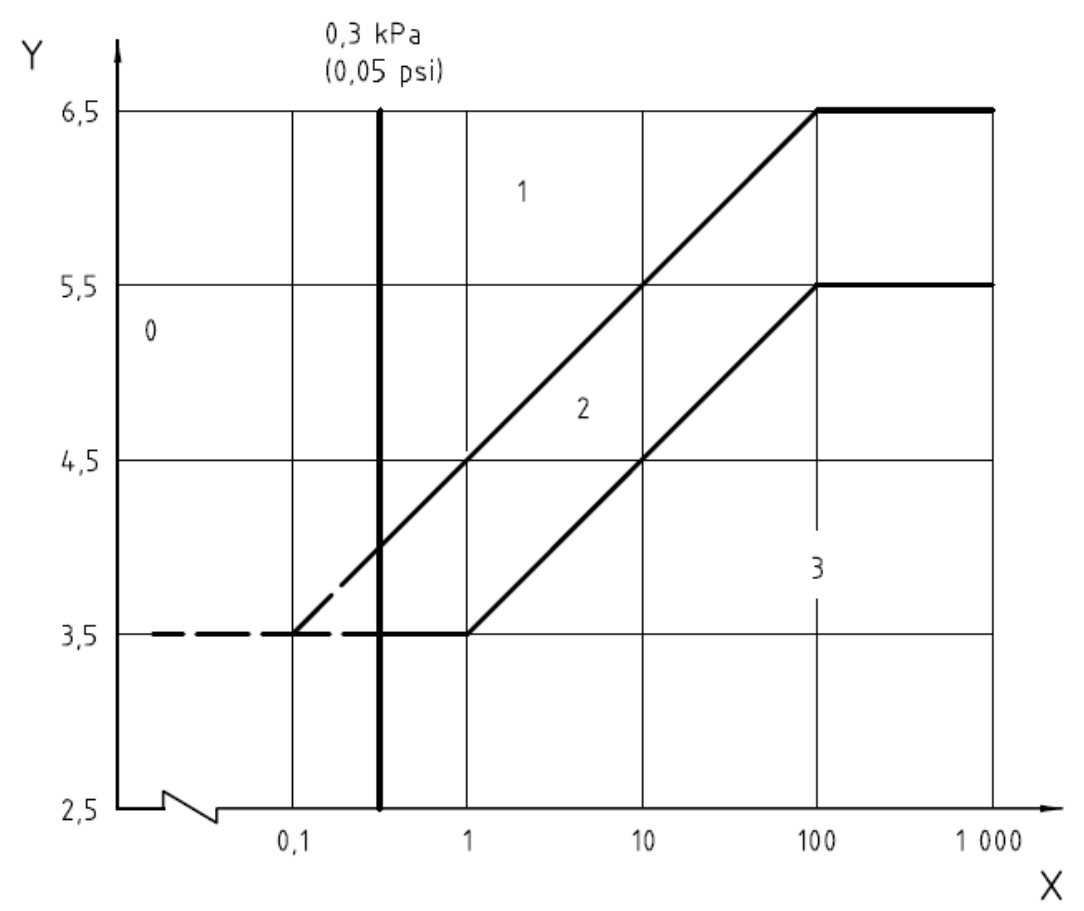

Key
$\mathrm{X} \quad \mathrm{H}_{2} \mathrm{~S}$ partial pressure, $\mathrm{kPa}$
$\mathrm{Y} \quad$ in situ $\mathrm{pH}$

Figure 2.3: NACE MR0175/ISO 15156 - Materials for use in $\mathrm{H}_{2} \mathrm{~S}$ containing environments in oil and gas environments [44]

In region 0 no precautions are required; and regions 1, 2, and 3 all require material and design precautions to be taken.

The electrolyte's conductivity plays a role in the rate of corrosion. As conductivity increases there will be an increase in the ion flow through the electrolyte and therefore increased corrosion current [45].

Fluid flow rates affect corrosion rates by preventing or promoting the formation of a passive scale. Higher flow rates can prevent scales from properly adhering to a materials surface. Under low flow or stagnant conditions solution impurities can be present and prevent the formation of passive films, progressing and even accelerating corrosion. 
Temperature also plays a large role in determining the rate of corrosion when $\mathrm{H}_{2} \mathrm{~S}$ is present. The study of corrosion related to $\mathrm{H}_{2} \mathrm{~S}$ has mainly been focused on $\mathrm{HIC}$ and SSCC at ambient temperatures. Limited testing has been done to understand aqueous $\mathrm{H}_{2} \mathrm{~S}$ corrosion rates at moderate or elevated temperatures. Figure 2.4 and Figure 2.5 [46] show how corrosion rate and the scale formed depend highly on temperature as well as $\mathrm{H}_{2} \mathrm{~S}$ activity. $\mathrm{H}_{2} \mathrm{~S}$ activity is a measure of the "effective concentration" of a species in a mixture

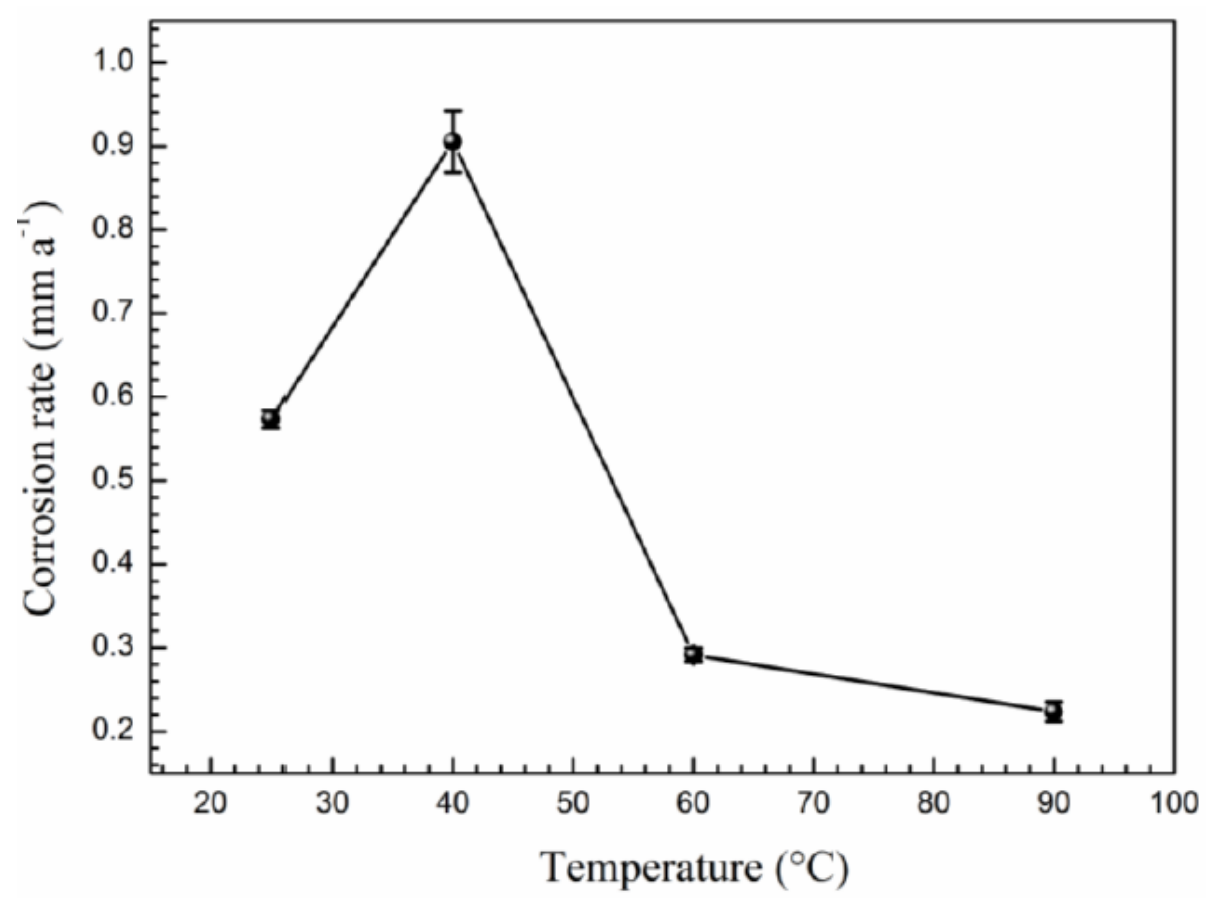

Figure 2.4: Corrosion rate vs temperature [46] 


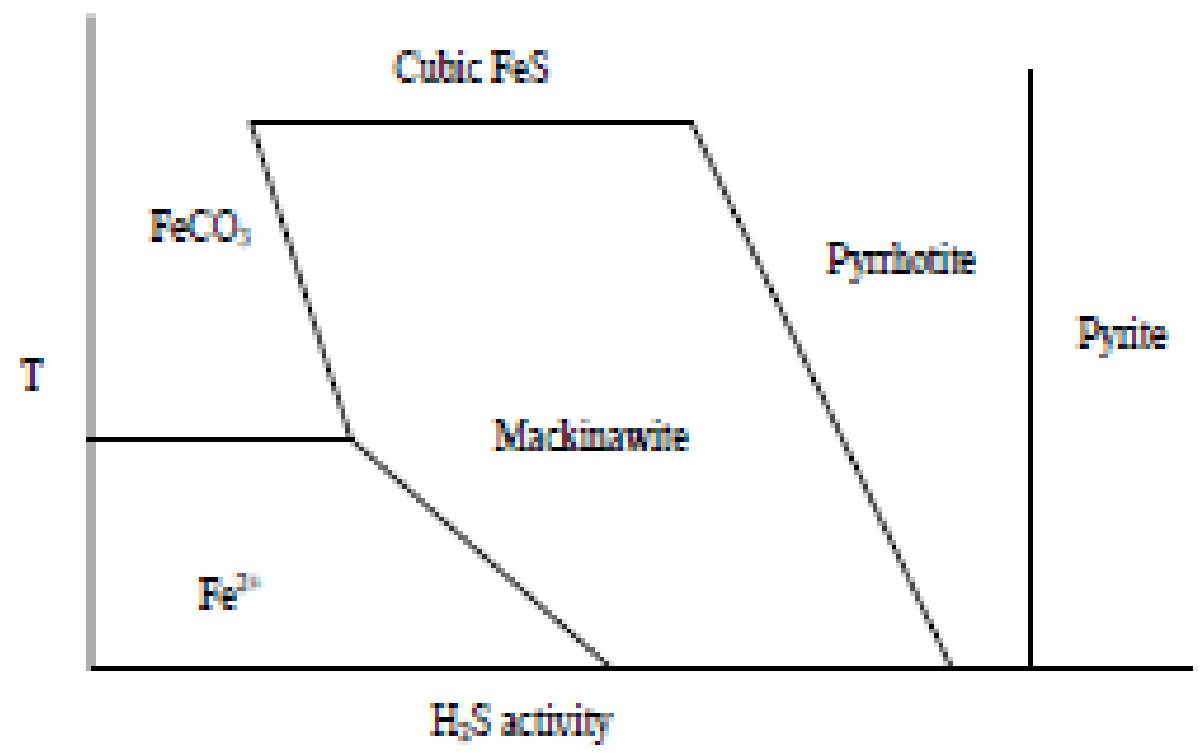

Figure 2.5: Corrosion scale depending on temperature vs $\mathrm{H}_{2} \mathrm{~S}$ activity [46]

As temperature increases from ambient the corrosion rates continue to increase and peaks at $40^{\circ} \mathrm{C}$. Afterwards corrosion rates decrease rapidly when the temperature is up to $60^{\circ} \mathrm{C}$, followed by a more gradual decrease between $60^{\circ} \mathrm{C}-90^{\circ} \mathrm{C}$ as temperature increases. It was proposed that corrosion rates initially increased due to the diffusion enhancement of corrosive species and the increase in both the $\mathrm{H}^{+}$concentration and the rate constant of corrosion reaction. High transport resistance of the corrosion film and the decreasing $\mathrm{H}^{+}$concentration were responsible for the decrease in corrosion rate with further increase of temperature above $40^{\circ} \mathrm{C}$. In addition, the corrosion film formed likely has a more dominant role in the decrease in corrosion rate than the dilution of $\mathrm{H}^{+}$ concentration. Depending on the solution temperature, $\mathrm{pH}$, and the length of exposure time, different corrosion films and products have been observed. At temperatures below $40^{\circ} \mathrm{C}$, lab testing commonly produces the iron sulfide film mackinawite. Above $40^{\circ} \mathrm{C}$ a 
combination of mackinawite and cubic iron sulfide (cubic FeS) has been observed. Cubic FeS is known to be a more adhesive and dense scale than mackinawite.

The presence of chlorides and other corrosive impurities can also play a large effect in determining the ability for a passive corrosion film to form and on the rate of corrosion of a materials surface.

\subsection{Synergistic effects of $\mathrm{H}_{2} \mathrm{~S}$ and $\mathrm{CO}_{2}$ on steel corrosion}

Studies of combined aqueous $\mathrm{CO}_{2}$ and $\mathrm{H}_{2} \mathrm{~S}$ corrosion have been investigated for over 60 years, starting with investigations on carbon steel pipelines [47]. More recently an increase in the amount of research in this area has been completed in different operating conditions and system types [48-50]. Small amounts of $\mathrm{H}_{2} \mathrm{~S}$ in a system have been found to change the corrosion mechanism and rate [51]. A shift in the preferred corrosion mechanism and product will occur when the corrosion kinetics of FeS formation becomes favorable to that of $\mathrm{FeCO}_{3}$.

To simplify the analysis and understanding of the corrosion mechanism present in systems which include both $\mathrm{CO}_{2}$ and $\mathrm{H}_{2} \mathrm{~S}$, a partial pressure relationship between $\mathrm{CO}_{2}$ and $\mathrm{H}_{2} \mathrm{~S}$ was developed. This was done to determine how much $\mathrm{H}_{2} \mathrm{~S}$ is required relative to $\mathrm{CO}_{2}$ to turn a sweet system into a sour one with the $\mathrm{H}_{2} \mathrm{~S}$ concentration $>0.5 \mathrm{ppm}$. A ratio of the partial pressures of $\mathrm{CO}_{2} / \mathrm{H}_{2} \mathrm{~S}=500$ was found to represent the transition point from being $\mathrm{CO}_{2}$ to $\mathrm{H}_{2} \mathrm{~S}$ dominant. When the partial pressure ratio is $<500$ an iron sulfide corrosion product can be expected to initiate [52] and dominate at a ratio $<20$. Above 500 an iron carbonate scale should prevail. Between a ratio range of 20 to 500 a transition from being fully $\mathrm{CO}_{2}$ dominate to $\mathrm{H}_{2} \mathrm{~S}$ dominate exists. This ratio has become a 
commonly used "rule of thumb" for a conversion from sweet to sour corrosion since its proposal at NACE CORROSION 1983 [53]. It is important to note that this ratio was developed under unique conditions to show that for the appropriate solubility products of ionization constants, and equilibrium constants, the co-existence of siderite and iron sulfide at $25^{\circ} \mathrm{C}$ is indicated when the partial pressures of $\mathrm{CO}_{2} / \mathrm{H}_{2} \mathrm{~S}=500$. Temperature and other solution imperfections were not considered in the conclusion that iron carbonate should prevail when the partial pressure of $\mathrm{CO}_{2} / \mathrm{H}_{2} \mathrm{~S} \geq 500$, and iron sulfide can be expected with a $\mathrm{CO}_{2} / \mathrm{H}_{2} \mathrm{~S}$ ratio $<500$.

Because of its popularity in use, this value has been recently re-evaluated and many questions and concerns have come up [54]. The transition point has shown to be highly sensitive to the thermodynamic value inputs. Slight changes in the solubility product and equilibrium constant values used will lead to extremely large changes in the transition value. Temperature has shown to have little effect on the ratio in the range of $20^{\circ} \mathrm{C}$ $100^{\circ} \mathrm{C}$, assuming a mackinawite corrosion product. If the corrosion product changes from mackinawite to pyrrhotite the ratio could increase from 500 to roughly 2500. Furthermore, a 1\% change in the free energy value of iron carbonite can increase the value to over 7600 [54].

\subsection{Summary of literature review}

Corrosion is known to occur and have caused well failures in the oil and gas industry including in SAGD wells. Well failures have a significant economic, regulatory, and environmental impact on an operating company's bottom line, as well as on the SAGD and oil and gas industry due to reputation and social rights. Based on the literature review 
completed and industry experience, no research has been completed to better understand corrosion in the high temperature high pressure conditions found in SAGD, specifically to those at Suncors Firebag asset. Component and well failures have occurred due to corrosion which is an economic, environmental, and regularity hazard to operations. The goal of this research is thus to:

- Better understand corrosion on wellhead gate valve gate face materials and evaluate an alternate material to use for prevention

- Better understand the severity of corrosion on downhole completion components under the given conditions which can be expected in SAGD operations

- Understand where the most severe corrosion is likely to occur

- Determine the dominating corrosion mechanisms present

- Understand how corrosion can change on different materials and at different locations in a well

Having a more thorough understanding of these factors will lead to improved well design, operating practices, and interventions to prevent corrosion occurring in SAGD wells. 


\section{Chapter Three: Experimental testing}

\subsection{Introduction}

To better understand corrosion rates and mechanisms in the annulus of producing SAGD wells, experiments were conducted in both lab and field environments. Lab testing was completed using HTHP autoclaves for real time and average corrosion rate measurements on selected materials in simulated downhole conditions. Materials tested were those of commonly used wellhead and other completion materials setup to represent conditions found in SAGD wells.

Field testing was completed to better understand corrosion in real world applications. Having a better understanding of the corrosion rates, scale composition, and morphology from field samples can help to better understand how and why corrosion is occurring, where it can be expected to be of the highest concern, and how to prevent it. Field testing consisted of installing corrosion coupons on specially designed clamps used to secure the ESP's cable to the external of the production tubing from surface to where the ESP is landed. Similar materials and corrosive setups were constructed in the clamps as was used in the autoclaves to allow for accurate and direct comparisons between the field and lab tests. This will allow for more accurate lab tests to be set up in the future for simulation testing. The following sections give a detailed explanation of the testing procedures and setups used, measurements taken, and analysis completed. 


\subsection{Lab testing}

HTHP autoclave testing was conducted to understand corrosion in SAGD wells on commonly used wellhead and completion materials in controlled setups with real time measurements. Materials tested include those of wellhead gate valve materials, production tubular materials, and selected other completion component materials.

Materials tested, the testing completed, and location of use in application are summarized in Table 3.1.

Table 3.1: Autoclave testing summary

\begin{tabular}{|c|c|c|c|}
\hline & Materials & Measurements & Test Purpose \\
\hline \multirow[t]{3}{*}{ Wellhead Materials } & 1018 Carbon Steel & $\begin{array}{l}\text { - Linear Polarization Resistance } \\
\text { - Weight Loss }\end{array}$ & - General CR \\
\hline & Deloro-40 HF & $\begin{array}{l}\text { - Linear Polarization Resistance } \\
\text { - Weight Loss } \\
\text { - Cyclic Potentiodynamic Potential } \\
\text { - Potentiostatic Potential }\end{array}$ & - General CR \\
\hline & Stellite-6 HF & $\begin{array}{l}\text { - Linear Polarization Resistance } \\
\text { - Weight Loss } \\
\text { - Cyclic Potentiodynamic Potential } \\
\text { - Potentiostatic Potential }\end{array}$ & - General CR \\
\hline \multicolumn{4}{|l|}{$\begin{array}{l}\text { Downhole } \\
\text { Materials }\end{array}$} \\
\hline & $J-55$ & - Weight Loss & $\begin{array}{l}\text { - Crevice CR } \\
\text { - Galvanic CR }\end{array}$ \\
\hline & $\mathrm{K}-55$ & $\begin{array}{l}\text { - Linear Polarization Resistance } \\
\text { - Weight Loss } \\
\text { - Zero Resistance Ammeter }\end{array}$ & $\begin{array}{l}\text { - General CR } \\
\text { - Crevice CR } \\
\text { - Galvanic CR }\end{array}$ \\
\hline & TN-55TH & $\begin{array}{l}\text { - Linear Polarization Resistance } \\
\text { - Weight Loss } \\
\text { - Zero Resistance Ammeter }\end{array}$ & $\begin{array}{l}\text { - General CR } \\
\text { - Crevice CR } \\
\text { - Galvanic CR }\end{array}$ \\
\hline & GLV-K55 & $\begin{array}{l}\text { - Linear Polarization Resistance } \\
\text { - Weight Loss } \\
\text { - Zero Resistance Ammeter }\end{array}$ & $\begin{array}{l}\text { - Crevice CR } \\
\text { - Galvanic CR }\end{array}$ \\
\hline & GLV-J55 & - Weight Loss & - Crevice CR \\
\hline
\end{tabular}


The appendix shows the materials mechanical properties, and references [5, 6, 8, 55] include material chemistries and general information as provided by the coupon manufacturers and suppliers. It is important to note that $\mathrm{J}-55, \mathrm{~K}-55$, and $\mathrm{TN}-55 \mathrm{TH}$ are all similar materials manufactured to API specification 5CT with the exception that the minimum tensile strength of the J-55 is lower than the K-55. Also TN-55TH is a proprietary thermal use carbon steel product supplied by Tenaris [5]. L-80 is a steel alloy also manufactured to API specification 5CT with controlled yield and hardness properties [56]. Test setups of general corrosion testing, as well as galvanic and crevice corrosion testing cells were constructed to represent downhole corrosion conditions.

Carbon steel was selected for testing as a baseline material due to its extensive use in oil and gas industry. Carbon steel overlaid with Deloro-40 HF or Stellite-6 HF was tested to compare their ability to prevent corrosion. These materials are used in wellhead gate valves on the gate face component which is used to isolate surface lines from the downhole fluids. This is depicted in Figure 3.1. 


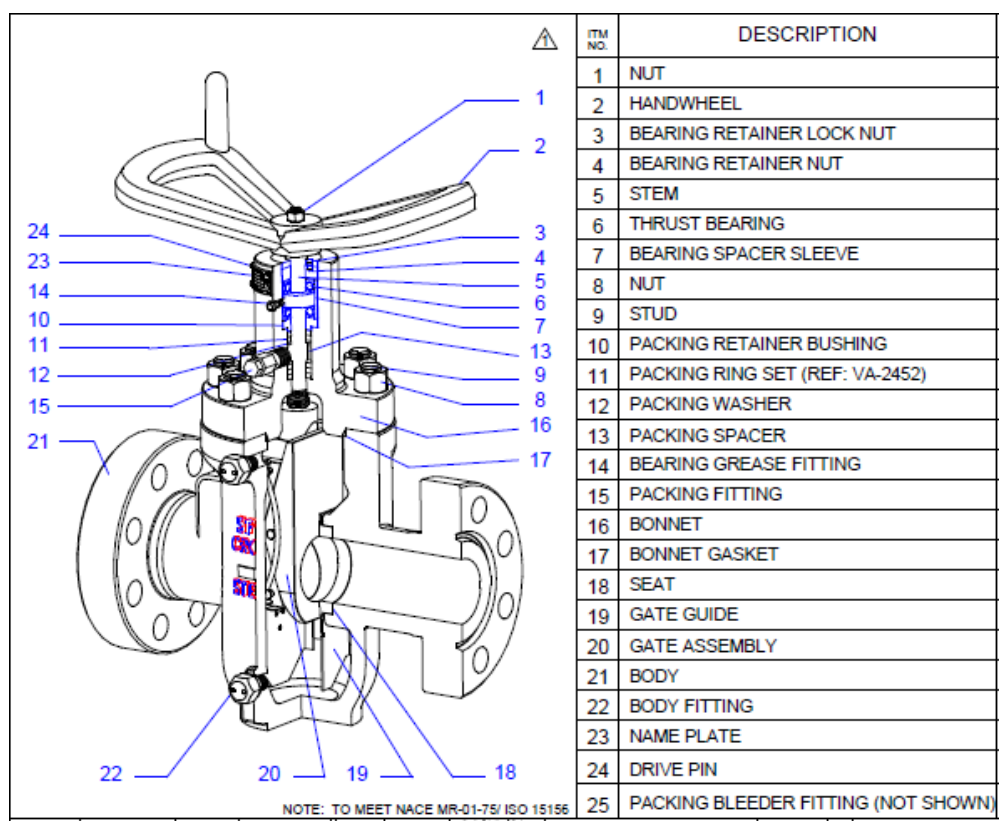

Figure 3.1: Gate valve design

The gate face is directly exposed to production fluids in stale or flowing conditions. Having the ability to properly operate these valves and achieve isolation is integral to maintaining well integrity. A Deloro-40 HF is currently being used in the valves on the gate face but found to be corroding and causing the valves to leak internally when exposed to fluid flow. The Stellite-6 HF was tested to determine its effectiveness in preventing corrosion, and the valves from leaking, as a potential future material upgrade change.

The K-55 and J-55 materials are commonly used in the oil and gas industry as a downhole tubular material. They are carbon steels manufactured to a specific API standard for use in oil and gas. This standard outlines select material properties which must be met and maintained for use in the oil and gas industry. More recently, tubing suppliers have started manufacturing their own proprietary thermal grades of J-55/K-55, tubulars, one of which is a TN-55TH. It is now commonly used in SAGD and selected for 
its improved thermal properties. TN-55TH has tighter tolerances on its chemical composition, as well as physical dimension and mechanical properties compared to standard API grade materials. L-80 is a third standard API carbon steel used in SAGD and was also tested. Compared to J-55/K-55, L-80 is a quenched and tempered material, not rolled or normalized as J-55/K-55 are, and has a more restrictive chemistry and higher yield and tensile strength properties. Finally, galvanized versions of J-55/K-55 materials were tested as it is an alloy used on select downhole components including ESP cables, and cable clamps.

The HTHP autoclaves used were constructed of Hastelloy 276-C alloy and have a capacity of approximately $300 \mathrm{~mL}$. All testing was carried out with $250 \mathrm{~mL}$ of field simulated brine in each cell. The temperature of the fluid in the autoclave is sensed by a thermistor probe, accurate to $+/-2^{\circ} \mathrm{C}[57,58]$, held at the center of the cell by a Hastelloy sleeve. Charging of the autoclave was done using an offset Hastelloy tube fitted with a pressure gauge and sour-service valve. Each cell is also equipped with a pressure relief valve used for purging test liquids directly in the cell. Figure 3.2 shows the assembled autoclaves used for testing. 


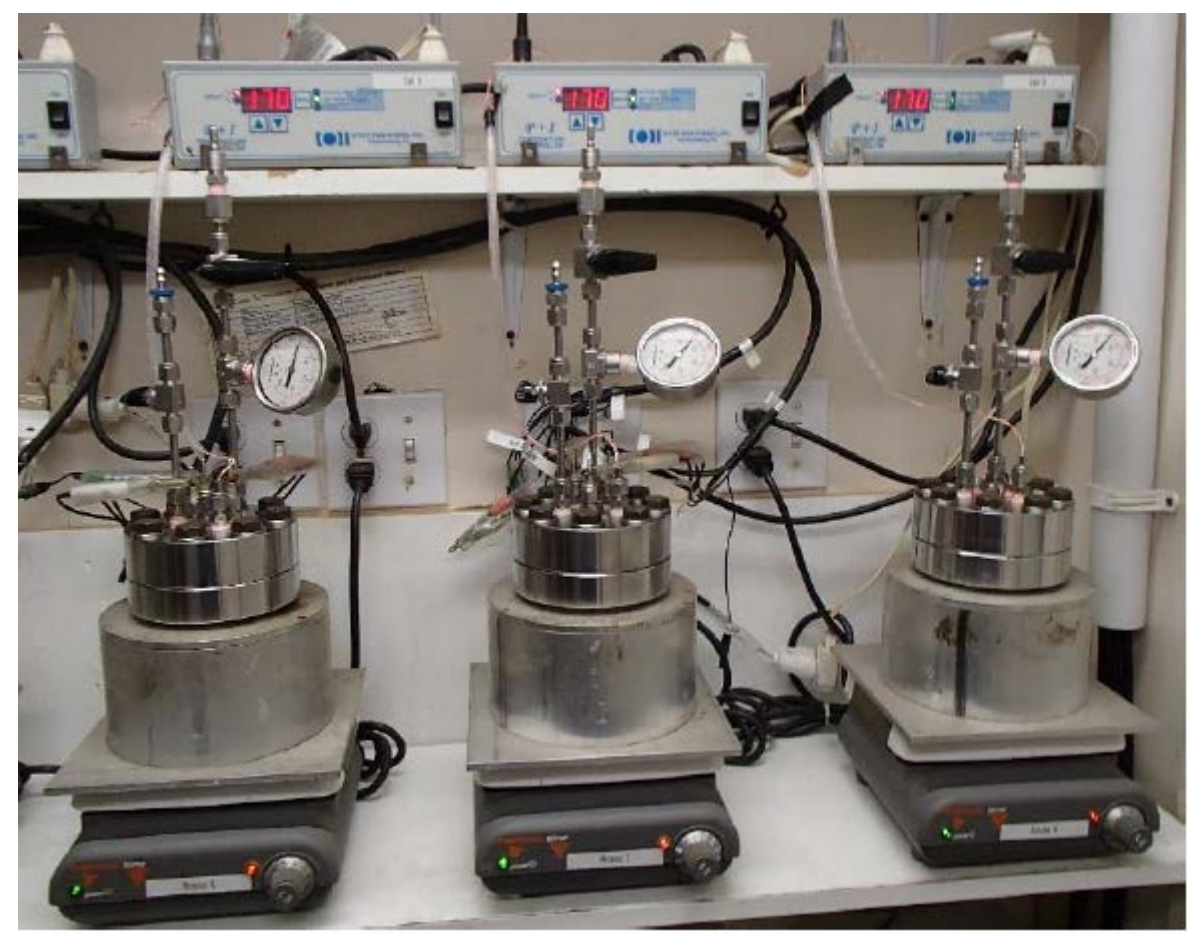

Figure 3.2: Assembled autoclave testing equipment

\subsubsection{Wellhead material autoclave testing}

The following section outlines the autoclave specifications used in testing, condition and brines used for tested, materials tested, and the measurements taken.

\subsubsection{Autoclave Setup and Measurements}

A three-electrode autoclave assembly, supplied by Cormetrics Ltd, was used with the electrodes suspended from the lid of the autoclave. The bottom was kept clear for a teflon coated magnetic stir-bar used to mix the fluids [59]. The hanging electrodes are configured to that of an equilateral triangle. Disc electrodes were $20 \mathrm{~mm}$ in diameter $\times 3$ $\mathrm{mm}$ in height for the working and counter electrodes. This set-up was used to simulate the conditions of the valve gate where it is retracted into the valve body during normal operations. In all tests the reference electrode was made of a Hastelloy 276-C material. 
The temperature of the fluid in the autoclave is sensed by a thermistor probe [57, 58], held at the center of the cell by a Hastelloy thermowell. Charging of the autoclave was by means of an offset Hastelloy tube, fitted with a pressure gauge and sour-service valve. Each cell is also equipped with a pressure relief valve which is used when purging the test liquids directly in the cells.

Weight loss (WL) and Linear Polarization Resistance (LPR) measurements were taken to measure corrosion rates on all materials. Further cyclic potentiodynamic polarization (CPP) and potentiostatic polarization (PP) testing was also completed to more accurately differentiate the performance between the Deloro-40 HF and Stellite-6 HF materials. LPR and Zero Resistance Ammeter (ZRA) measurements were obtained at 30 minute intervals by connecting each cell to a Gamry PC4-300 potentiostat and controller [60], via a Gamry ECM8 multiplexer [61]. Data acquisition was performed by means of Gamry's DC105 software package. The LPR test setup included using a grooved teflon washer mounted on the top surface of the disc to create a crevice corrosion condition that is conducive to localized corrosion activity. This assembly is shown in Figure 3.3.

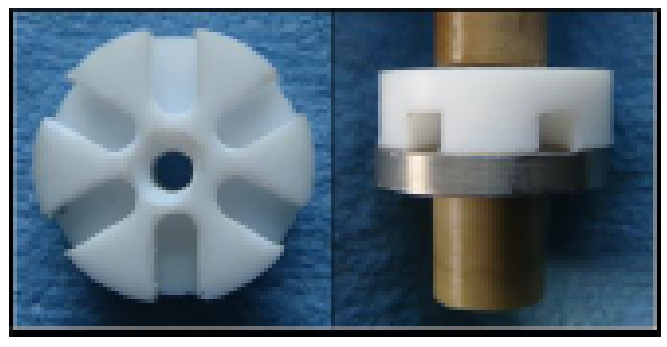

Figure 3.3: Crevice washer and electrode assembly

For this testing, the working electrode consisted of 1018 carbon steel which had a total exposed surface area of $5.94 \mathrm{~cm}^{2}$. This was used for all corrosion rate calculations. 
The electrodes were solvent rinsed and weighed prior to the test. Weight loss corrosion rates are reported as an average of the working electrode based on a total exposure period of 163 hours ( $~ 7$ day). In the CPP and potentiostatic polarization tests the working disc electrode was mounted on the electrode poles and sealed off on the bottom using a PEEK cap. PEEK is an inert and biocompatible polyetheretherketone tubing material [62].

Electrodes were solvent rinsed and weighed prior to the test.

During the CPP scans, electrochemical measurements were obtained at 1 second intervals, and 15 minute intervals for the PP testing. This was done by connecting each cell to a Gamry PC4-300 potentiostat and controller, via a Gamry ECM8 multiplexer. Data acquisition was by means of Gamry’s DC105 software package.

\subsubsection{Coupon materials and autoclave setup}

Table 3.2 lists the materials tested, where they are used in application, and test measurements taken.

Table 3.2: Materials and location of use

\begin{tabular}{|c|l|c|}
\hline Material & \multicolumn{1}{|c|}{ Location of Use } & Analysis Completed \\
\hline 1018 Carbon Steel & Gate valve internal components & LPR, WL \\
\hline Deloro-40 HF & Gate valve gate face overlay & LPR, WL, CPP, PP \\
\hline Stellite-6 HF & $\begin{array}{l}\text { Gate valve gate face overlay } \\
\text { (for potential use) }\end{array}$ & LPR, WL, CPP, PP \\
\hline
\end{tabular}

For LPR testing the disc style coupons were milled from the materials and mounted in the crevice corrosion device. CPP testing used disc style coupons milled from each material and secured on the electrode poles with the PEEK cap. The Deloro-40 HF and Stellite-6 HF materials were made using these materials matching the required coupon configuration but tapping the threaded connection within the discs was not able to 
be completed. To allow for the CPP measurements, a silver adhesion paste was utilized to allow for electrical continuity between the disc and mounting rod. This alternative to the threaded connection is commonly used in electrochemical testing and has proven to be a comparable alternative. Based on the data generated and stable open circuit potential it is believed that the test set-up worked properly.

\subsubsection{Solution and testing conditions}

The synthetic brine used in the autoclave was prepared based on a water sample analysis from a SAGD well. The brines composition is displayed in Table 3.3.

Table 3.3: Synthetic brine composition

\begin{tabular}{|c|c|c|c|c|c|c|}
\hline $\begin{array}{c}\text { Sodium } \\
(\mathrm{mg} / \mathrm{L})\end{array}$ & $\begin{array}{c}\text { Potassium } \\
(\mathrm{mg} / \mathrm{L})\end{array}$ & $\begin{array}{c}\text { Magnesium } \\
(\mathrm{mg} / \mathrm{L})\end{array}$ & $\begin{array}{c}\text { Calcium } \\
(\mathrm{mg} / \mathrm{L})\end{array}$ & $\begin{array}{c}\text { Chloride } \\
(\mathrm{mg} / \mathrm{L})\end{array}$ & $\begin{array}{c}\text { Bicarbonate } \\
(\mathrm{mg} / \mathrm{L})\end{array}$ & $\begin{array}{c}\text { Sulfate } \\
(\mathrm{mg} / \mathrm{L})\end{array}$ \\
\hline 266.0 & 15.5 & 3.5 & 9.98 & 141.0 & 450.0 & 43.0 \\
\hline
\end{tabular}

This synthetic brine was pre-purged with pure $\mathrm{CO}_{2}$ for 2 hours prior to use in testing and had a pH of 5.50 after pre-purging. Acidic gas quantities of $6.9 \%$ mole of $\mathrm{CO}_{2}$ and $6.48 \%$ mole of $\mathrm{H}_{2} \mathrm{~S}$ with a system pressure of $3000 \mathrm{kPa}$ was used based on a well gas analysis. Autoclave charge pressures used are listed in Table 3.4. Due to the relatively short test duration, the pressures are believed to have reduced an insignificant amount during the test. This can be considered negligible.

Table 3.4: Autoclave charge pressures

\begin{tabular}{|c|c|c|c|}
\hline Total Pressure $(\mathrm{kPa})$ & $\mathrm{CO}_{2}(\mathrm{kPa})$ & $\mathrm{H}_{2} \mathrm{~S}(\mathrm{kPa})$ & $\mathrm{N} 2(\mathrm{kPa})$ \\
\hline 3000 & 207 & 194 & 2599 \\
\hline
\end{tabular}


A testing temperature of $170^{\circ} \mathrm{C}$ was used. This is the maximum autoclave operating temperature. The sealed autoclaves were placed inside individual mantles and heated to the set test temperature.

\subsubsection{Downhole material autoclave testing}

Autoclave corrosion testing was completed on select commonly used completion materials including K-55, GLV-J55, and TN-55TH. K-55 and TN-55TH are downhole tubular materials, and the GLV-J55 is an ESP cable and ESP cable clamp material.

To understand general corrosion rates on individual materials the autoclaves were setup for LPR corrosion rate measurements and pre/post-test weight loss measurements and analysis. Crevice corrosion rate tests were also performed by setting up the coupons to be in close contact in the autoclave. This testing was designed to evaluate the severity of localized corrosion attack in crevices created between materials in contact downhole. Localized crevices could be an area of potentially severe corrosion attack. Material combinations used in this testing include K-55+TN-55TH, K-55+GLV-J55 and K-55+K55. Analysis completed includes visual observations and general weight loss corrosion rate analysis.

Finally, galvanic corrosion analysis was completed to evaluate the effects of dissimilar metals coming into contact on corrosion rate. A potentiostat connected to the autoclave in ZRA mode was used to evaluate the corrosion current density, which is directly related to corrosion rate, in the material. In ZRA mode the working and counter electrodes are shorted together so that there is a zero-net voltage drop across the cell. Thereby the current flowing between the two electrodes due to the potential difference can be measured. The direction of current flow is indicated by a positive or negative 
current density. If the potential difference between the two materials is great enough the more electronegative metal of the couple will preferentially corrode.

\subsubsection{Autoclave setup and measurements}

For the LPR and ZRA testing, a three-electrode assembly was suspended from the lid of the autoclave as shown in Figure 3.4 and Figure 3.5, while keeping the bottom clear for a teflon-coated magnetic stir-bar.

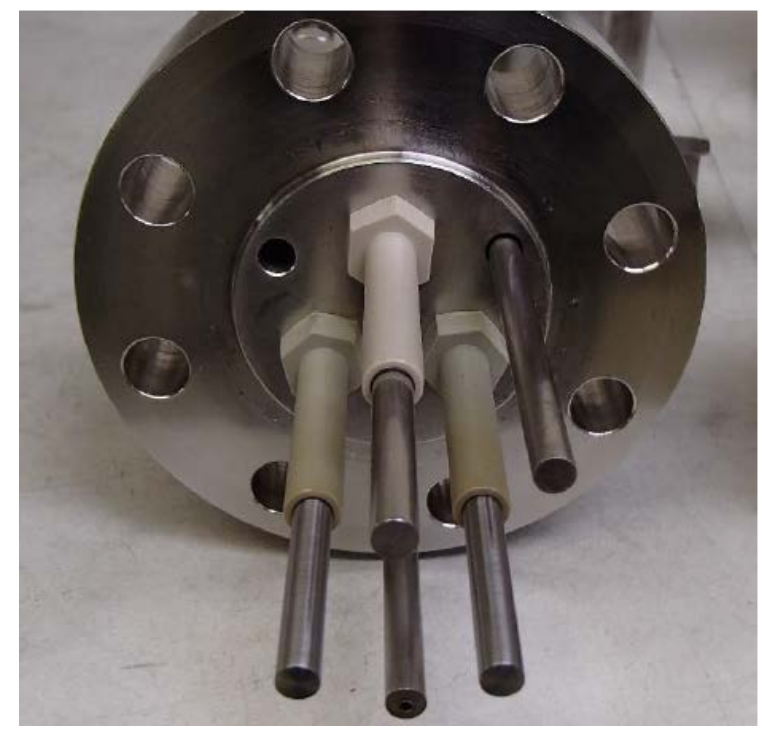

Figure 3.4: Autoclave lid for general LPR testing 


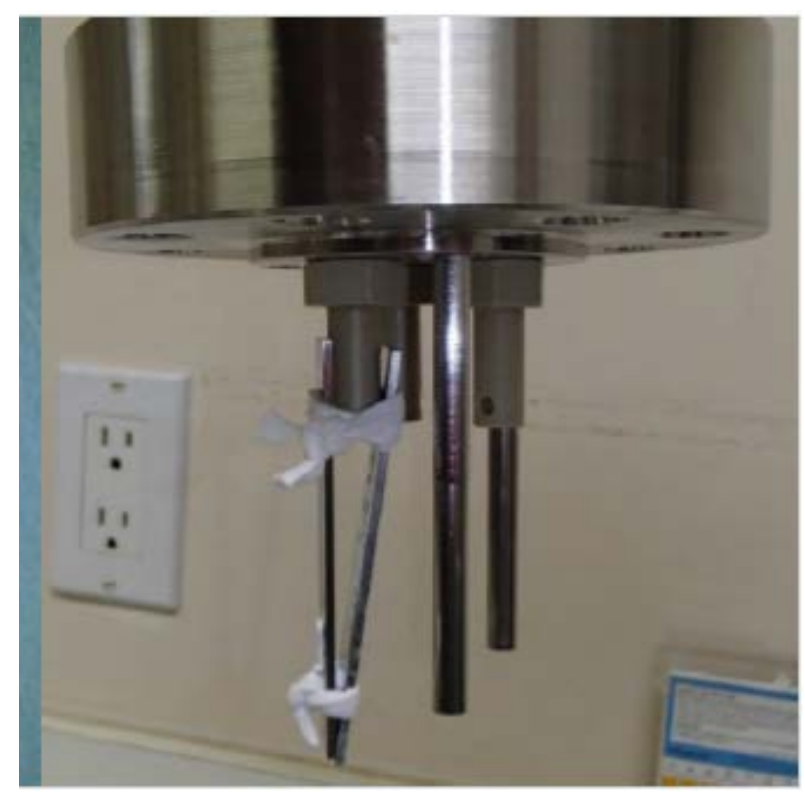

Figure 3.5: Galvanized J-55 \& K-55 coupon pair tied at the base

The configuration of the electrodes is that of a closely spaced equilateral triangle, with each cylindrical electrode having dimensions of $63 \mathrm{~mm}$ x $38 \mathrm{~mm}$. The reference electrode was made from Hastelloy 276-C, while the working and counter electrodes were the materials being evaluated. The inlet tube used to purge and charge the cell with fluids is directly beneath the reference electrode. The electrodes are electrically isolated from the autoclave cell via the PEEK shafts visible in the photograph. Electrodes were solvent rinsed and weighed prior to the commencement of the test period. The surface area of each rod electrode utilized in the corrosion rate calculations was $7.92 \mathrm{~cm}^{2}$. LPR and ZRA measurements were obtained at 30-minute intervals by connecting each cell to a Gamry PC4-300 potentiostat and controller, via a Gamry ECM8 multiplexer. Data acquisition was by means of Gamry’s DC105 software package. 
To measure the current due to galvanic coupling, a potentiostat in ZRA mode was used. The corrosion rate, measured via weight loss, and visual observations of each electrode from the galvanic pair are reported.

For crevice testing the strip coupons were attached to the short PEEK insulators suspended from the lid of the autoclave. The top of each coupon pair was mounted on the side of the PEEK insulator and the bottom is held together to create a contact point and artificial crevice. The coupon dimensions are $1.27 \mathrm{~cm}$ x $7.62 \mathrm{~cm}$ x $0.16 \mathrm{~cm}$ (WxLxT) with $0.64 \mathrm{~cm}$ diameter mounting holes located $1.27 \mathrm{~cm}$ from either end. The coupons were solvent rinsed and weighed prior to testing. The total exposed surface area of 20.9 $\mathrm{cm}^{2}$ was used for weight loss corrosion rate calculations.

The crevice testing setup was provided in Figure 3.5. Here, strip style coupons were tied tightly together at the bottom and then mounted from short PEEK shafts attach to the lid of the autoclave. A high temperature strip of 100\% PTFE was used to attached the coupons to each other and mount them from the lid of the autoclave. After preparing the 3 different crevice setups, a $250 \mathrm{~mL}$ volume of the purged synthetic brine, composition shown in Table 3.6 in the following section, was added to each autoclave before assembling with the lids and sealed together. Finally, the charged autoclave cells were placed inside individual heating mantles with magnetic stirrers and brought up to a final test temperature of $170^{\circ} \mathrm{C}$. A magnetic stir-bar was also present in the autoclave so that fluids can be gently stirred throughout test duration of the testing.

\subsubsection{Coupon materials and testing setup}

Rod style electrodes were milled from K-55 and TN-55TH samples with two of the milled K-55 electrodes being electro-galvanized. The rod style electrodes were used 
in the general and galvanic corrosion tests. Additionally, strip style coupons were milled from tubular samples for use in the crevice testing. These coupons were milled to the same physical dimensions as the GLV-J55 and K-55 coupons. Table 3.5 summarizes the materials tested, their location and application for use, and the measurements taken for testing.

Table 3.5: Materials and location of use

\begin{tabular}{|c|c|c|}
\hline Material & Location and Application for Use & Analysis Completed \\
\hline K-55 & Tubular Material & LPR, Crevice \& Galvanic \\
\hline TN-55TH & Tubular Material & LPR, Crevice \& Galvanic \\
\hline GLV-J55 & Clamp and ESP Cable & Crevice \\
\hline GLV-K55 & Clamp and ESP Cable & Galvanic \\
\hline
\end{tabular}

\subsubsection{Solution and testing conditions}

A condensed water sample from the field was provided for compositional analysis to determine its composition and the quantities of calcium, chloride, bicarbonate, and sulfate present. Using this compositional analysis, a synthetic brine was prepared for use in the autoclave tests, and its composition is shown in Table 3.6.

Table 3.6: Synthetic brine composition

\begin{tabular}{|c|c|c|c|}
\hline $\begin{array}{c}\text { Calcium } \\
(\mathrm{mg} / \mathrm{L})\end{array}$ & $\begin{array}{c}\text { Chloride } \\
(\mathrm{mg} / \mathrm{L})\end{array}$ & $\begin{array}{c}\text { Bicarbonate } \\
(\mathrm{mg} / \mathrm{L})\end{array}$ & $\begin{array}{c}\text { Sulfate } \\
(\mathrm{mg} / \mathrm{L})\end{array}$ \\
\hline 9.98 & 141 & 450 & 43 \\
\hline
\end{tabular}

The brine was pre-purged with $\mathrm{CO}_{2}$ for 2 hours to deoxygenate the brine before testing. The $\mathrm{pH}$ of the brine was 4.36 after the pre-purge for the LPR and Crevice testing, and 4.34 in the galvanic testing. The gas composition used in testing was $30 \%$ molar $\mathrm{CO}_{2}$ 
and $8 \%$ molar $\mathrm{H}_{2} \mathrm{~S}$ based on a system pressure of $1000 \mathrm{kPa}$. Autoclave charge pressures used in the experiment are listed in Table 3.7.

Table 3.7: Autoclave charge partial pressures

\begin{tabular}{|c|c|c|c|}
\hline Total Pressure $(\mathrm{kPa})$ & $\mathrm{CO}_{2}(\mathrm{kPa})$ & $\mathrm{H}_{2} \mathrm{~S}(\mathrm{kPa})$ & $\mathrm{N} 2(\mathrm{kPa})$ \\
\hline 1000 & 300 & 80 & 620 \\
\hline
\end{tabular}

ZRA experiments were run over a 4-day exposure while LPR and crevice tests were completed with 7-day exposure times. A maximum autoclave testing temperature of $170^{\circ} \mathrm{C}$ was used. This is below maximum SAGD operating temperatures which can be more than $220^{\circ} \mathrm{C}$ and is due to autoclave material limitations.

\subsection{Field testing}

Field corrosion coupon testing has been completed to determine the effects of corrosion under actual operating conditions for longer duration periods. In this analysis corrosion coupons were manufactured and installed in the annulus of producing SAGD wells. The purpose of this testing was to determine corrosion rates on commonly used SAGD completion materials at different elevations in the production annulus as well as for corrosion rate and mechanism determination and comparisons to the controlled lab testing.

Here corrosion coupons were installed in specially designed production tubing instrumentation clamps used to fasten downhole instrumentation lines to the production tubing. These clamps are shown in Figure 3.6 and were manufactured to protect the coupons during installation and to prevent unwanted coupon contact with other materials. 


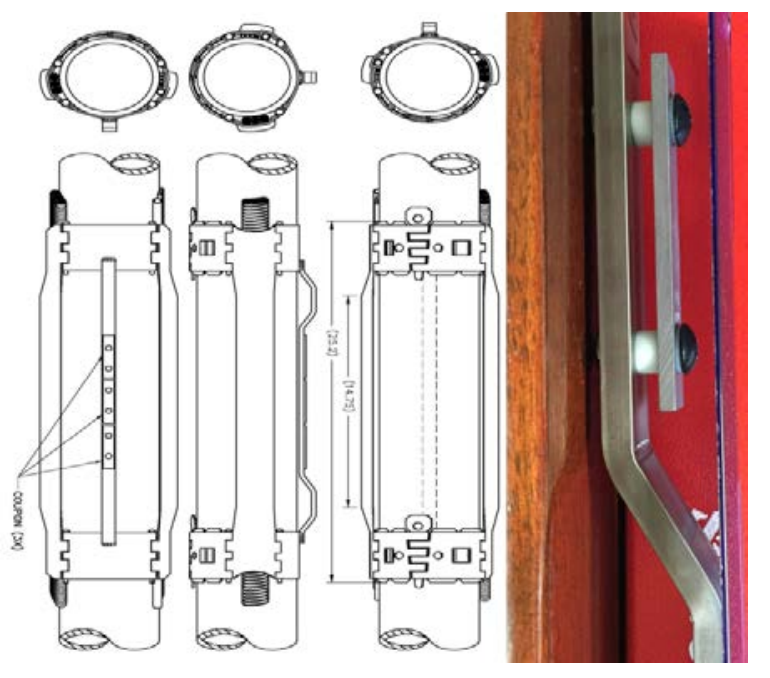

Figure 3.6: Clamp and coupon installation setup

Five sets of clamps with coupon holders were installed at select well elevations.

This was done to determine variations in corrosion rate and mechanism at different elevations due to the presence of varying fluid compositions and flow conditions. This is shown in Figure 3.7 and Table 3.8. The measure mKB "meters kelly bushing” is a depth measurement taken from a reference location, the kelly bushing, on a drilling rig. It is the measure of a wells depth along the wellbore.

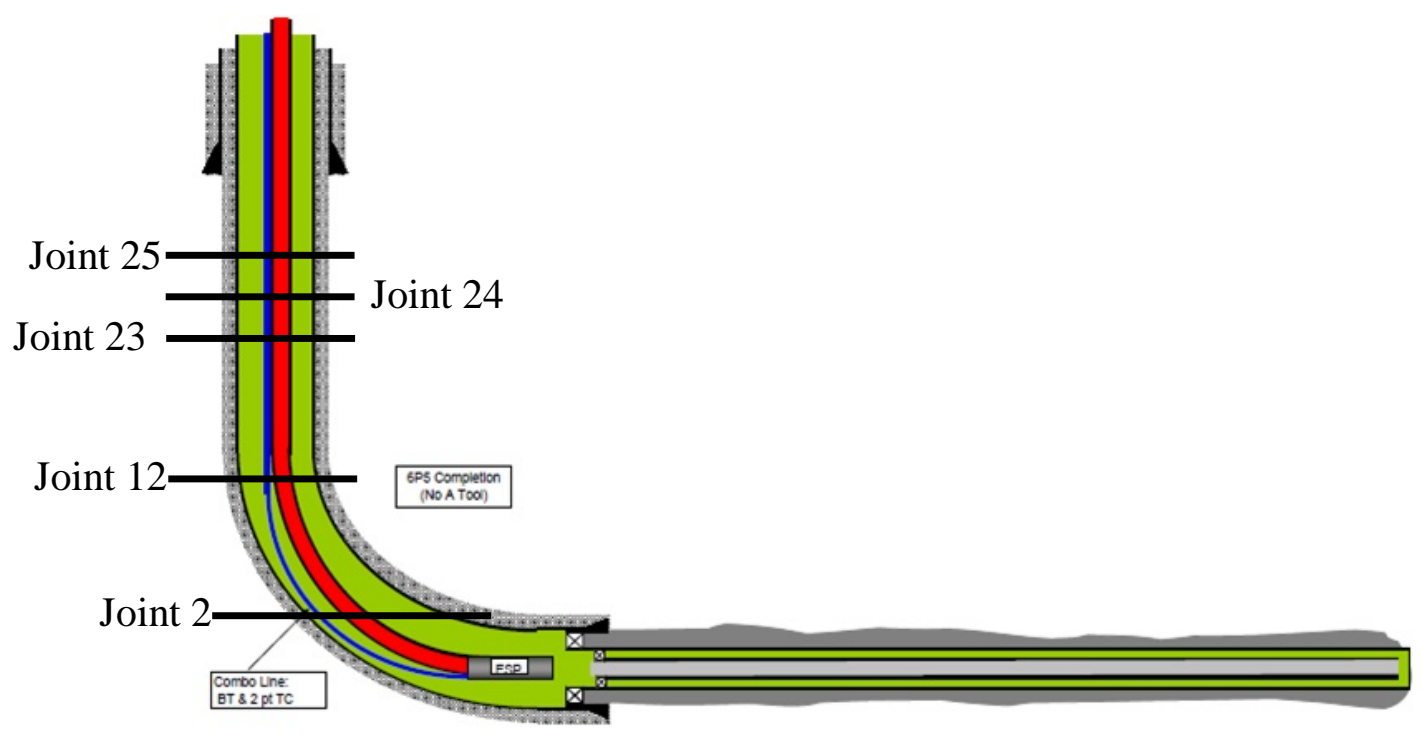

Figure 3.7: Coupon installation depths 


\section{Table 3.8: Corrosion coupon installation depths}

\begin{tabular}{|l|l|}
\hline Component & Depth (mKB) \\
\hline ESP Depth (mKB) & 537.58 \\
\hline ESP Depth (mTVD) & 334.00 \\
\hline Joint 2 & 505.15 \\
\hline Joint 12 & 372.47 \\
\hline Joint 23 & 223.25 \\
\hline Joint 24 & 209.76 \\
\hline Joint 25 & 196.17 \\
\hline
\end{tabular}

Each clamp had three separate corrosion cell setups on it. Setups included standalone material testing on the J-55 and L-80 materials, as well as a galvanic/crevice setup between J-55 and GLV-J55 coupons. Three of the clamps were installed on tubing joints at, above, and below where the annular liquid level is believed to be. Due to varying operating conditions in a well, the range of fluid level elevation is approximately $30 \mathrm{~m}$. A fourth clamp was installed half way between the ESP and liquid level. And the fifth clamp was installed on the tubing joint above the ESP. The fluid level top within the well can be estimated using surface and ESP pressure measurements. Field testing work is summarized in Table 3.9. 
Table 3.9: Field coupon testing summary

\begin{tabular}{|c|l|l|l|}
\hline Materials & Measurements & Analysis & Test Purpose \\
\hline J-55 & WL & $\begin{array}{l}\text { XRD, SEM, } \\
\text { EDX }\end{array}$ & $\begin{array}{l}\text { - General CR } \\
- \text { Morphology } \\
- \text { Scale } \\
\text { Composition }\end{array}$ \\
\hline L-80 & WL & XRD, SEM, \\
& EDX & $\begin{array}{l}- \text { General CR } \\
- \text { Morphology } \\
\text { - Scale } \\
\text { Composition }\end{array}$ \\
\hline GLV-J55 & WL & XRD, SEM, & $\begin{array}{l}\text { - General CR } \\
- \text { Morphology } \\
\text { EDX }\end{array}$ \\
& & Scale \\
& & & Composition \\
\hline
\end{tabular}

\subsubsection{Coupon materials, clamp design, and installation design}

Table 3.10 lists the materials analysed in the downhole corrosion tests.

Table 3.10: Downhole corrosion coupons

\begin{tabular}{|c|c|c|}
\hline Material & Location of Use & Analysis Completed \\
\hline J-55 & Tubular Material & Corrosion Rate and Morphology \\
\hline L-80 & Tubular Material & Corrosion Rate and Morphology \\
\hline GLV-J55 + J-55 & Clamp and ESP Cable & Corrosion Rate and Morphology \\
\hline
\end{tabular}

$\mathrm{J}-55$ and L-80 were tested due to their common use in oil and gas tubular applications and the combination of the GLV-J55+ J-55 was to better understand galvanic and crevice corrosion between completion and tubular components. K-55 was not tested due to sample availability and its compositional similarity to J-55. Enough so that comparisons to the K-55 coupon corrosion rates from the lab testing can be made. J-55 and L-80 materials have both mechanical and chemical differences. L-80 was tested for it being a higher carbon content steel with increased strength and hardness properties to 
understand the effects of the SAGD conditions present on this type of material. See appendix for general material property differences.

Five specially designed instrumentation clamps were installed in a well for a total of 20 coupons. Coupons were bolted on the clamp and separated from the clamp using a teflon spacer. In the galvanic and crevice testing setup between the GLV-J55 and J-55, no washer or separator was used to isolate each coupon. The same teflon spacer was still used to isolate it from the clamp.

Coupon samples were manufactured to the NACE Standard RP0775-2005

"Preparation, Installation, Analysis, and Interpretation of Corrosion Coupons in Oilfield Operations” [63]. The corrosion coupon dimensions were as follows:

1. J-55 and GLV-J55 coupons for crevice/galvanic testing: 1/16" X 1/2" X 3" with two 1/4" diameter holes. Each hole located 1/2” in from the end and centered. The coupon corners are squared.

2. L80 and J-55 coupon: 1/8" X 1/2" X 3" with two 1/4" diameter holes. Each hole located 1/2” in from the end and centered. The coupon corners are squared.

\subsubsection{Downhole operating conditions}

Figure 3.8 to Figure 3.10 show the wells operating conditions throughout the testing period. Including the estimated average liquid level in the well, surface and bottom hole pressure (BHP), as well as the downhole ESP and casing surface temperatures respectively. Figure 3.8 also shows the estimated liquid level in the wells annulus with the coupon elevations. The joint 2 coupon is located just above the ESP, continually submerged in the emulsified fluid. The joint 12 coupon was submerged in oil 
for the majority of the coupons installation. The coupons on joints 23, 24, and 25 were likely both submerged and above the liquid level throughout the testing.

The liquid level in a well varies depending on the wells operating conditions and setpoints. Changes in ESP speed, production tubing and casing surface pressure setpoints, all of which cause BHP deviations, will lead to changes in the fluid level due to differential pressure changes between the BHP and casing surface pressure. Changes in annular pressures or temperatures, because of well operating condition changes, can also lead to an increase or decrease in the annular gas flow and condensation rates based on changing saturation conditions. During the testing these parameters were out of my control as they are adjusted to optimize the wells operation and oil production based on plant and site requirements. As can be seen in Figure 3.9 the casing surface pressure setpoint is steady and that changes in downhole operating parameters is what more commonly dictates the liquid level in the well. Understanding the liquid level elevation is important as corrosion issues have been found here in other wells based on past failure analysis.

Figure 3.10 shows the wells downhole and casing surface temperate trends. This shows downhole temperatures being at $200^{\circ} \mathrm{C}$ for much of the testing period and up to $215^{\circ} \mathrm{C}$ for periods of time. The operating BHP is shown to be between $2000 \mathrm{kPa}-2500$ $\mathrm{kPa}$ for the majority of the trial, with saturation temperatures of approximately $212.4^{\circ} \mathrm{C}$ to $223.9^{\circ} \mathrm{C}$ respectively. This indicates that at the ESP fluids were for the most part in a liquid form.

Casing temperatures can give an indication as to when the wells annulus may be flowing gas or not. Casing annular gas flow meter data is not available in this well. The 
steam saturation temperature at $1000 \mathrm{kPa}$ is approximately $180.0^{\circ} \mathrm{C}$. When operating conditions and temperatures reach this level, that annular fluid, containing water, will begin to vaporize and the casing will likely start flowing fluids to surface and be produced. Some of the fluids may condense as temperature and pressure drop from the liquid level to surface. This will cause condensation and possibly further corrosion at higher well elevations.

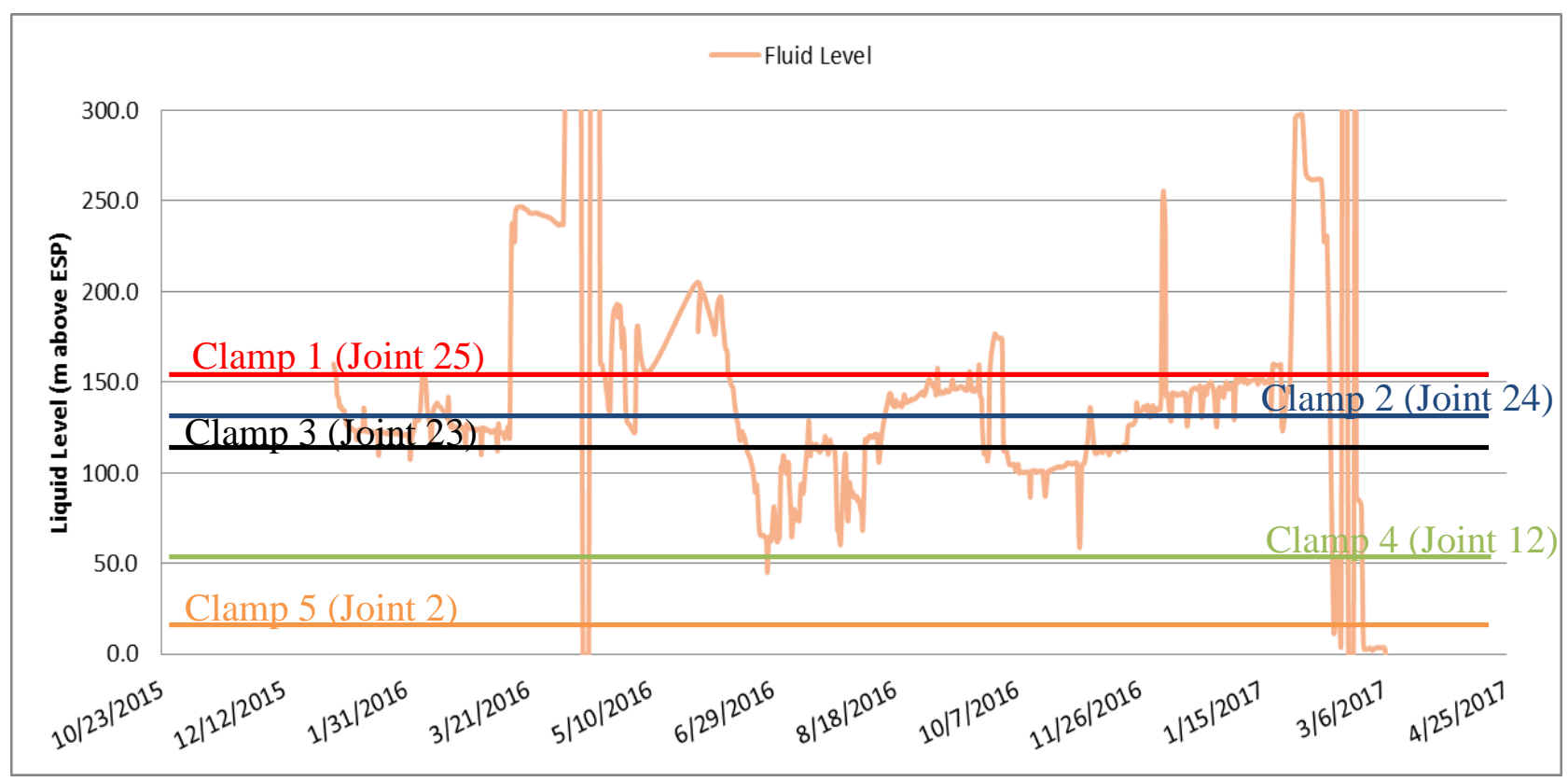

Figure 3.8: Annular fluid level 


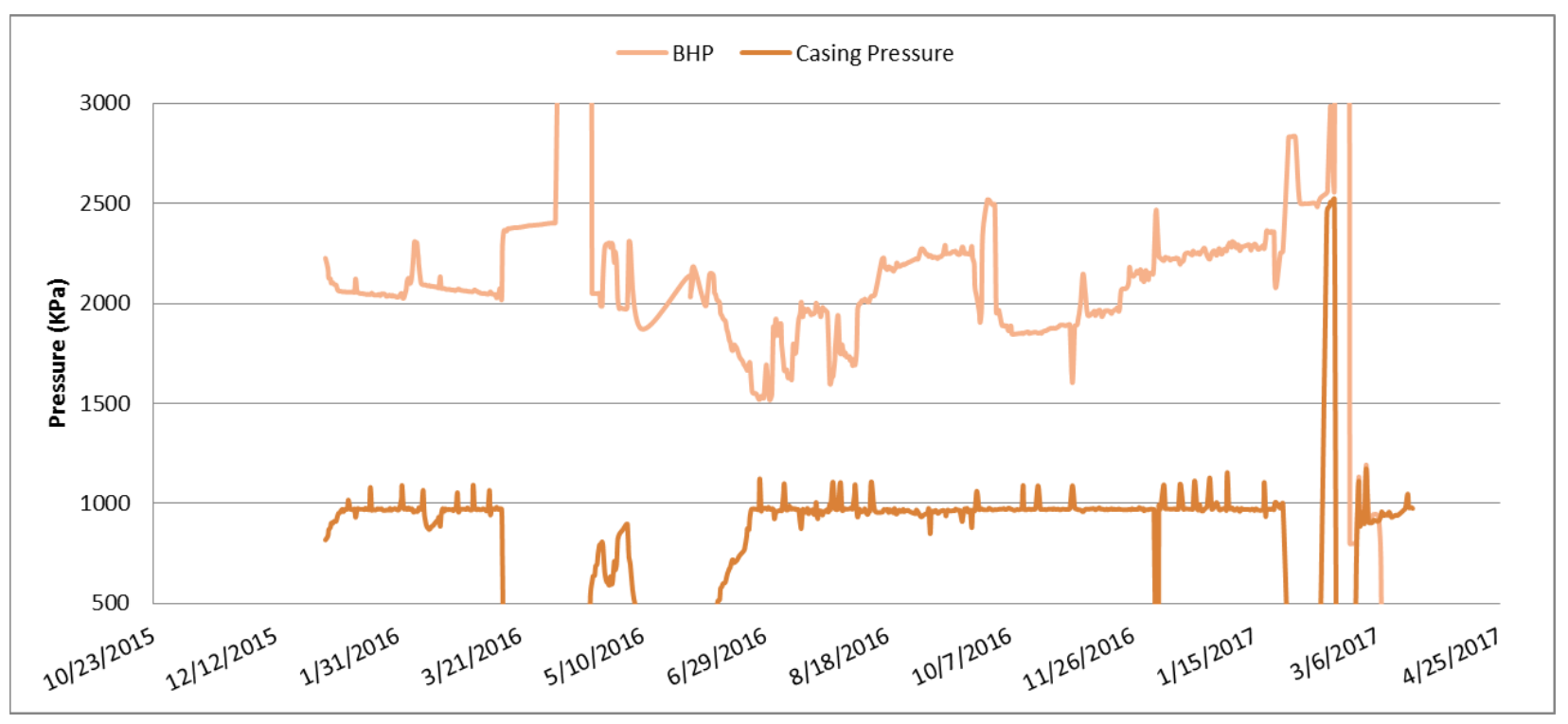

Figure 3.9: Bottom hole and casing surface pressures

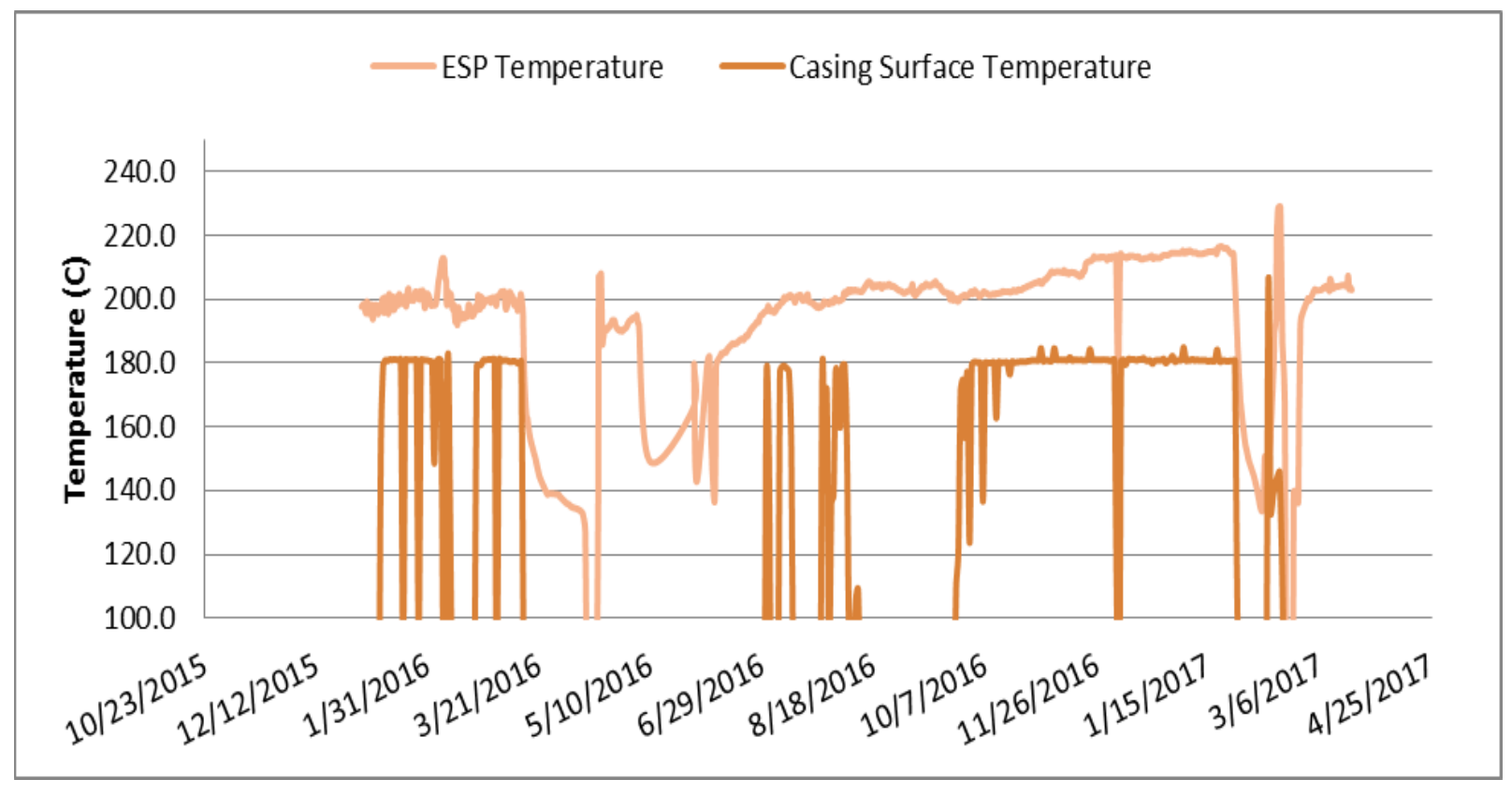

Figure 3.10: Operating temperatures 


\subsubsection{Field testing analysis}

Similar to the lab testing, selecting the proper corrosion analysis techniques to analyze the corrosion coupons is important to accurately determine corrosion rates and mechanisms. Corrosion coupon analysis techniques used include:

- Visual inspections

- Weight loss analysis for averaged corrosion rates

- X-ray diffraction (XRD) for corrosion scale composition: Determines the atomic and molecular structure of a crystal. Unidentified compounds can be noted when homogeneous and single phase materials are present.

- Scanning Electron Microscopy (SEM): Produces sample images containing information about the sample's surface topography

- Energy-Dispersive X-ray Spectroscopy (EDS): An analytical technique used for the elemental analysis of a sample

O NOTE: EDS is typically only completed to support XRD analysis should clarifications be required or XRD discrepancy readings found. No XRD issues were noted and therefore this data not displayed. 


\section{Chapter Four: Testing results and analysis}

This section discusses and analyzes the testing results for the lab and field tests completed. Analysis completed includes corrosion rate, current, and potential testing. Also completed were morphology imaging, visual inspections, and comparative scale compositional analysis.

Corrosion rate calculations and analysis were done using NACE standard SP0775-2013 [63]. This standard outlines how corrosion rates are calculated, and categorizes corrosion severity based on corrosion coupons installed in oil and gas operations. The categories are presented in Table 4.1.

\section{Table 4.1: NACE corrosion categories}

\begin{tabular}{|c|c|}
\hline Category & Corrosion Rate Range $(\mathrm{mm} / \mathrm{y})$ \\
\hline Low & $<0.025$ \\
\hline Moderate & $0.025-0.15$ \\
\hline High & $0.16-0.25$ \\
\hline Severe & $>0.25$ \\
\hline
\end{tabular}

\subsection{Lab testing results and analysis}

This section presents the results from the wellhead [64] and downhole material testing $[65,66]$ completed in a controlled laboratory environment. Wellhead material weight loss, LPR, potentiostatic polarization, and CPP testing results on 1018 carbon steel, Deloro-40 HF, and Stellite-6 HF materials are presented. The downhole material testing results from the K-55, TN-55TH, and GLV-J55 materials are also shown along with a discussion on the findings. 


\subsubsection{Wellhead material testing results}

The LPR and weight loss corrosion rate tests are summarized in Table 4.2 and shown in Figure 4.1 and Figure 4.2 to display the corrosion rate resting completed using LPR. Post-testing photographs are shown in Figure 4.3.

Table 4.2: Corrosion rate data summary

\begin{tabular}{|c|c|c|c|c|}
\hline Material & $\begin{array}{c}\text { Initial LPR } \\
(\mathrm{MPY} / \mathrm{mm} / \mathrm{y})\end{array}$ & $\begin{array}{c}\text { Final LPR } \\
(\mathrm{MPY} / \mathrm{mm} / \mathrm{y})\end{array}$ & $\begin{array}{c}\text { Weight Loss } \\
(\mathrm{mg})\end{array}$ & $\begin{array}{c}\text { Weight Loss CR } \\
(\mathrm{MPY} / \mathrm{mm} / \mathrm{y})\end{array}$ \\
\hline 1018 Carbon Steel & $70.43 / 1.79$ & $15.05 / 0.38$ & 28.4 & $9.66 / 0.25$ \\
\hline Deloro-40 HF & 0.00 & $1.38 / 0.035$ & 0.10 & $0.03 / 0.00076$ \\
\hline Stellite-6 HF & $0.61 / 0.015$ & $0.95 / 0.024$ & -10.60 & N/A \\
\hline
\end{tabular}

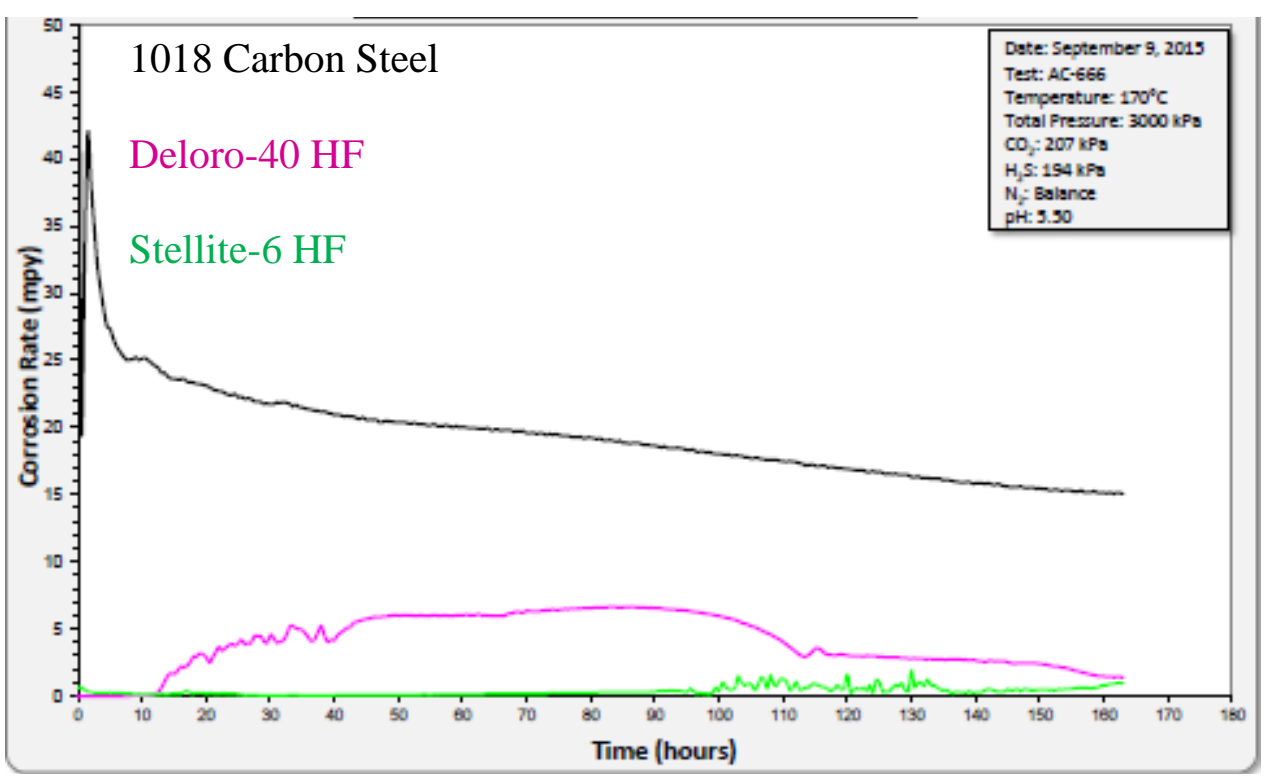

Figure 4.1: Wellhead material LPR autoclave crevice corrosion testing 


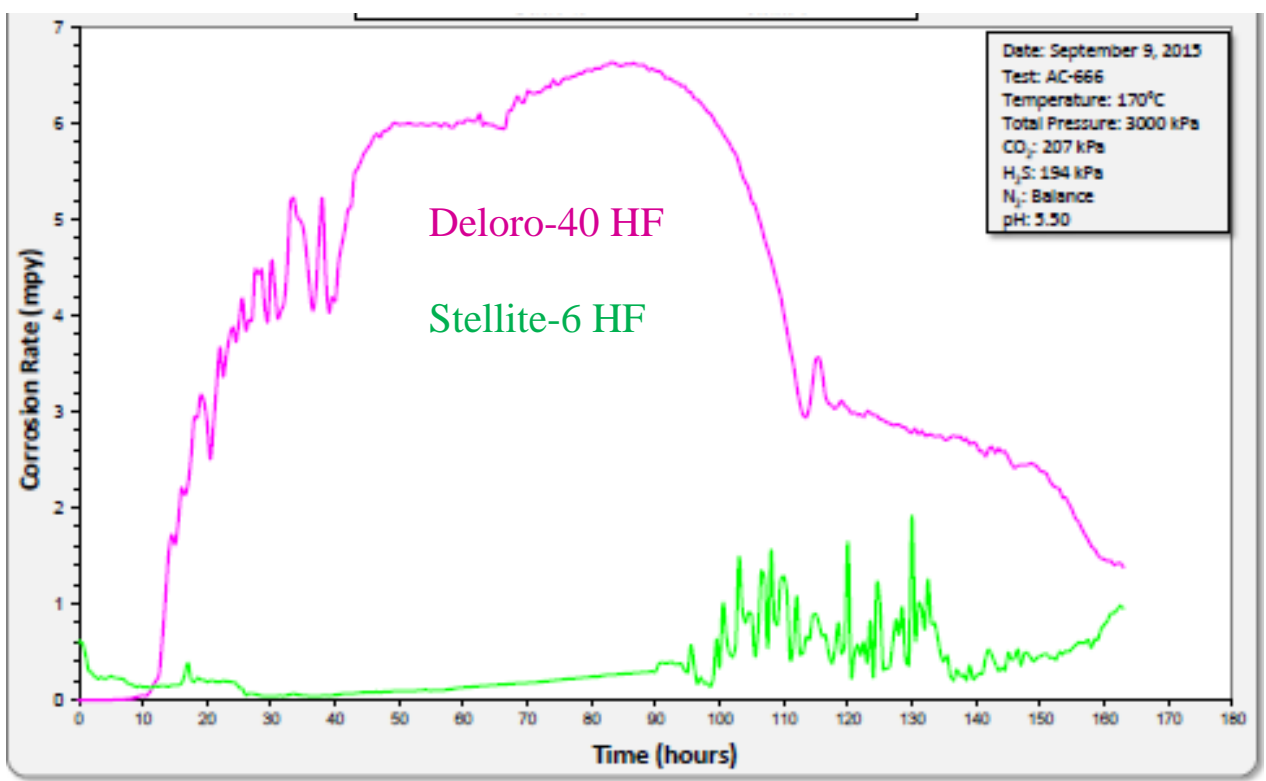

Figure 4.2: Magnified LPR autoclave crevice corrosion testing trend

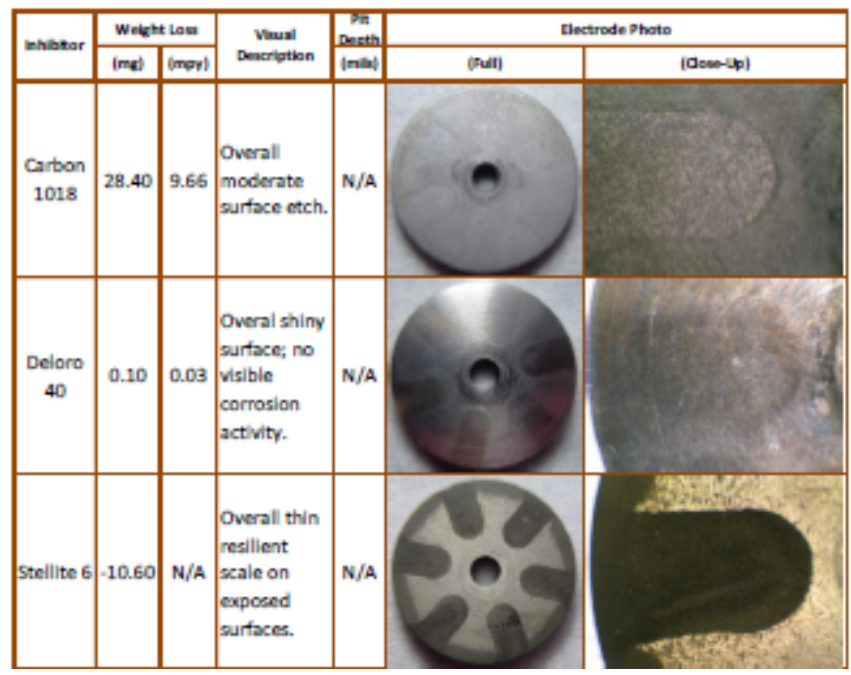

Figure 4.3: Post-test weight loss data and electrode photographs

The 1018 carbon steel weight loss corrosion rate was calculated to be $0.25 \mathrm{~mm} / \mathrm{y}$ (9.66 MPY). The initial LPR corrosion rate was $1.789 \mathrm{~mm} / \mathrm{y}$ (70.43 MPY), which then trended down sharply to $\sim 0.635 \mathrm{~mm} / \mathrm{y}$ (25 MPY) as shown in Figure 4.1. This was followed by a gradual decrease for the remainder of the 7-day test period. This spike followed by a decrease indicates initially high corrosion rates followed by the formation 
of a passivating corrosion scale. It is believed that FeS scales become stable and uniform after 24h [50]. This is observed on the 1018 CS samples, but not on the HF materials. This is likely due to their corrosion resistant properties and a longer time required for a passive film to form. A moderate etching attack was noted in the creviced areas of the coupon, as well as the exposed bottom surface indicating no preferential corrosion had occurred in the creviced areas compared to the flat surfaces. Although preferential corrosion can be expected, it is likely to have not occurred here due to the steels susceptibility to rapid rates of initial corrosion and uniform scale formation. In this relatively undisturbed environment the passive scale remains intact and limits any preferential corrosion from occurring.

The Deloro-40 HF material had a very low initial weight loss corrosion rate of $0.001 \mathrm{~mm} / \mathrm{y}(0.03 \mathrm{MPY})$. The recorded weight loss of $0.1 \mathrm{mg}$ is equal to the accuracy of the analytical balance used to weigh the electrodes and may be considered negligible. The Deloro-40 HF LPR corrosion rate displayed a peak level of $\sim 0.152 \mathrm{~mm} / \mathrm{y}$ (6 MPY) before decreasing to $\sim 0.0254 \mathrm{~mm} / \mathrm{y}$ (1 MPY) by the end of the test period. No visible corrosion activity was noted on the electrode surface when observed under 10 times magnification. Deloro-40 HF peak corrosion rates were reached 3-4 days into the testing, as compared to the carbon steel which peaked in $<1$ day. Past research has shown it difficult to determine the exact mechanism of corrosion and corrosion resistance for HF alloys [67, 68]. A hypothesis in the longer time taken to reach peak rates before decreasing to stabilize is that it could be due to the lower corrosion susceptibility of the Deloro-40 HF material more time required for a passive scale to form. But once formed, becomes a more passive system. The Stellite-6 HF material also had a very low LPR corrosion rate and trended 
below $0.0254 \mathrm{~mm} / \mathrm{y}$ (1 MPY) for the duration of the test. The Stellite-6 HF measured a negative weight loss reading of $-10.6 \mathrm{mg}$. This was not expected as it indicates that the sample had gained weight and more scale had formed than Stellite-6 HF material corroded. Similar to the Deloro-40 HF trend, it took several days for peak corrosion rates to be reached before decreasing because of the time required for a passive scale to form.

Both the Deloro-40 HF and Stellite-6 HF materials were strong performers in resisting corrosion. To better differentiate the Deloro-40 HF and Stellite-6HF materials for use in application, further CPP and potentiostatic polarization testing was completed to better understand the materials tendency to pit and ability to re-passivate should it occur. A summary of the results are listed in Table 4.3 and Table 4.4 with the Deloro-40 HF and Stellite-6 HF CPP data trends shown in Figure 4.4 and Figure 4.5.

Table 4.3: CPP testing summary

\begin{tabular}{|c|c|c|c|}
\hline Material & $\begin{array}{c}\text { Pit Potential } \\
\text { (mV vs Eoc) }\end{array}$ & $\begin{array}{c}\text { Apex Potential } \\
\text { (mV vs Eoc) }\end{array}$ & $\begin{array}{c}\text { Re-passivation Potential } \\
\text { (mV vs Eoc) }\end{array}$ \\
\hline Deloro-40 HF & 82 & 581 & -3.9 \\
\hline Stellite-6 HF & 194 & 635 & 60 \\
\hline
\end{tabular}

Table 4.4: PP testing summary

\begin{tabular}{|c|c|c|}
\hline Material & $\begin{array}{c}\text { Initial Current Density } \\
\left(\mathrm{uA} / \mathrm{cm}^{2}\right)\end{array}$ & $\begin{array}{c}\text { Final Current Density } \\
\left(\mathrm{uA} / \mathrm{cm}^{2}\right)\end{array}$ \\
\hline Deloro-40 HF & 500.5 & 11.7 \\
\hline Stellite-6 HF & 236.2 & -29 \\
\hline
\end{tabular}




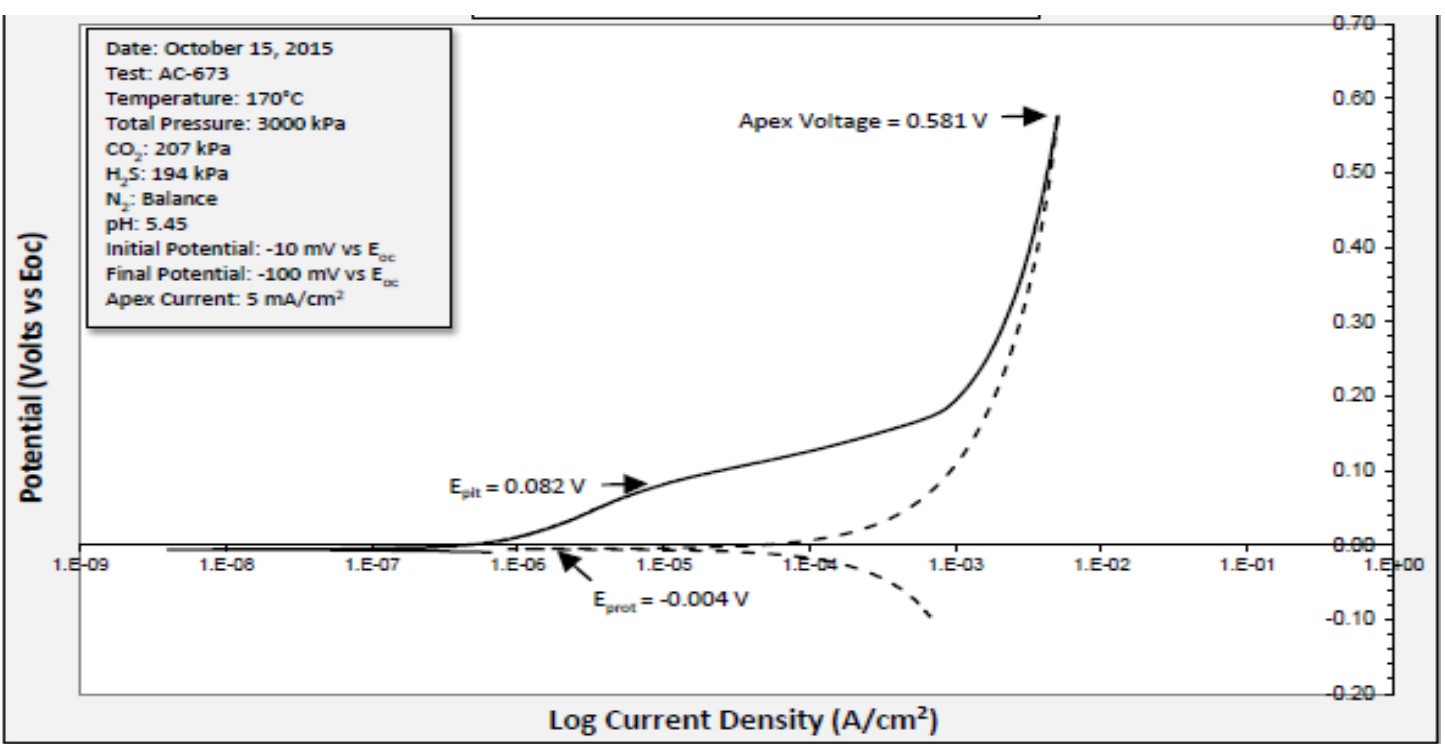

Figure 4.4: Deloro-40 HF CPP data (Solid - Anodic, Dashed - Cathodic Sweeps)

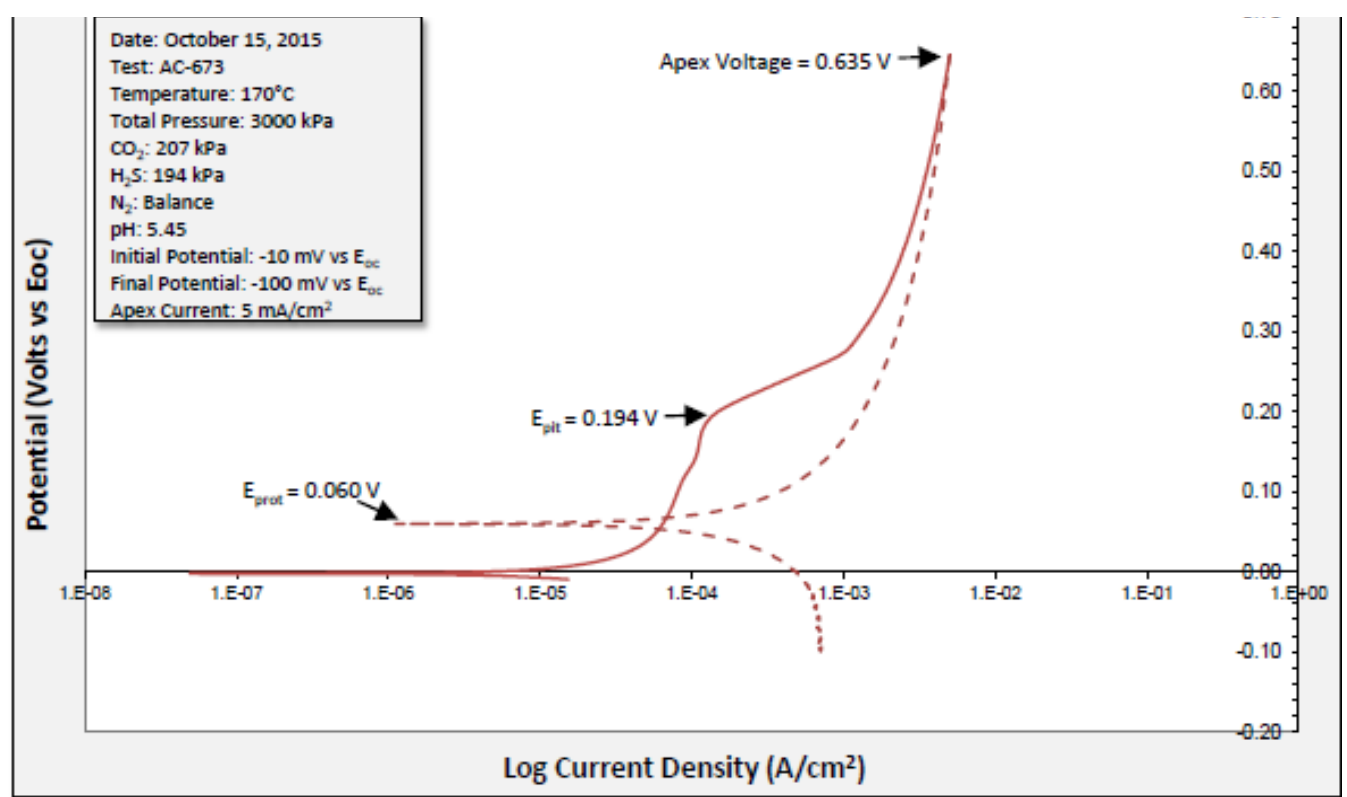

Figure 4.5: Stellite-6 HF CPP data (Solid - Anodic, Dashed - Cathodic Sweeps)

The Deloro-40 HF trend shows an initially gradual linear response to the applied anodic potential. An inferred pitting potential ( $E_{\text {Pit }}$, point of pitting initiation) is seen at $82 \mathrm{mV}$ versus the Open Circuit Potential (OCP, $\left.\mathrm{E}_{\mathrm{OC}}\right)$. Increasing anodic potentials were 
applied to the electrode until a peak current density was achieved. The point at which this occurred for the Deloro-40 HF was of $5 \mathrm{~mA} / \mathrm{cm}^{2}$ and $581 \mathrm{mV}$, this is the apex potential. The potential was then swept in a cathodic direction to $100 \mathrm{mV}$ below (cathodic to) the $E_{O C}$. The reverse sweep for the Deloro-40 HF material did not intersect with the anodic sweep. When the reverse sweep does not intersect with the anodic sweep, this indicates a positive hysteresis loop and that if any pitting were to occur that it would progress in an aggressive manner as the material is less likely to quickly form a passive film [69].

The Stellite-6 HF material had a more prominent pitting potential of $194 \mathrm{mV}$ as shown in Figure 4.5. Although the rapid increase in current density over a relatively small potential change is indicative of a tendency to pit, the potential at which this occurred is more than double that of the Deloro-40 HF indicating it to be a more resistant alloy to corrosion and pitting. Additionally, a higher apex potential of $635 \mathrm{mV}$ was observed, as in Figure 4.5, for the Stellite-6 HF in comparison to the Deloro-40 HF. This indicates the material is able to withstand more anodic (aggressive) potentials before the peak current density is reached and is indicative of a more noble metal. During the cathodic sweep the plotted line intersected with that of the anodic sweep indicating a negative hysteresis loop. This type of loop is indicative of a more corrosion resistant material, as any pitting that may occur is likely to passivate rather than progress further [70, 71]. The point at which current density reaches its lowest value on the reverse scan is labelled as the repassivation potential ( $E_{\text {Pr ot }}$ ). The Stellite-6 HF material displayed a higher $E_{\text {Pr ot }}$ which again is indicative of a material that will quickly re-passivate and prevent further pit growth. 
The potentiostatic polarization testing results in Figure 4.6 show the Deloro-40 HF material had a higher initial current density in response the constant applied potential of $60 \mathrm{mV}$ than did the Stellite-6 HF. Its current density also trended higher for most of the test. The downward trend towards lower current density values indicates the formation and presence of a passivating film. In both the LPR and PP testing corrosion rates started increasing after 10 hours of testing before reaching peak corrosion rates/current densities and slowly trending downwards.

The Stellite-6 HF had an initial current density of $236.2 \mu \mathrm{A} / \mathrm{cm}^{2}$, roughly half that of the Deloro-40 HF. The current response trended down throughout and eventually read negative (cathodic) current values. These cathodic current values are unexpected in response to an applied anodic potential but is likely due to the presence of a highly passivating and resilient corrosion scale on the electrode surface.

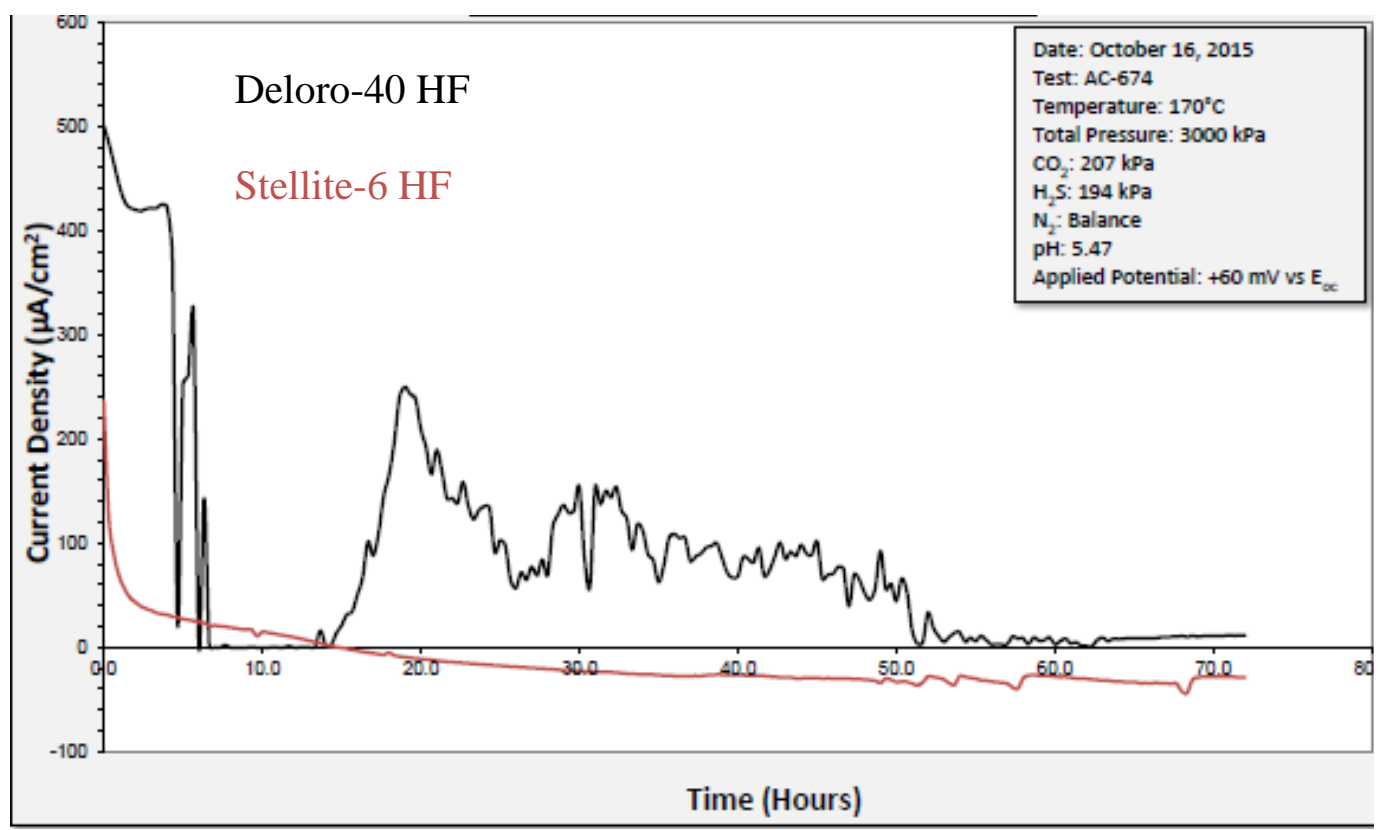

Figure 4.6: Deloro-40 HF and Stellite-6 HF potentiostatic test data 


\subsubsection{Downhole material testing results}

Table 4.5 and Figure 4.7 summarize the LPR corrosion rate data for both the K-55 and TN-55TH materials.

Table 4.5: Downhole material LPR corrosion rate summary

\begin{tabular}{|l|r|r|l|r|}
\hline \multirow{2}{*}{ Electrode Material } & \multicolumn{2}{|c|}{ LPR Corrosion Rate } & \multicolumn{2}{c|}{ Weight Loss } \\
\cline { 2 - 5 } & $\begin{array}{l}\text { Initial } \\
(\mathrm{MPY} / \mathrm{mm} / \mathrm{y})\end{array}$ & $\begin{array}{l}\text { Final } \\
(\mathrm{MPY} / \mathrm{mm} / \mathrm{y})\end{array}$ & $\begin{array}{l}\text { Mass } \\
(\mathrm{mg})\end{array}$ & $\begin{array}{l}\text { Corrosion Rate } \\
(\mathrm{MPY} / \mathrm{mm} / \mathrm{y})\end{array}$ \\
\hline $\mathrm{K}-55$ & $7.42 / 0.188$ & $9.57 / 0.243$ & 35.0 & $11.73 / 0.297$ \\
\hline $\mathrm{TN}-55 \mathrm{TH}$ & $7.74 / 0.196$ & $9.6 / 0.243$ & 37.5 & $12.56 / 0.319$ \\
\hline
\end{tabular}

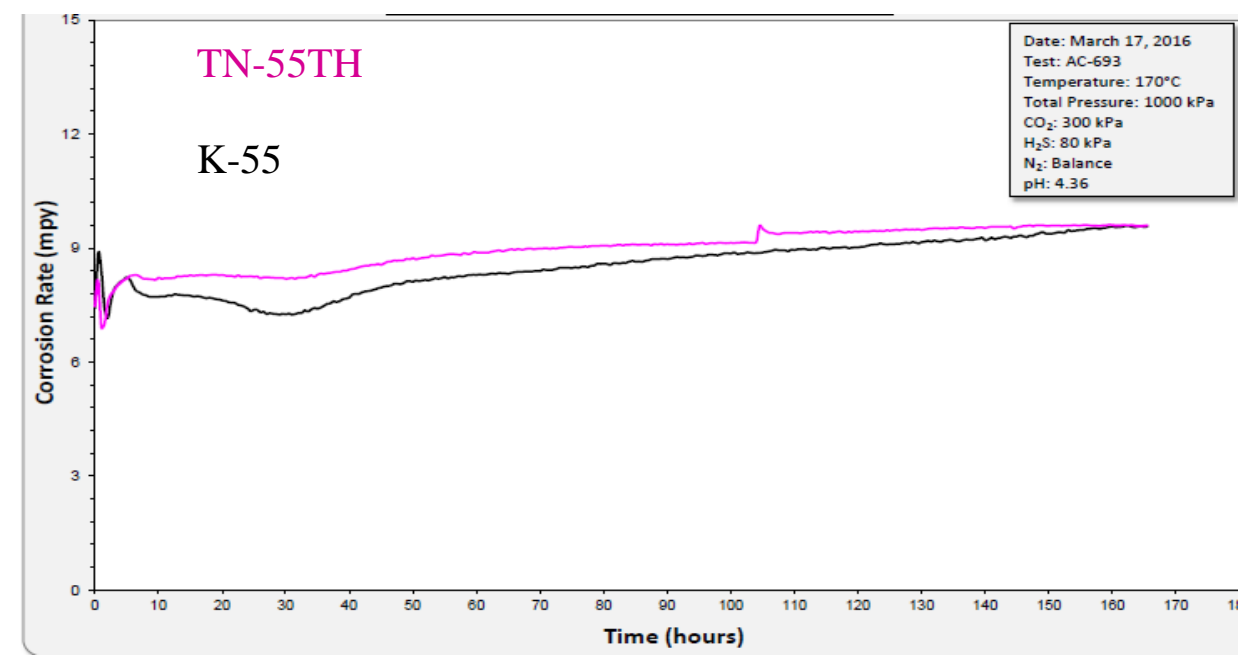

Figure 4.7: LPR K-55 and TN-55TH corrosion rate vs time

Both of the LPR corrosion rate trends initially increase rapidly, followed by a decrease, and then slowly trend upwards to a stable and equilibrium corrosion rate. The corrosion mechanism present is believed to be that of a solid-state reaction where initially a very adhesive, thin, and protective scale forms. This is followed by a sequence of internal stresses cracking the scale causing a re-growth which leads to a secondary less passive outer scale to form [72] and why the corrosion rates slowly increased before coming to a slightly higher and stable corrosion rate. 
The LPR corrosion rate for the K-55 material trended from an initial $0.188 \mathrm{~mm} / \mathrm{y}$ (7.42 MPY) up to a final stable corrosion rate of $0.243 \mathrm{~mm} / \mathrm{y}$ (9.57 MPY). The low and stable LPR trend indicates the presence of a passivating corrosion scale. The electrodes had an overall moderate surface etch with a corresponding weight loss corrosion rate of $0.298 \mathrm{~mm} / \mathrm{y}$ (11.73 MPY). There was no indication of localized corrosion activity on the electrode surface as seen in Figure 4.8.

The TN-55TH sample had a very similar LPR trend to that of K-55. The LPR corrosion rate trended higher for the majority of the test but they were nearly identical by the end of the exposure period. The electrode weight loss was slightly higher at 0.319 mm/y (12.56 MPY) which corresponds well with the slightly higher LPR trend. There was no indication of localized corrosion activity as the electrodes had a similar overall moderate surface etch as seen in Figure 4.8.

These trends are opposite to that of the 1018 CS trends found in the wellhead testing. A difference between these tests is the $\mathrm{pH}$ of the brine. The wellhead materials brine was $\mathrm{pH} 5.50$ and the downhole testing at $\mathrm{pH} 4.36$. The lower $\mathrm{pH}$ can delay the formation of a passive scale and allow corrosion rates to increase until the corrosion product solubility limit is reached for a protective film to form. 


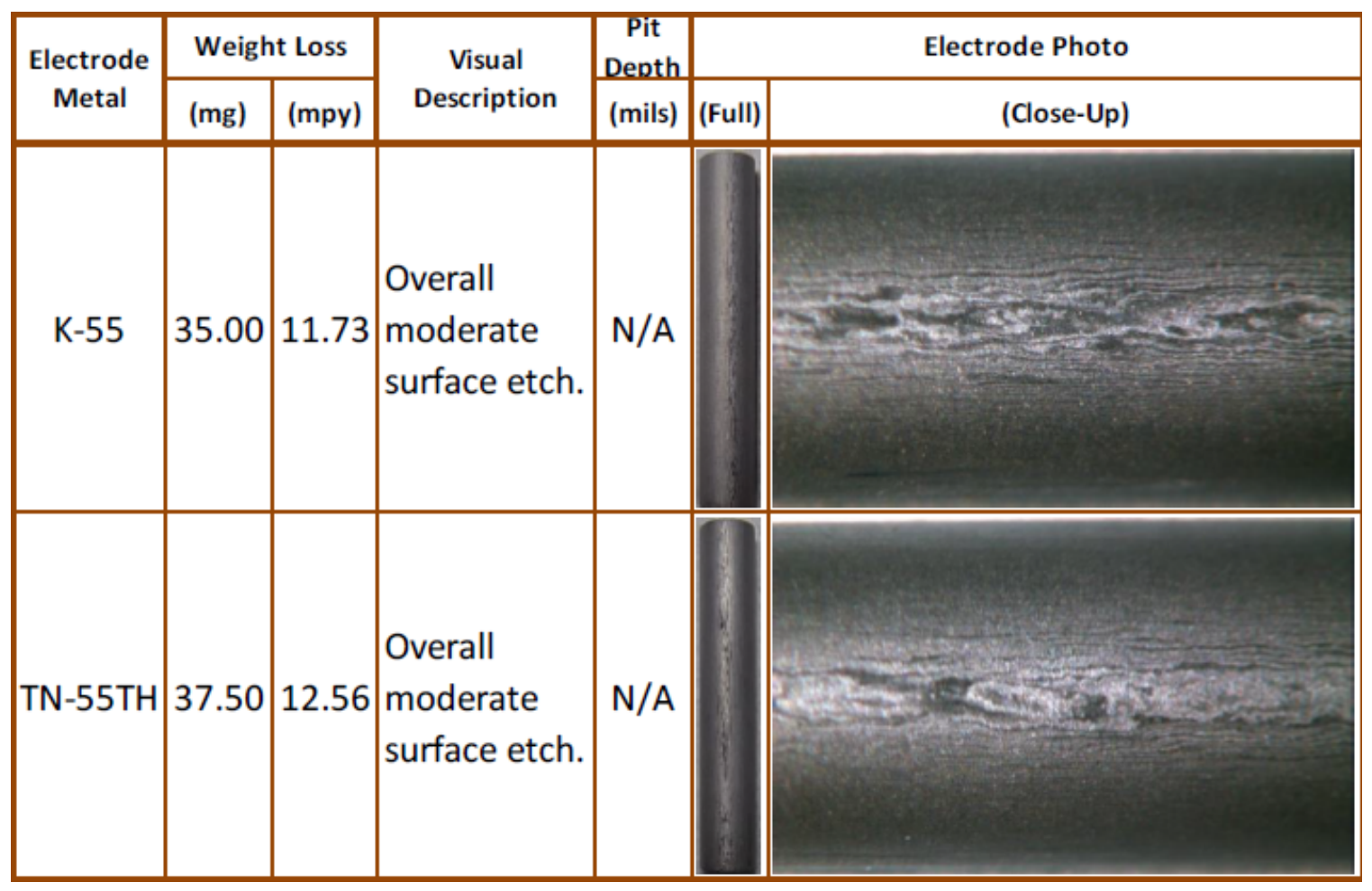

Figure 4.8: LPR Test - Weight loss data and electrode photographs

Table 4.6 summarizes the crevice corrosion rate test data for the K-55+TH-55TH, and K-55+GLV-J55 crevice couples and Figure 4.9 shows post-test images.

Table 4.6: Downhole material crevice corrosion rate testing summary

\begin{tabular}{|l|l|l|l|l|l|l|}
\hline \multirow{2}{*}{ Coupon Pair } & \multicolumn{2}{|c|}{ K-55+TN-55TH } & \multicolumn{2}{c|}{ K-55+ GLV-J55 } & \multicolumn{2}{c|}{ K-55+K-55 } \\
\hline Individual Coupon & K-55 & TN-55TH & K-55 & GLV-J55 & K-55 & K-55 \\
\hline $\begin{array}{l}\text { Corrosion Rate } \\
\text { (MPY/mm/y) }\end{array}$ & $9.5 / 0.241$ & $9.69 / 0.246$ & $\begin{array}{l}10.87 / \\
0.276\end{array}$ & $5.41 / 0.137$ & $8.48 /$ & $8.49 /$ \\
\hline
\end{tabular}




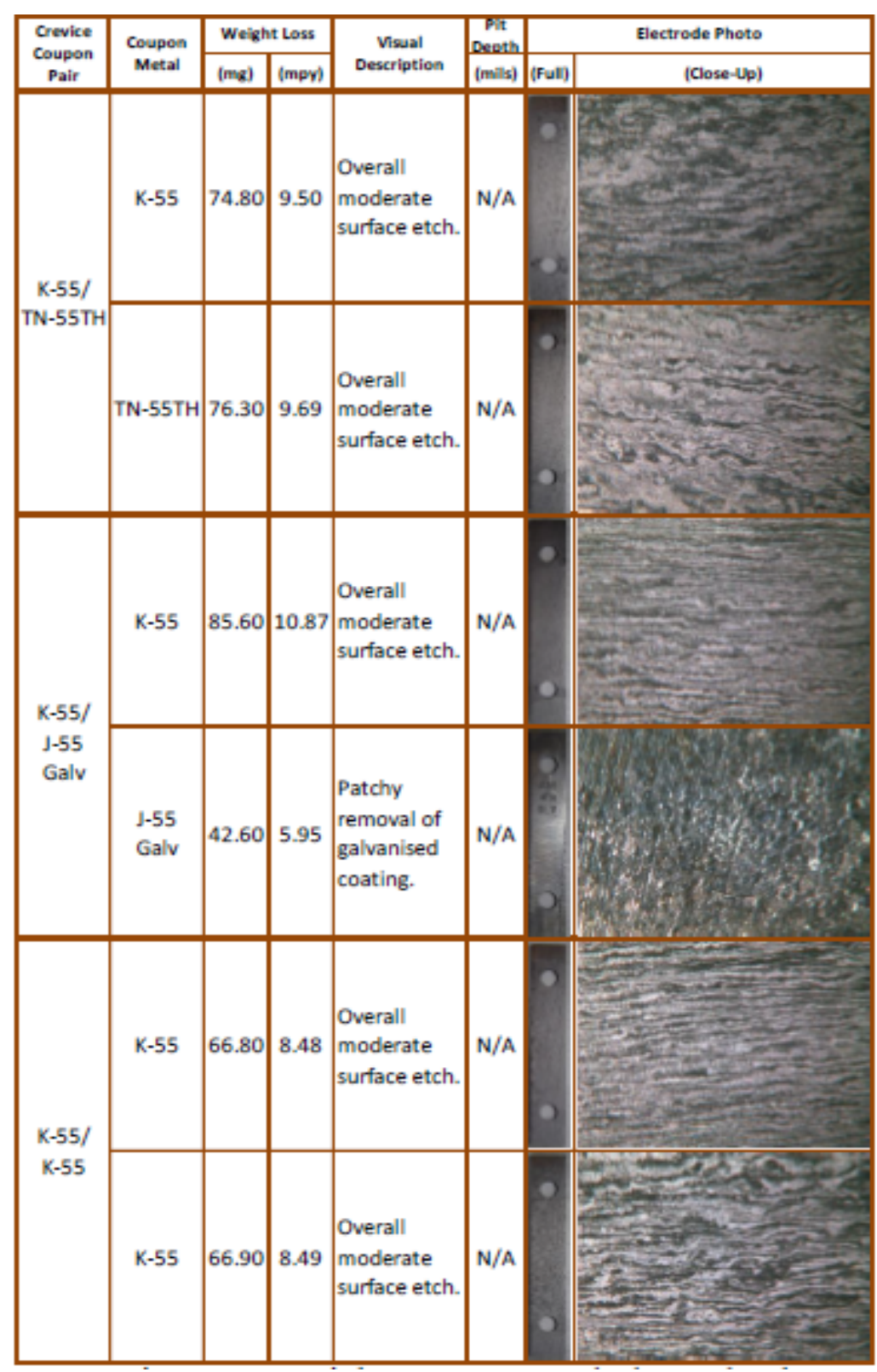

Figure 4.9: Crevice test - Weight loss data and electrode photographs

The K-55+TN-55TH coupon pair had very similar weight loss corrosion rates with the K-55 at $0.241 \mathrm{~mm} / \mathrm{y}$ (9.50 MPY) being slightly lower than the $0.246 \mathrm{~mm} / \mathrm{y}$ (9.69 MPY) for the TN-55TH. Although the TN-55TH had a slightly higher weight loss corrosion rate, the difference in corrosion rate is not significant enough to determine its corrosion performance versus that of a K-55 alloy. The two coupons had a similar overall 
moderate surface etch. No localized or preferential attack was noted at the point of contact or crevice formed by the coupon pair as Figure 4.9 indicates. This is unexpected as creviced conditions are known to accelerate corrosion rates. The similar corrosion rates and no visual localized attack is likely due to the relatively short exposure period, similar materials, and static testing conditions. These factors will not allow for enough of a difference in the bulk fluid to localized area fluid properties and therefore variations in corrosion rates between the open and creviced surfaces.

Crevice corrosion testing indicated the K-55+ GLV-J55 coupon pair had very different weight loss corrosion rates. The K-55 weight loss corrosion rate of 10.87 MPY $(0.276 \mathrm{~mm} / \mathrm{y})$ was double that of the GLV-J55 at $5.95 \mathrm{MPY}(0.151 \mathrm{~mm} / \mathrm{y})$. The K-55 had an overall moderate surface etch with a shinier appearance due to the formation of a $\mathrm{Zn}$ based film. The low weight loss corrosion rate observed in the GLV-J55 coupon corresponds well with the observed physical condition of the post-test coupon in Figure 4.9. There was no visually identifiable localized attack on either coupon. The low corrosion rate noted on the galvanized coupon is likely due to zinc passivation. Galvanized materials protect the base metals in two ways, being a barrier and the formation of a zinc patina [73]. The zinc patina is formed by the conversion of the galvanized coating into corrosion products. Typically zinc oxide $(\mathrm{ZnO})$ and zinc hydroxide $\left(\mathrm{Zn}(\mathrm{OH})_{2}\right)$ are initially formed. Later in the corrosion cycle these products interact with carbon dioxide in the environment to form zinc carbonate $\left(\mathrm{ZnCO}_{3}\right) . \mathrm{ZnCO}_{3}$ is a passive, stable film that adheres to the galvanized surface to protect the base galvanized material. It is not water soluble and will not dissolve into the bulk fluid. In the conditions tested the galvanized zinc coating does not react with $\mathrm{H}_{2} \mathrm{~S}$ to form a zinc 
sulfide (ZnS) and hydrogen gas, or $\mathrm{ZnO}$ reacting with $\mathrm{H}_{2} \mathrm{~S}$ to form a zinc sulfide and water. The temperatures of formation for these products are $>450^{\circ} \mathrm{C}$, which is typically not found in oil and gas wells [74]. Also under the conditions tested $\mathrm{ZnS}$ is insoluble which does not promote the corrosion process to occur. Weight loss corrosion rates on the galvanized components should be taken with caution due to the removal of the galvanized coating when cleaning off the scales.

Similar to the K-55+TN-55TH pairing, the K-55+K-55 coupon pair had nearly identical weight loss corrosion rates of 8.48 MPY \& 8.49 MPY (0.215 mm/y). Neither coupon in this pair displayed any localized or preferential corrosion attack due to the artificial crevice. Both coupons had an overall moderate surface etch as Figure 4.9 depicts. This is again expected due to the materials similarity.

Table 4.7 summarizes the galvanic corrosion rate test results and Figure 4.10, Figure 4.11, and Figure 4.12 illustrate the test period trends and post-test surface images.

Table 4.7: Downhole material galvanic testing corrosion rate summary

\begin{tabular}{|l|l|l|l|l|}
\hline \multirow{2}{*}{ Coupon Pair } & \multicolumn{2}{|c|}{ K-55+TH-55TH } & \multicolumn{2}{c|}{ K-55+ GLV-J55 } \\
\hline Individual Coupon & K-55 & TN-55TH & K-55 & GLV-J55 \\
\hline $\begin{array}{l}\text { Corrosion Rate } \\
\text { (MPY/mm/y) }\end{array}$ & $18.18 / 0.462$ & $17.87 / 0.454$ & $10.11 / 0.257$ & $9.3 / 0.236$ \\
\hline
\end{tabular}




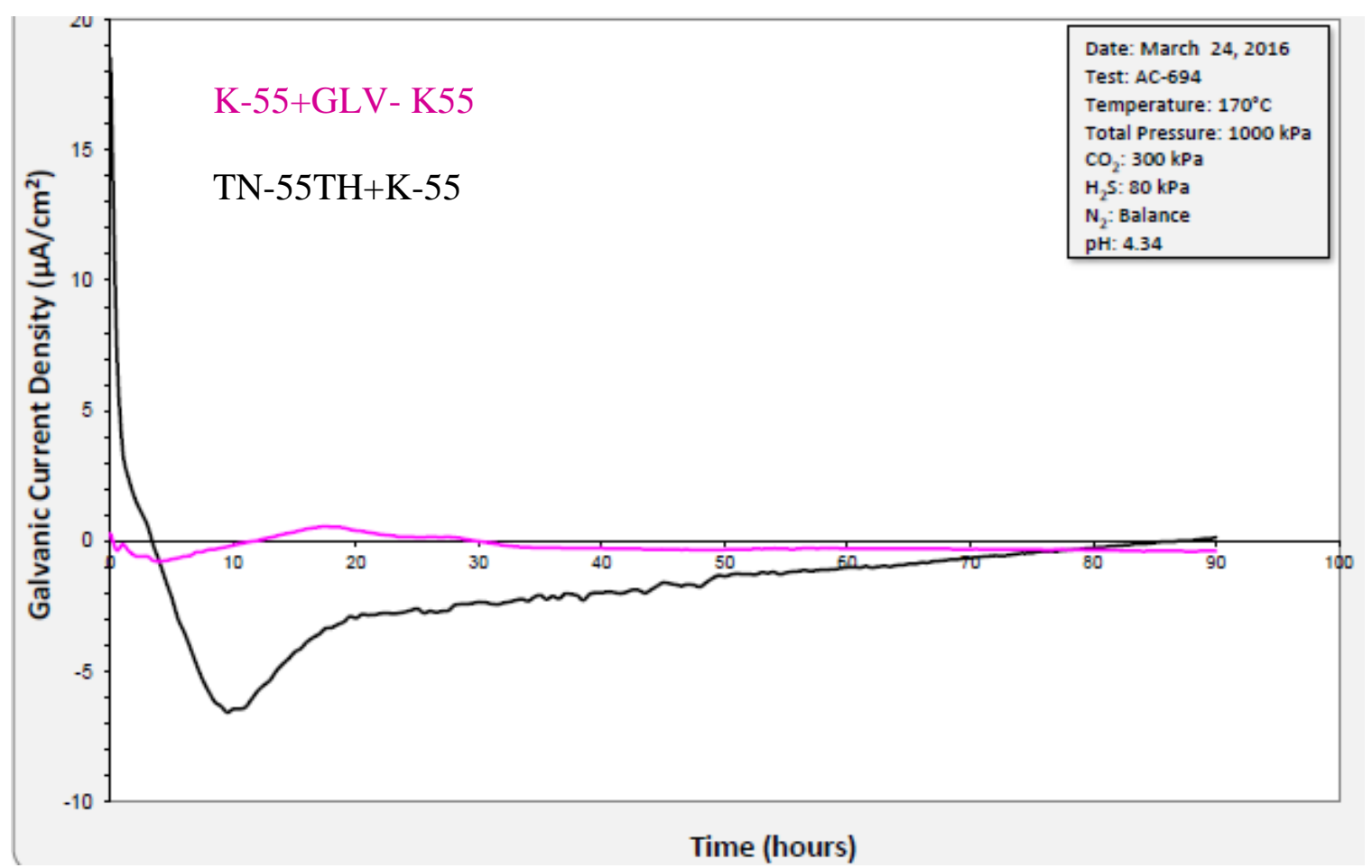

Figure 4.10: Galvanic current density vs time

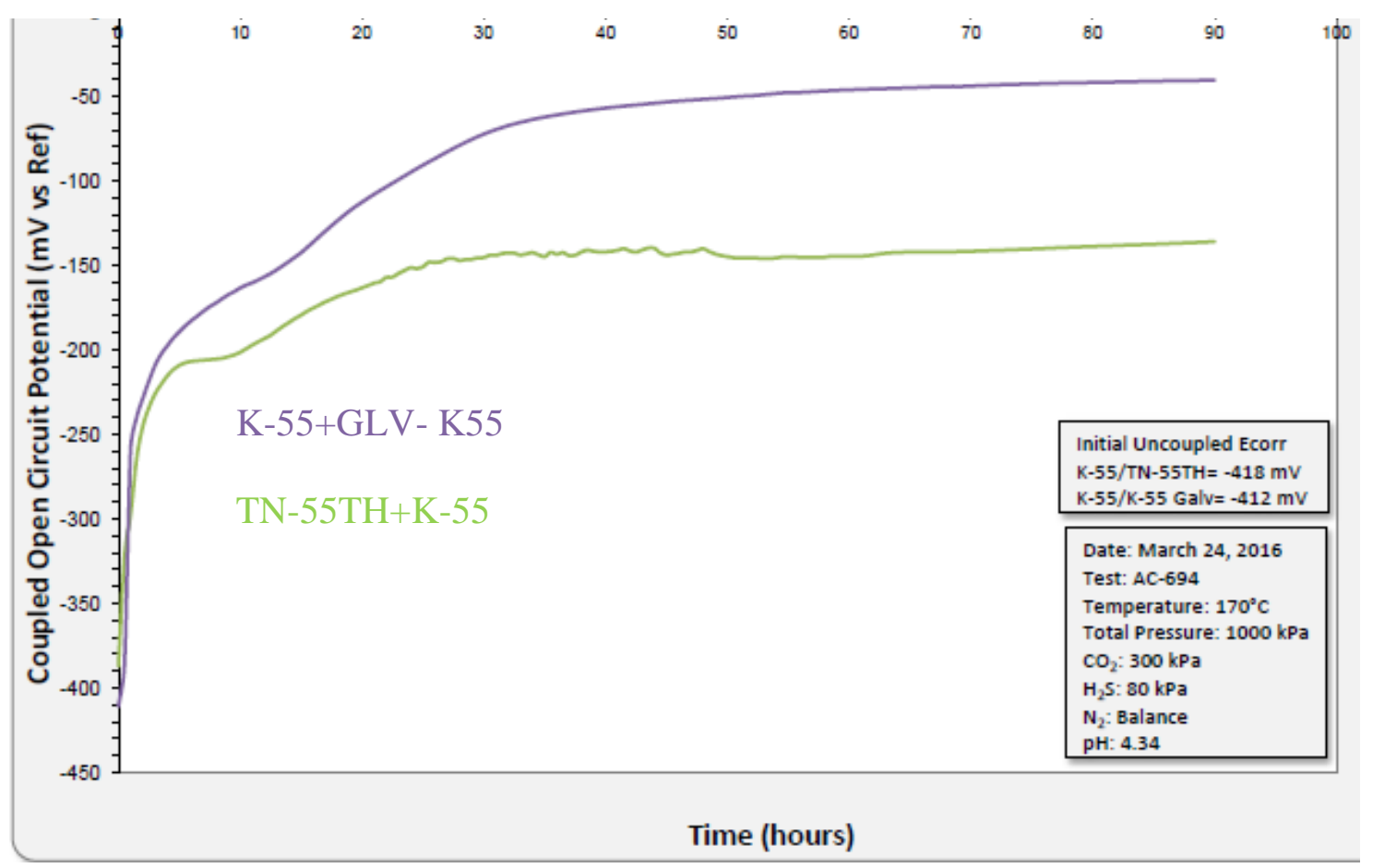

Figure 4.11: Galvanic coupled open circuit potential vs time 


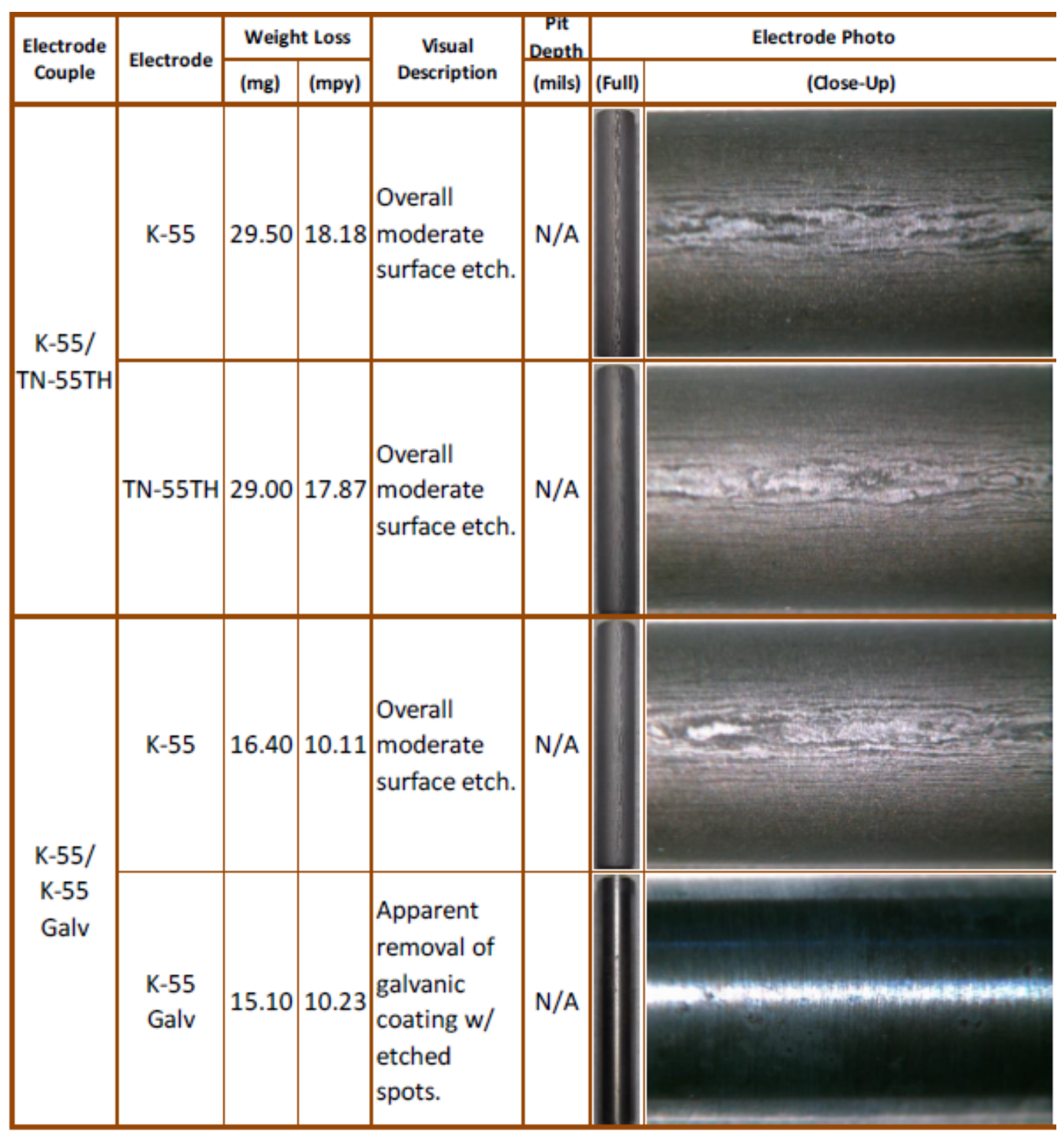

Figure 4.12: Galvanic test - Weight loss data and electrode photographs

The K-55+TN-55TH galvanic pair resulted in a fluctuating galvanic current graph. The measured current density fluctuated from an initial $18.54 \mu \mathrm{A} / \mathrm{cm}^{2}$ to -6.55 $\mu \mathrm{A} / \mathrm{cm}^{2}$ over the first 10 hours as Figure 4.10 indicates. The current then trended up 
towards a net zero current flow between the coupled electrodes. Positive current readings indicate a net current flow from the K-55 to the TN-55TH. Negative current readings indicate a net current flow from the TN-55TH to the K-55 coupon. The current density readings are low and do not indicate a strong galvanic interaction where one metal is clearly corroding preferentially over the other. Galvanic corrosion typically results in significantly higher forward current flow. The coupled OCP versus the reference electrode increased from an initial $-387 \mathrm{mV}$ to stabilize around $-140 \mathrm{mV}$ (Figure 4.11). A less anodic potential generally indicates decreasing corrosivity. In harsh environments a potential difference $<-150 \mathrm{mV}$ is desirable, which is observed here [75].

The weight loss corrosion rates of 18.18 MPY $(0.462 \mathrm{~mm} / \mathrm{y})$ for the K-55 and 17.87 MPY $(0.454 \mathrm{~mm} / \mathrm{y})$ for the TN-55TH are higher than those recorded in the LPR and crevice tests. This increase is likely partially due to the reduced exposure time in the galvanic testing of 90 hours versus 165.5 hours in the LPR and crevice testing.

The current flow between the K-55 and GLV-K55 was very low. It trended from $0.76 \mu \mathrm{A} / \mathrm{cm}^{2}$ to $+0.58 \mu \mathrm{A} / \mathrm{cm}^{2}$. Positive current readings indicate a net current flow from the K-55 electrode while negative readings correspond to a net current flow from the GLV-K55 electrode. The low current reading trends recorded indicate galvanic corrosion between the two materials was minimal. The coupled K-55 and GLV-K55 OCP stabilized at $\sim-40 \mathrm{mV}$ versus the reference electrode. This potential is significantly less anodic than the K-55+TN-55TH couple. This is expected based on the galvanized zinc coating and formation of $\mathrm{ZnO}$ as noted above. The weight loss of the $\mathrm{K}-55$ electrode when coupled with the GLV-K55 was significantly less than the K-55 electrode when coupled with TN-55TH as was displayed in Table 4.6. Again, the galvanized coating 
further limited any galvanic current, and corrosion, from occurring between the dissimilar galvanized finish to the K-55 sample.

\subsubsection{Lab testing discussion and summary}

Both the Deloro-40 HF and Stellite-6 HF were strong performers in the LPR and weight loss evaluation methods compared to the 1018 carbon steel. Weight loss testing indicated close to negligible corrosion rates over the 7-day testing period and final LPR corrosion rates of $0.035 \mathrm{~mm} / \mathrm{y}(1.38 \mathrm{MPY})$ and $0.024 \mathrm{~mm} / \mathrm{y}$ (0.95 MPY) for the Deloro40 HF and Stellite-6 HF materials respectively. This compared to the 1018 carbon steel having a weight loss corrosion rate of $0.25 \mathrm{~mm} / \mathrm{y}$ (9.66 MPY) and $0.38 \mathrm{~mm} / \mathrm{y}(15.05$ MPY) for a final LPR corrosion rate reading. It was difficult to separate the performance of the Deloro-40 HF and Stellite-6 HF materials in the initial weight loss and LPR tests. The Stellite-6 HF showed only a slightly improved overall LPR trend. To differentiate further their performance CPP and potentiostatic polarization testing was completed. In the CPP testing the Stellite-6 HF material had superior performance with higher apex of $635 \mathrm{mV}$ and pitting potential of $194.0 \mathrm{mV}$ compared to the Deloro-40 HF with apex and pitting potentials of $581.0 \mathrm{mV}$ and $82.0 \mathrm{mV}$, respectively. Further re-passivation potentiostatic polarization testing also displayed the Stellite-6 HF materials superior performance. The Stellite-6 HF samples initial PP current density was measured to be $236.2 \mu \mathrm{A} / \mathrm{cm}^{2}$ and trended down for the 4-day test to eventually read cathodic (negative) values to end at $-29.0 \mu \mathrm{A} / \mathrm{cm}^{2}$. Whereas the Deloro-40 HF material had an initial current density close to double the Stellite-6 HF of $500.0 \mu \mathrm{A} / \mathrm{cm}^{2}$ with a final reading of 11.7 $\mu \mathrm{A} / \mathrm{cm}^{2}$ and remaining anodic throughout the 4-day test period. 
In the second set of autoclave testing, downhole completion materials were analyzed in 3 testing setups under SAGD conditions. General corrosion rate testing was done on K-55 and TN-55TH. Crevice corrosion testing was completed on 3 material combinations including K-55+TH-55TH, K-55+GLV-J55, and K-55+K-55, and finally galvanic corrosion testing on the materials and combinations of K-55+TH-55TH and K55+GLV-K55.

The K-55 and TN-55TH general weight loss corrosion rate measurements indicated mild to moderate corrosion rates of $0.297 \mathrm{~mm} / \mathrm{y}$ (11.73 MPY) and $0.319 \mathrm{~mm} / \mathrm{y}$ (12.56 MPY), respectively. The LPR corrosion rates for both alloys were relatively stable and trended closely. Both showed final corrosion rates of $0.243 \mathrm{~mm} / \mathrm{y}$ (9.60 MPY). Testing results and trends indicate that a passive corrosion scale formed to protect the electrodes from the aggressive conditions and that both materials share similar amounts of corrosion susceptibility.

There was also no evidence of increased corrosion due to the presence of an artificial crevice in any of the three crevice corrosion tests. The K-55 coupons corrosion rates showed similar results in each of the three crevice setups. The average corrosion rate for the K-55 coupons was $0.237 \mathrm{~mm} / \mathrm{y}$ (9.34 MPY). The TN-55TH had a corrosion rate of $0.276 \mathrm{~mm} / \mathrm{y}$, similar to that of the K-55, with no localized corrosion due to crevice attack visually apparent. The GLV-J55 coupon had the lowest corrosion rate, close to half of the K-55 it was creviced with, at $0.137 \mathrm{~mm} / \mathrm{y}$ (5.41 MPY). This likely indicates the galvanizing coating protected the surface of the coupon from corrosion. No visual localized corrosion damage was noted at the crevice. 
Galvanic testing results showed there was no galvanic effect between the K-55 and TN-55TH materials, the corrosion rates were $0.462 \mathrm{~mm} / \mathrm{y}(18.18 \mathrm{MPY})$ and 0.454 $\mathrm{mm} / \mathrm{y}$ (17.87 MPY) respectively. This is expected as they have a similar chemical composition, mechanical, and physical properties. A slightly lower corrosion rate was found on the GLV-K55 coupon at $0.236 \mathrm{~mm} / \mathrm{y}$ (9.3 MPY) compared to $0.257 \mathrm{~mm} / \mathrm{y}$ (10.11 MPY) on the K-55 coupon. The current flow between the K-55 and GLV-K55 was very low indicating minimal galvanic corrosion between the two materials.

These results show low to moderate corrosion rates could be expected under the conditions tested. Lab testing corrosion rates of $0.254 \mathrm{~mm} / \mathrm{y}$ (10 MPY) for an uninhibited specimen exposed to test brine could be considered a severe corrosion rate. The K55+TN-55TH galvanic tests showed corrosion rates up to $0.462 \mathrm{~mm} / \mathrm{y}$ (18.18 MPY). Although these rates are considered severe, they are not overly concerning based on the field testing, and past field failure analysis. If corrosion rates of $0.254 \mathrm{~mm} / \mathrm{y}$ (10 MPY) are found in the field, it would be rated as high and of concern. In a lab, the coupons are exposed over a short duration relative to field monitoring which artificially increases the resulting corrosion rate. Other conditions in the field can also help to prevent corrosion, including the presence of oil which acts as a corrosion inhibitor, or other scales. The galvanized materials appeared to prevent corrosion due to the formation of a zinc patina which prevents direct material exposure and was shown to decrease corrosion currents and potentials to levels much less than would be required for corrosion to occur.

In the future, based on economics and funding, completing XRD analysis on lab samples would be beneficial in confirming the corrosion scale compounds present in each test. Specifically confirming the type of Zn filming compound formed. 


\subsection{Field testing results and analysis}

In this section results and analysis of the downhole corrosion coupons are presented and discussed. Analysis completed included weight loss corrosion rates, compositional XRD, EDS, and SEM morphology analysis.

The corrosion coupons were removed from the well on Feb 19 ${ }^{\text {th }}, 2017$ (after 330 days of exposure) as per the installation and removal procedure created before the coupons were installed [76].

\subsubsection{Downhole material pre and post-test acid washing images}

Figure 4.13 - Figure 4.19 show the coupons as received before and after acid cleaning.

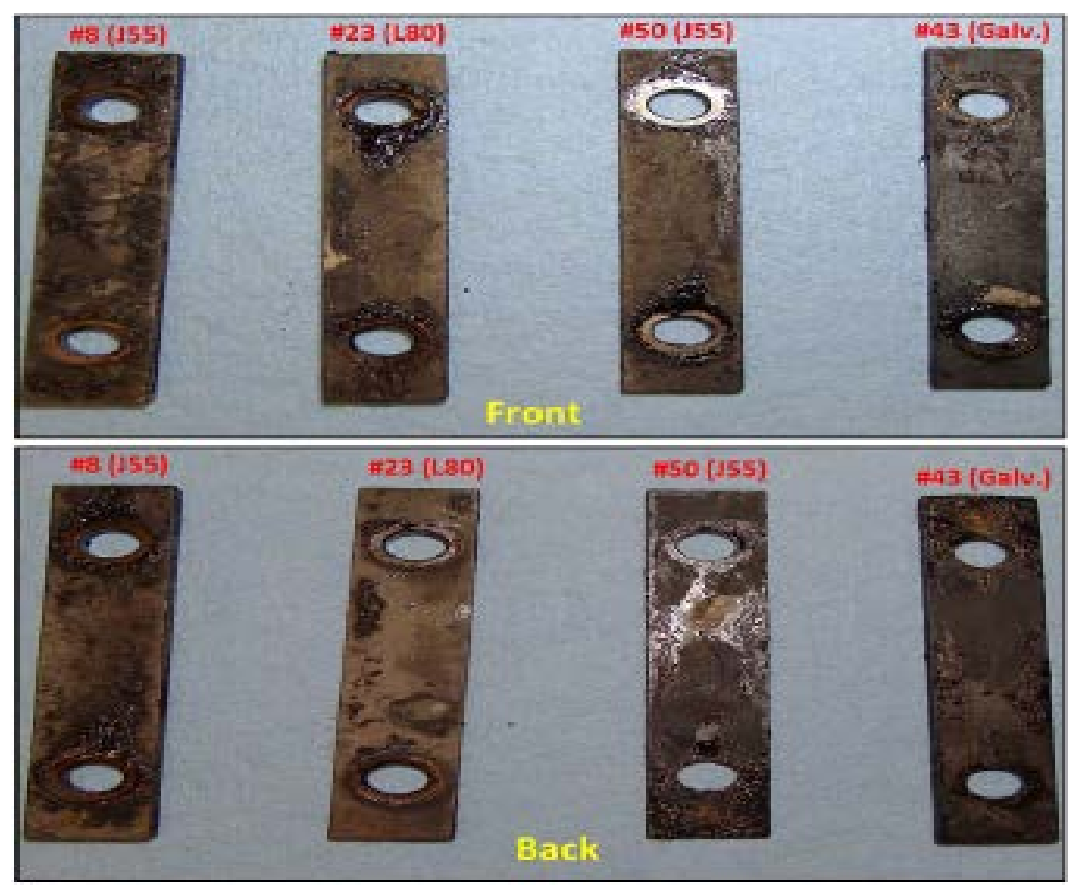

Figure 4.13: Joint 2 Corrosion coupons as received 


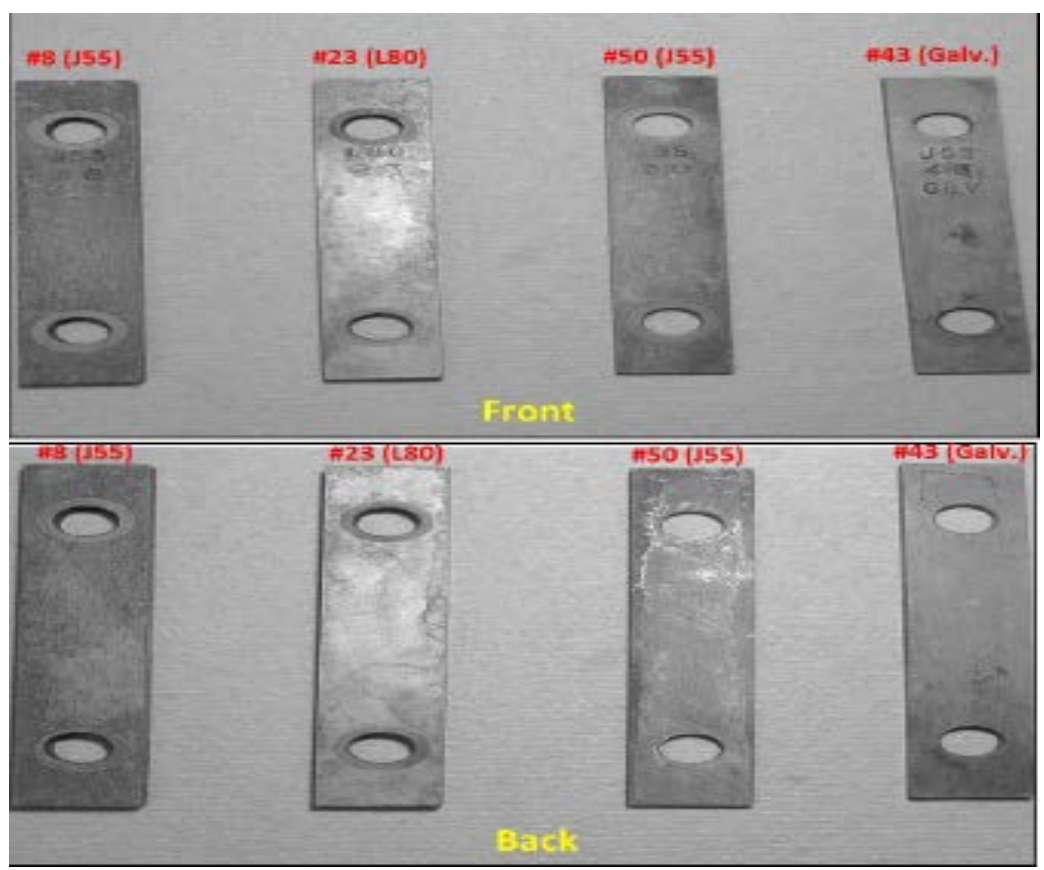

Figure 4.14: Joint 2 Corrosion coupons post cleaning
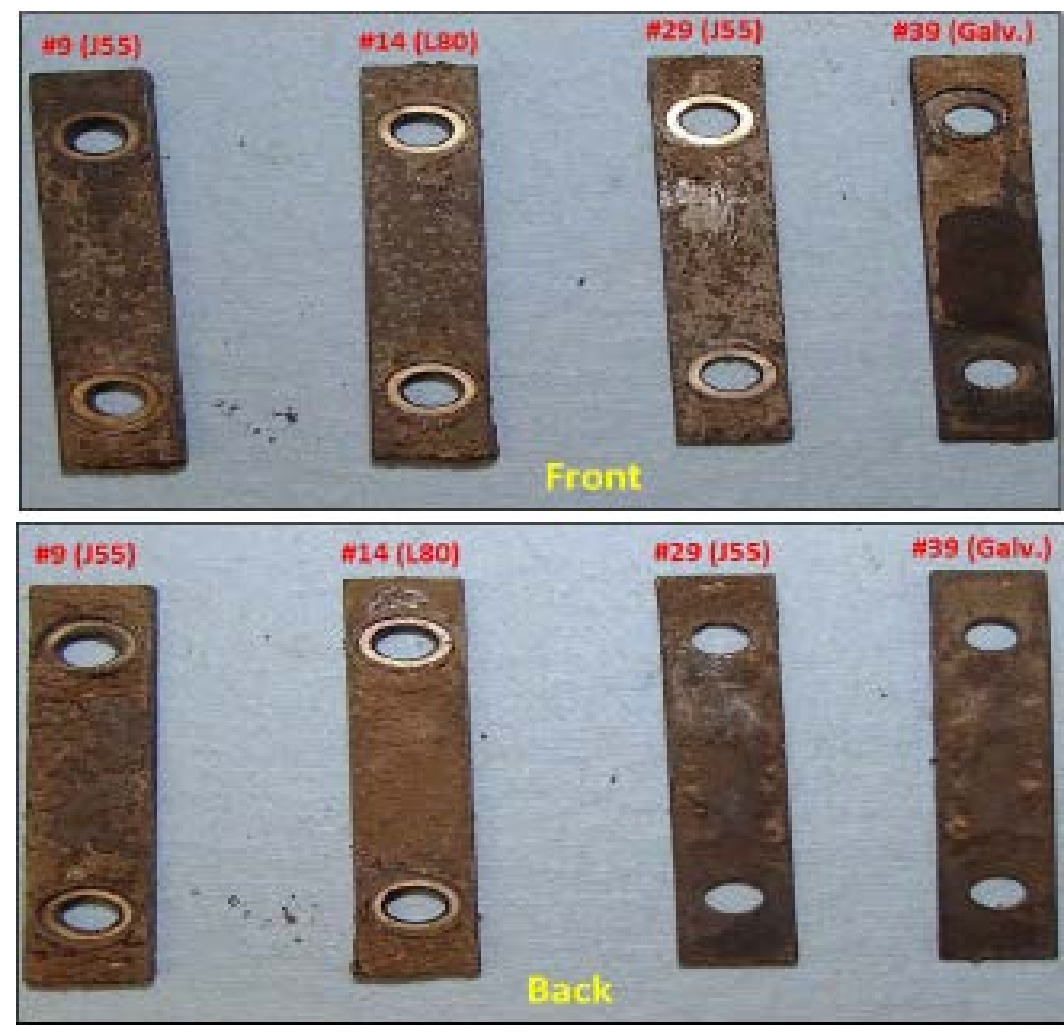

Figure 4.15: Joint 23 Corrosion coupons as received 


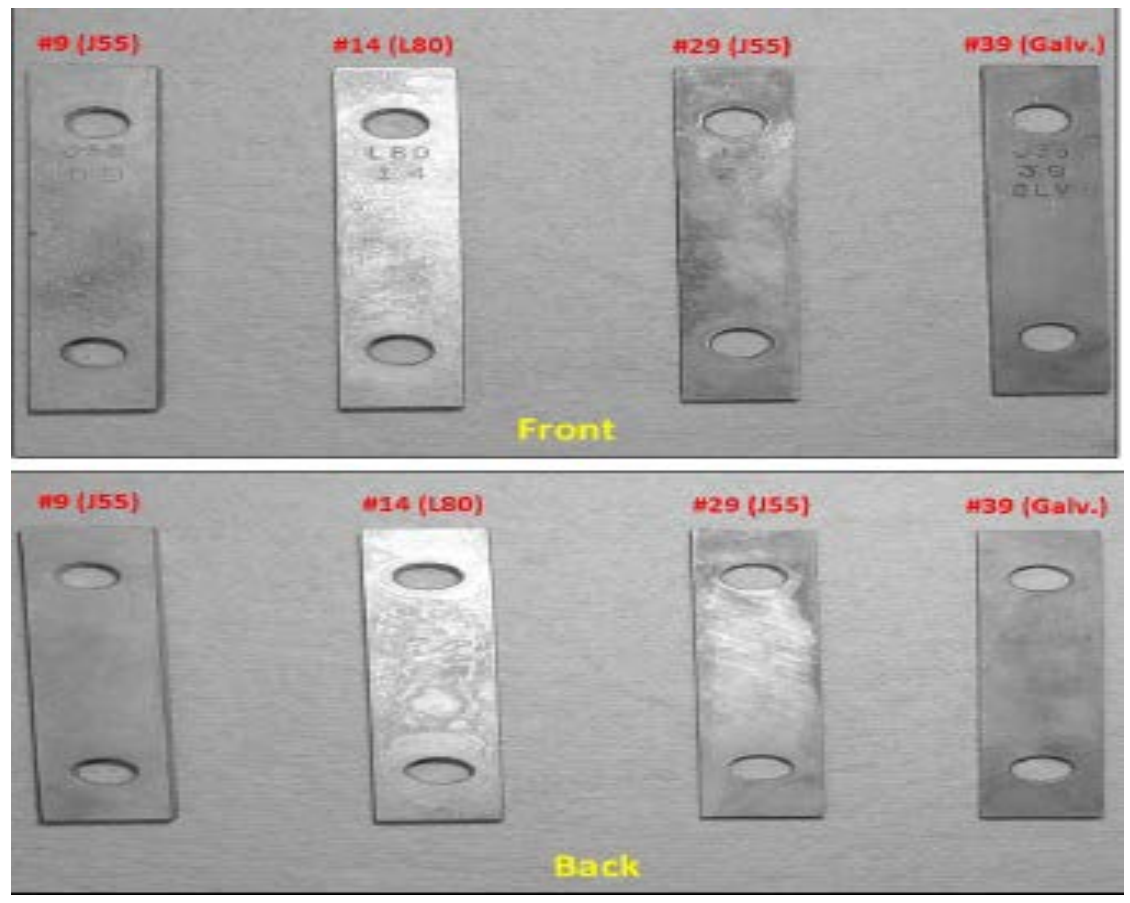

Figure 4.16: Joint 23 Corrosion coupons post cleaning

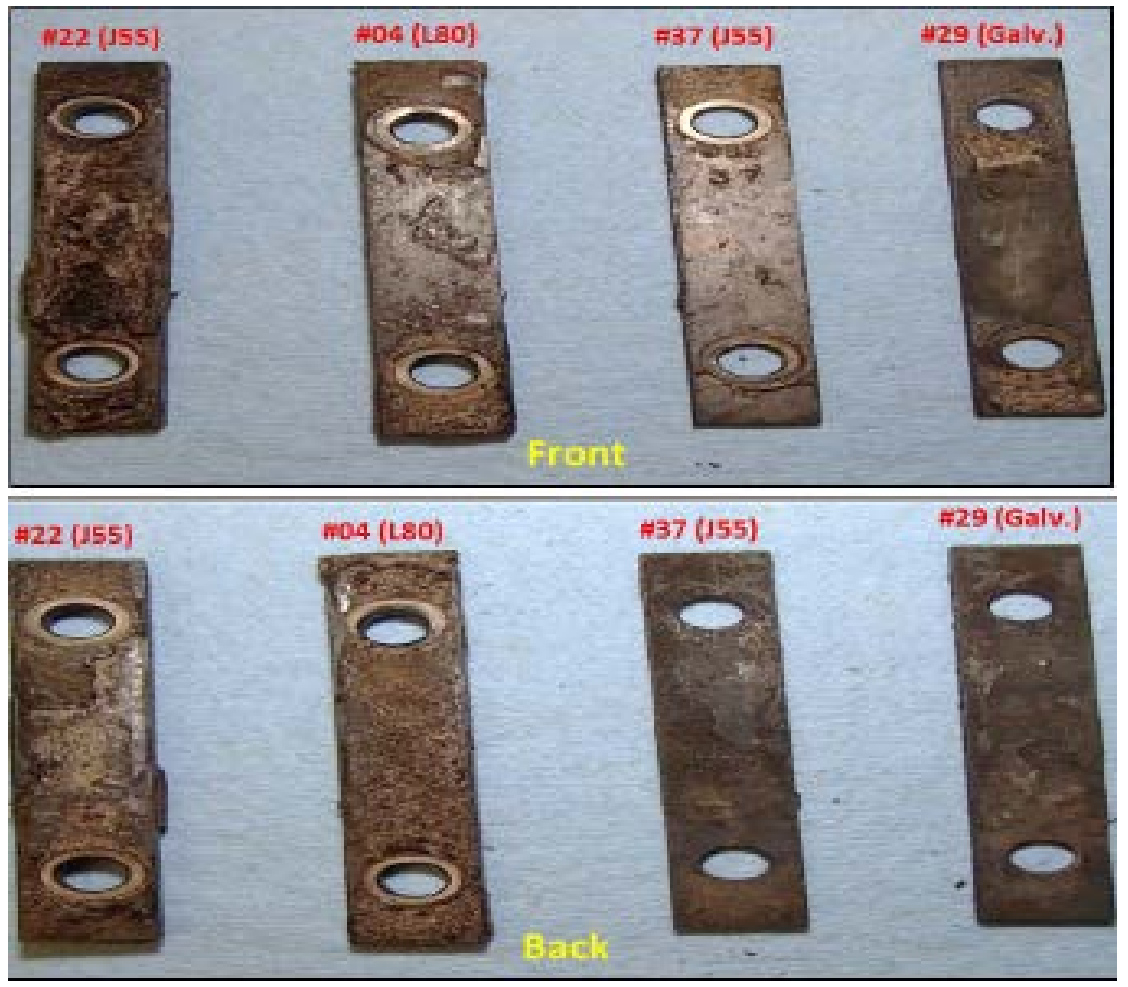

Figure 4.17: Joint 25 Corrosion coupons as received 

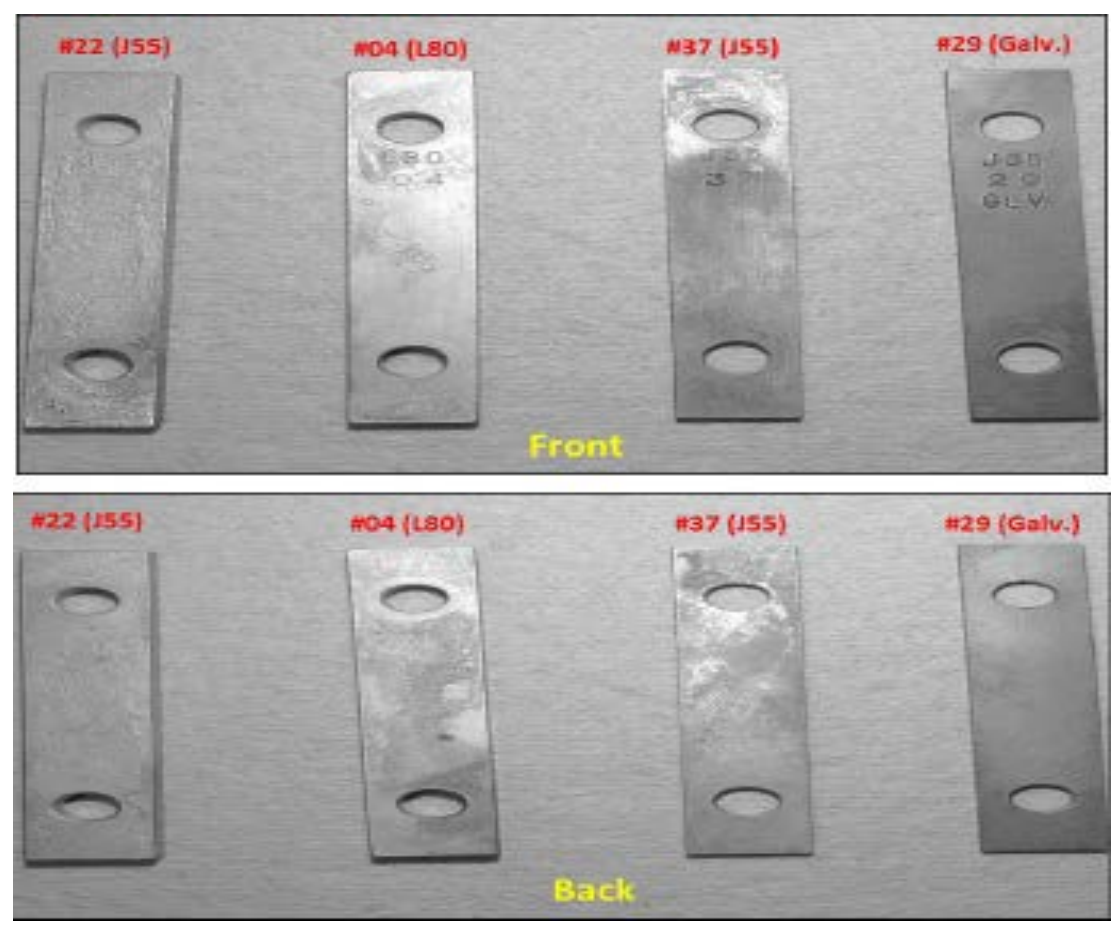

Figure 4.18: Joint 25 Corrosion coupons post cleaning

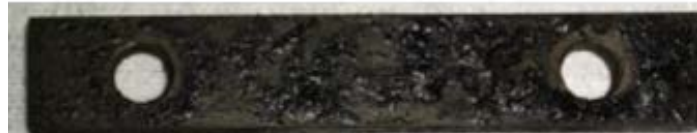

09 L80

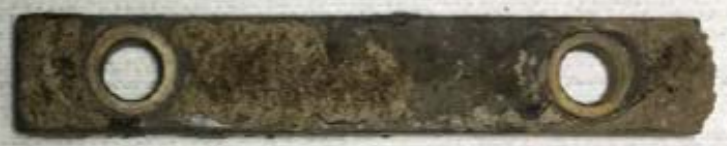

$16 \mathrm{~J} 55$

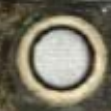

$18\llcorner 80$

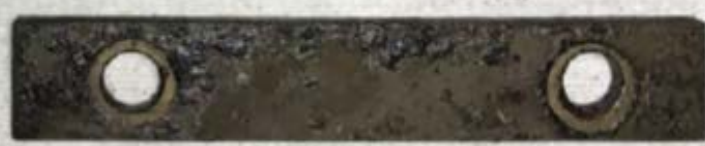

$20 \mathrm{~J} 55$

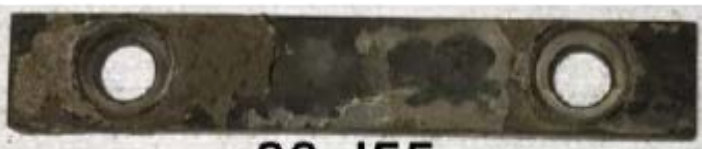

$33 \mathrm{~J} 55$

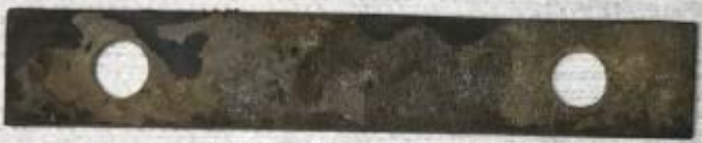

35 J55 GLV

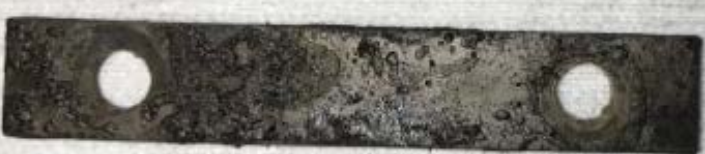

47 J55 GLV

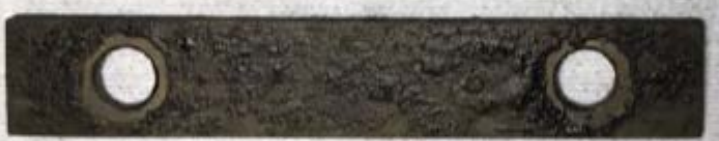

49 J55

Figure 4.19: Joint 12 and 24 coupons as received (UofC) 
These images show similar surface physical characteristics on each coupon materials at the various depths. The lower coupons from the joint 2 and 12 clamps appear to be darker in color compared to the coupons on the joint 23, 24, and 25 clamps. This is likely due to the fluid separation occurring downhole. The lower coupons are likely exposed to an oil + water + gas emulsion or oil on its own, depending on the levels at which fluid separation occurs. The coupons at higher well elevations are exposed to the separated produced water and other less dense compounds in the fluid. At production temperatures and pressures water ( $864 \mathrm{~kg} / \mathrm{m}^{3}$ [77]) is less dense than oil $\left(\sim 878.1 \mathrm{~kg} / \mathrm{m}^{3}\right)$, causing water to be the top fluid in the wells annulus once emulsion separation occurs.

\subsubsection{Corrosion rate results and analysis}

The following section outlines the corrosion rate calculation and analysis completed on the installed coupons. For calculating corrosion rates a density of 7.86 $\mathrm{g} / \mathrm{cm}^{3}$ [78] was used for the J-55 and L-80 coupons. Calculated corrosion rates are all average, uniform, weight loss corrosion rates based on the coupons pre and post-test weigh changes and that they all visually appeared to have corroded uniformly over the entire surface. Select L-80 coupons at higher elevations in the well appear to have experience pitting corrosion. For these corrosion rate calculations, pitting corrosion rate calculation methods were used as per NACE Standards [63].

The reported corrosion rates for the coupled J-55+GLV-J55 coupons should also be considered with care. This is due to difficulty in calculating the exposed surface area for these coupons considering the way in which the J-55 was coupled with the GLV-J55 coupons. Also, only average weight loss corrosion rates were calculated on the 
galvanized samples, pitting analysis and pitting corrosion rates were not considered or reported.

Figure 4.20 - Figure 4.23 displays the weight loss and corrosion rate testing results on all coupons. Figure 4.20 and Figure 4.21 show the coupons weight loss and corrosion rate at the various depths.

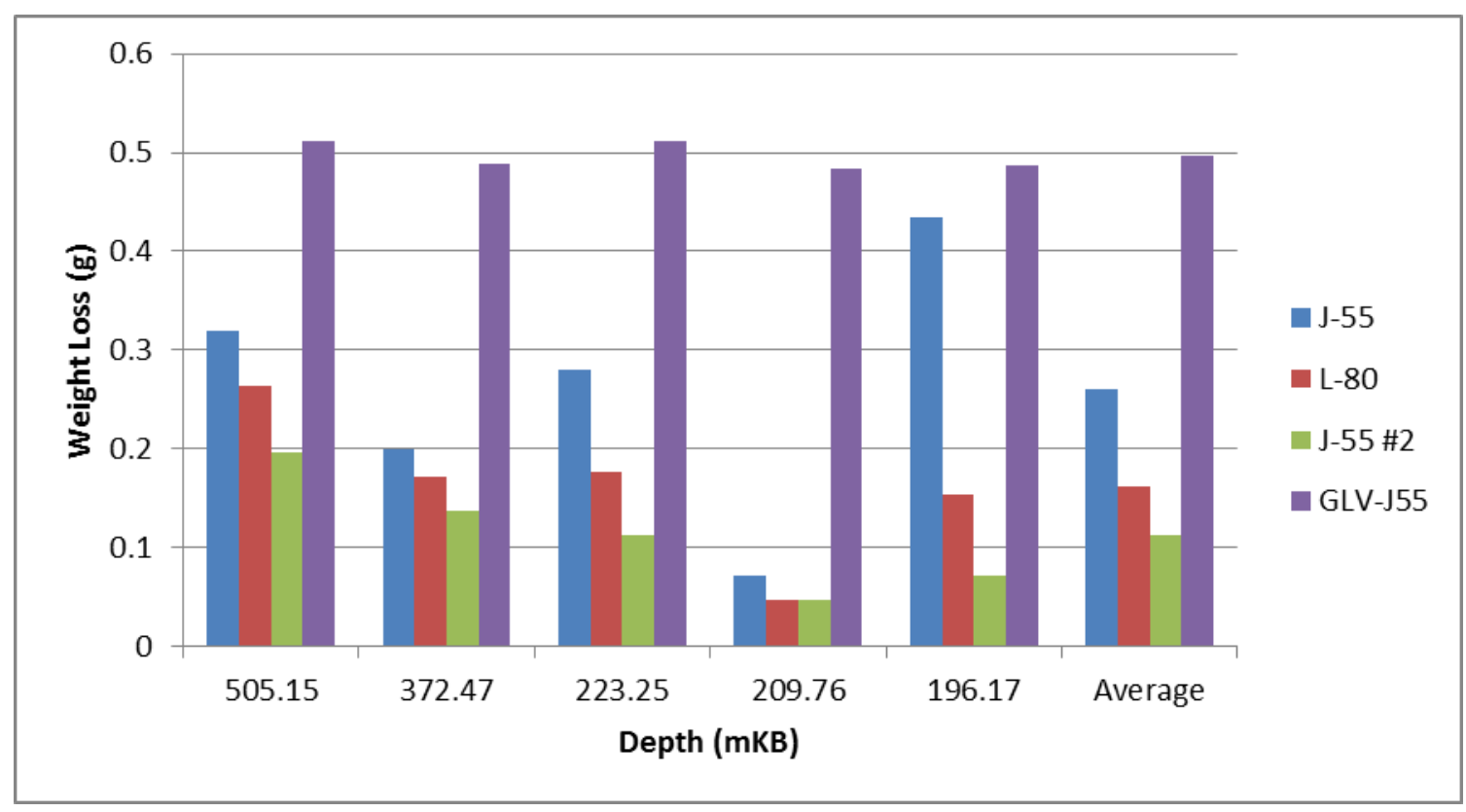

Figure 4.20: Weight loss by depth and varying material 


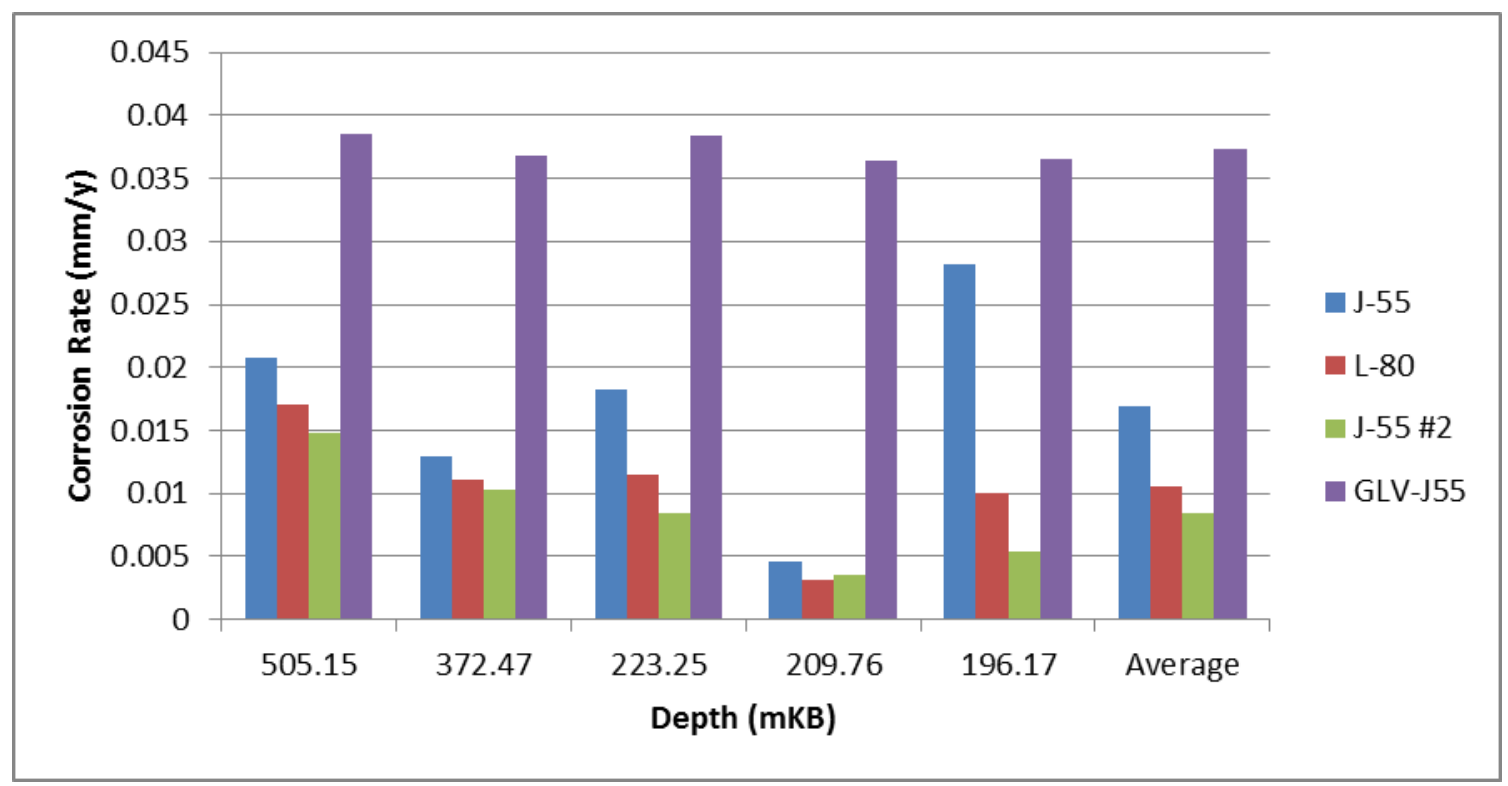

Figure 4.21: Corrosion rate by depth and varying material

These results show that the single J-55 material experienced the highest corrosion rate at each depth, followed by the L-80 coupons, and finally the second J-55 coupon coupled with the GLV-J55. The much higher corrosion rate and weight loss results for the GLV-J55 coupons is likely due to the sacrificial nature of the zinc coating to the coupled J-55 coupon as well as higher dissolution rate of zinc in hydrochloric acid during the acid cleaning process. For that reason it is difficult to compare its corrosion rate with the others. The galvanized samples appear to experience a similar "corrosion" rate at each installation location.

Figure 4.22 and Figure 4.23 show each materials weight loss and corrosion rate at different well depths. 


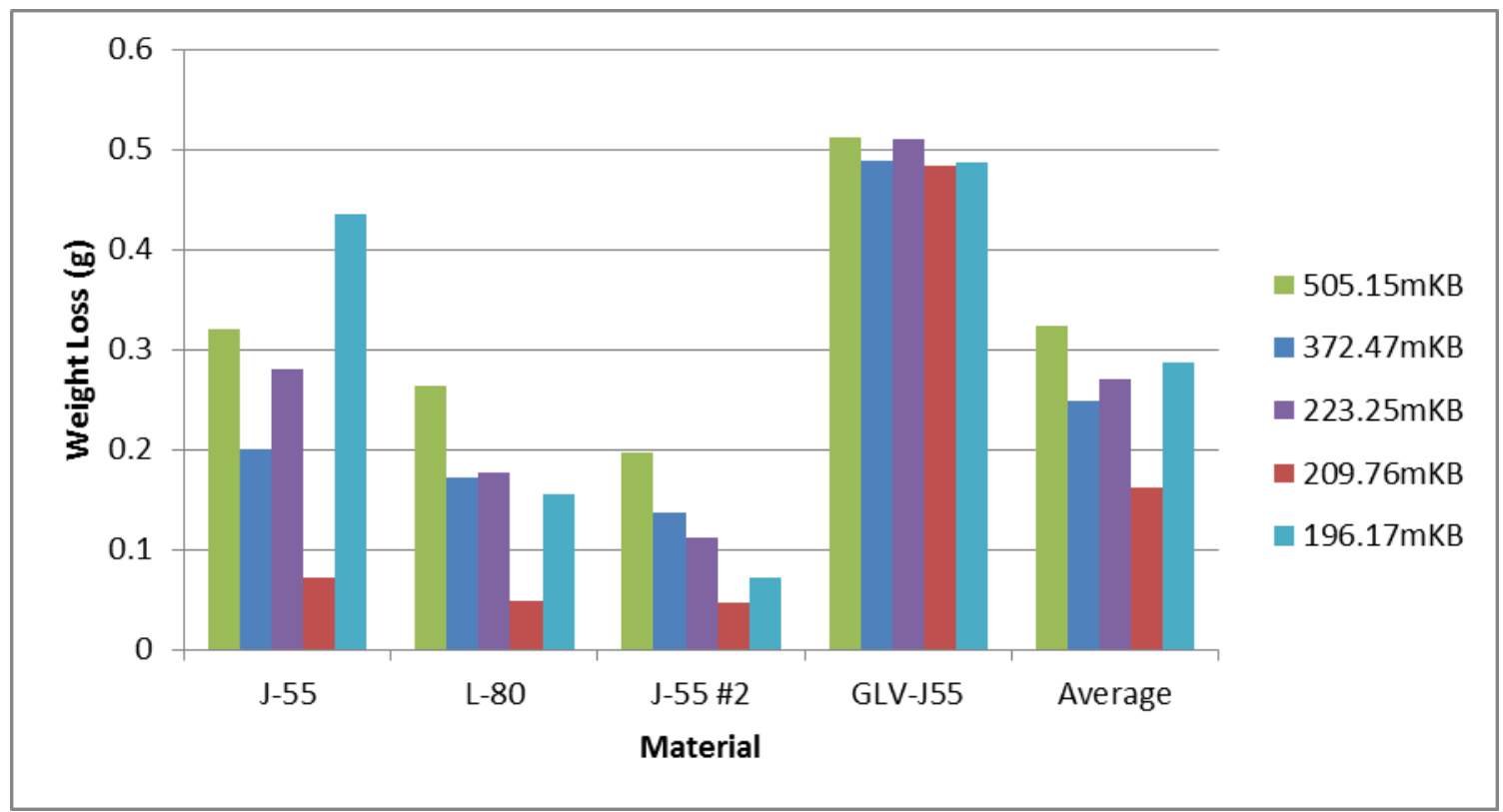

Figure 4.22: Weight loss by material and varying depth

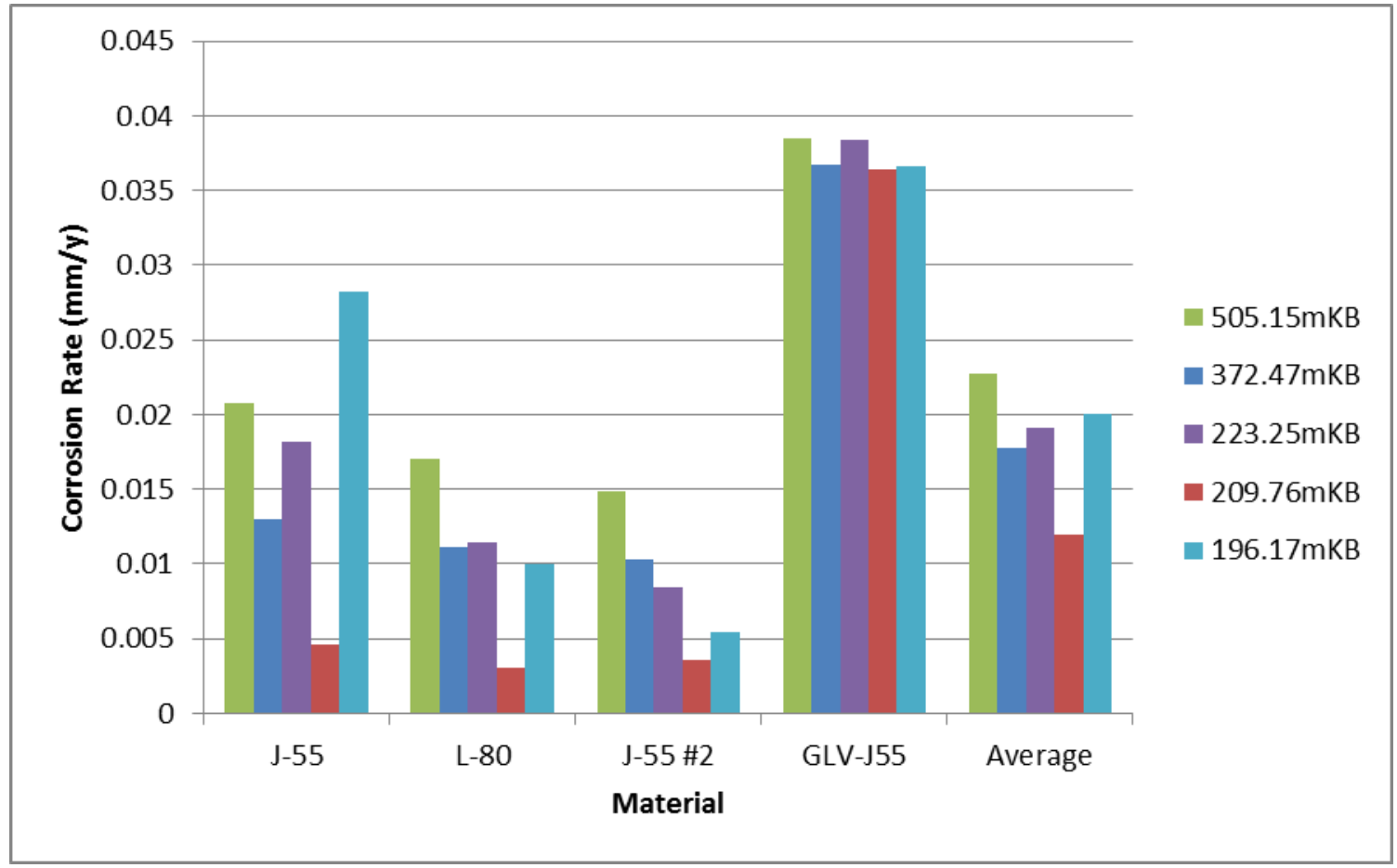

Figure 4.23: Corrosion rate by material and varying depths

These results shows the highest uniform corrosion rates will occur at lower well elevations, closer to the ESP, on all materials and decrease moving up the well from the 
ESP to approximatly the liquid level. Corrosion rates actually increase on the joint 25 (196.17mKB) clamp coupons for each material. The location/area of the increase is often where past field failures have been found to occur and could be due to higher concentrations of aqueous acidic gases and more a more conductive electrolite with less oil present to coat the metal surfaces. If the coupons were above the liquid level, condensates formed at high well elevations can contact the coupons and cause higher rates of localozed corrosion

The average corrosion rate on the bottom joint 2 coupons was $0.0228 \mathrm{~mm} / \mathrm{y}$, and $0.0119 \mathrm{~mm} / \mathrm{y}$ for the top joint 25 coupons. At each depth the non-coupled J-55 experienced the highest corrosion rates, followed by the L-80, and finally the second J-55 coupon coupled with the GLV-J55 coupon. With the exception of the J-55 coupon from the joint 2 clamp at $505.15 \mathrm{mKB}$ (lowest depth), all corrosion rates can be classsified as "low" based on standard NACE standards.

The L-80 coupons at higher elevations in the well appear to have experienced pitting corrosion as shown in Figure 4.15. Pitting corrosion rates on the L-80 coupons were $0.113 \mathrm{~mm} / \mathrm{y}$ (4.45MPY) on the joint $25 \mathrm{clamp}$ at $196.17 \mathrm{mKB}$, and $0.225 \mathrm{~mm} / \mathrm{y}$ (8.85MPY) on the joint 23 clamp at 223.25mKB. The coupons lower in the well did not appear to have suffered from pitting corrosion. It is likely that at higher well elevations the more aqueous environment, increased fluid movement due to vapor flashing, and possible creviced and galvanic conditions could all promote an environment more susceptible to pitting. Pitting corrosion is often of greater concern than uniform corrosion as its rates are higher and often leads to catastrophic material failures [79, 80]. 


\subsubsection{Corrosion scale results and analysis}

Visual inspections on the coupons installed in the joint 2, 23, and 25 clamps at depths $505.15 \mathrm{mKB}, 223.47 \mathrm{mKB}$, and $196.17 \mathrm{mKB}$ respectively are documented and presented in Table 4.8 to Table 4.10 before and after acid cleaning. XRD analysis was completed on the J-55 coupons at each depth. XRD analysis was only completed on the one non-coupled J-55 coupon at each location due to its cost.

Visual inspection comments on the joint 12 and 24 clamp coupons at $372.47 \mathrm{mKB}$ and $209.76 \mathrm{mKB}$ are show in Figure 4.24 to Figure 4.31.

Table 4.8: Joint 2 (505.15mKB) coupon observations

\begin{tabular}{|c|l|l|l|}
\hline & \multicolumn{2}{|c|}{ Description of Coupon } & \\
\hline Alloy Type & After Solvent Wash & $\begin{array}{l}\text { After Acid } \\
\text { Cleaning }\end{array}$ & Corrosion Scales \\
\hline J-55 & $\begin{array}{l}\text { - Front: Covered with thin grey scale } \\
\text { - Back: Covered with thin grey and black } \\
\text { scale }\end{array}$ & $\begin{array}{l}\text { General } \\
\text { Corrosion }\end{array}$ & $\begin{array}{l}\text { - Pyrrhotite } \\
\text { - Magnetite } \\
\text { - Quartz }\end{array}$ \\
\hline L-80 & $\begin{array}{l}\text { - Front: Covered with thin grey scale } \\
\text { - Back: Mainly covered with thin grey } \\
\text { scale }\end{array}$ & $\begin{array}{l}\text { General } \\
\text { Corrosion }\end{array}$ & N/A \\
\hline J-55 & $\begin{array}{l}\text { - Front: Covered with thin grey scale } \\
\text { - Back: Mainly covered with thin grey } \\
\text { scale and heavier deposits on the edges }\end{array}$ & $\begin{array}{l}\text { General } \\
\text { Corrosion }\end{array}$ & N/A \\
\hline GLV-J55 & $\begin{array}{l}\text { - Front/Back: Mainly covered with thin } \\
\text { grey scale }\end{array}$ & $\begin{array}{l}\text { General } \\
\text { Corrosion }\end{array}$ & N/A \\
\hline
\end{tabular}


Table 4.9: Joint 23 (223.47mKB) coupon observations

\begin{tabular}{|c|c|c|c|}
\hline & \multicolumn{2}{|c|}{ Description of Coupon } & \multirow[b]{2}{*}{ Corrosion Scales } \\
\hline Alloy Type & After Solvent Wash & $\begin{array}{l}\text { After Acid } \\
\text { Cleaning }\end{array}$ & \\
\hline$J-55$ & $\begin{array}{l}\text { - Front: Mainly covered with thin, } \\
\text { black scale with some thick, white } \\
\text { deposits } \\
\text { - Back: Mainly covered with thin, } \\
\text { black scale with some thick, white } \\
\text { deposits }\end{array}$ & $\begin{array}{l}\text { Etched surface } \\
\text { with patchy } \\
\text { corrosion }\end{array}$ & $\begin{array}{l}\text { - Cristobalite } \\
\text { - Quartz } \\
\text { - Pyrrhotite }\end{array}$ \\
\hline L-80 & $\begin{array}{l}\text { - Front: Mainly covered with thick } \\
\text { white deposits } \\
\text { - Back: Mainly covered with thin, } \\
\text { black scale and some areas of thick, } \\
\text { white deposits }\end{array}$ & $\begin{array}{l}\text { Patchy } \\
\text { corrosion with } \\
\text { some pitting }\end{array}$ & N/A \\
\hline$J-55$ & $\begin{array}{l}\text { - Front: Mainly covered with thin, } \\
\text { grey and black scale with some } \\
\text { thick, white deposits } \\
\text { - Back: Mainly covered with thin, } \\
\text { grey scale with some thick, white } \\
\text { deposits }\end{array}$ & $\begin{array}{l}\text { General } \\
\text { corrosion with } \\
\text { patchy attack } \\
\text { adjacent to the } \\
\text { edges }\end{array}$ & N/A \\
\hline GLV-J55 & $\begin{array}{l}\text { - Front: Mainly covered with thin, } \\
\text { black scale with some thick, white } \\
\text { deposits } \\
\text { - Back: Mainly covered with white } \\
\text { deposits }\end{array}$ & $\begin{array}{l}\text { General } \\
\text { Corrosion }\end{array}$ & N/A \\
\hline
\end{tabular}


Table 4.10: Joint 25 (196.17mKB) coupon observations

\begin{tabular}{|c|l|l|l|}
\hline & \multicolumn{2}{|c|}{ Description of Coupon } & \\
\hline \multirow{5}{*}{ Alloy Type } & After Solvent Wash & After Acid Cleaning & Corrosion Scales \\
\hline & $\begin{array}{l}\text { - Front: Mainly covered with } \\
\text { thick, white and brown } \\
\text { deposit } \\
\text { - Back: Heavily covered with } \\
\text { brown deposits }\end{array}$ & $\begin{array}{l}\text { Spots and Patches } \\
\text { of Corrosion }\end{array}$ & $\begin{array}{l}\text { - Cristobalite } \\
\text { - Quartz }\end{array}$ \\
\hline \multirow{5}{*}{ L-80 } & $\begin{array}{l}\text { - Front: Mainly covered with } \\
\text { thick, white deposits } \\
\text { - Back: Partially covered with } \\
\text { thick, white deposits }\end{array}$ & $\begin{array}{l}\text { General corrosion } \\
\text { with some patches } \\
\text { of attack on the } \\
\text { front }\end{array}$ & N/A \\
\hline J-55 & $\begin{array}{l}\text { - Front: Partially covered with } \\
\text { thick, white deposits } \\
\text { - Back: Covered with white } \\
\text { and brown deposits }\end{array}$ & $\begin{array}{l}\text { General corrosion } \\
\text { with some patches } \\
\text { of attack on the } \\
\text { front }\end{array}$ & N/A \\
\hline GLV-J55 & $\begin{array}{l}\text { - Front: Mainly covered with } \\
\text { thin, black scale } \\
\text { - Back: Mainly covered with } \\
\text { thin, black scale and some } \\
\text { white deposits }\end{array}$ & General Corrosion & N/A \\
\hline
\end{tabular}

All of the coupons show that before acid cleaning a darker grey, brown and or black scale, are present with some samples showing white deposits. It is known that iron sulfide scales, mackinawite, pyrite, triolite, pyrrhotite, have a darker appearance. Mackinawite is grey or black in color, while pyrrhotite has a more bronze/brown appearance [81, 82]. It is also known that magnetite scales have a gray with brownish appearance [83, 84]. Magnetite was only found on the joint $2 \mathrm{~J}-55$ coupon. Although it is not an expected corrosion product it could be formed due to the presence of $\mathrm{CO}_{2}$ and it being released from the emulsion closer to the ESP at higher concentrations. It is also possible that it converted to magnetite from a sulfide based scale as a result of being exposed to oxygen after being removed from installation [85]. Magnetite has been noted 
in past corrosion inspection failure analysis reports [86]. The white scales are likely those of silicate compounds, quartz and/or cristobalite which have a clear or white color [8790].

After cleaning, except for the L-80 coupons on the higher elevation clamps, the coupons appeared to corrode uniformly. The L-80 coupons located on the higher clamps experienced visible localized pits on the front and side edges. This is similar to past failure analysis and inspection reports results [17] which also indicate pitting corrosion to occur more prolifically at higher elevations in wells. Relative to the other materials, L-80 is a stronger and harder material with no corrosion resisting alloying components and can be more susceptible to pitting corrosion as the pit tip is less likely to re-passivate [79, 80]. SEM images for all coupons on the joint 12 and 24 clamps are shown in Figure 4.24 to Figure 4.31. The J-55 coupon SEM images from these joints are shown in Figure 4.24 and Figure 4.25. 


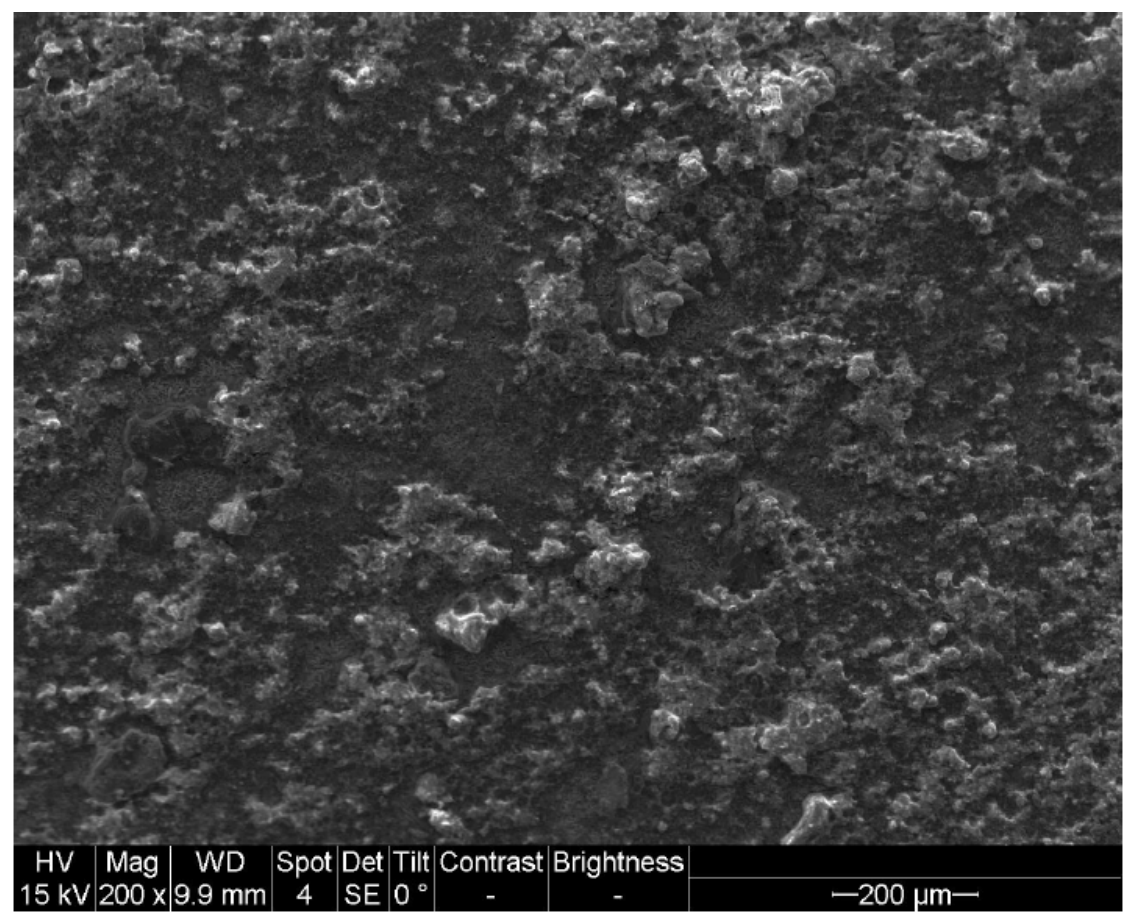

Figure 4.24: Joint 12, J-55 at 372.47 mKB SEM; (Coupon 20)

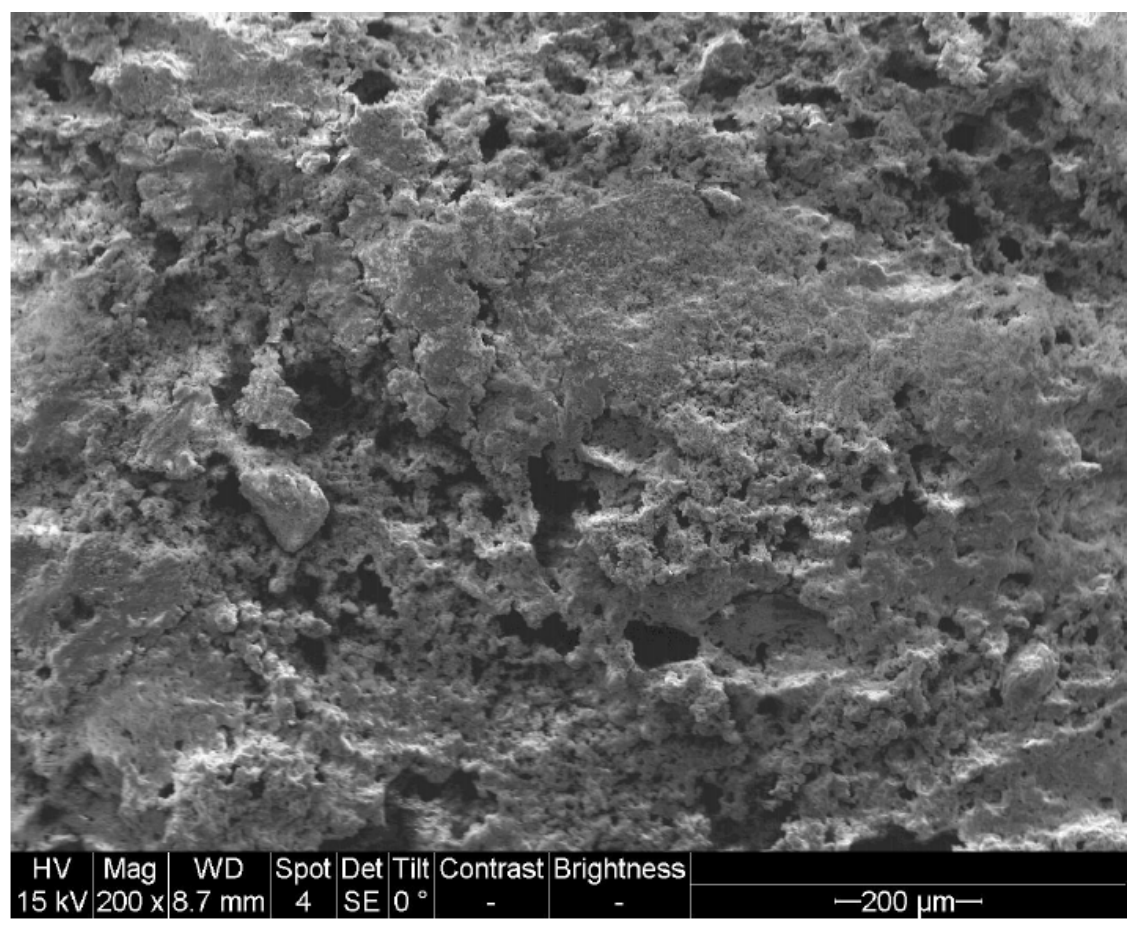

Figure 4.25: Joint 24, J-55 at 209.76 mKB SEM; (Coupon 16) 
These images show that the lower joint $12 \mathrm{~J}-55$ coupon has less scale, corrosion product present and appears to have corroded more than the joint 24 sample. The joint 24 sample was also lighter in appearance and had more complete scale coverage over the samples surface.

Imaging on the L-80 coupons, Figure 4.26 and Figure 4.27, indicate a similar pattern as the J-55 images with the lower joint 12 coupon having a darker, less complete scale coverage and the occurrence of a more uniform corrosion.

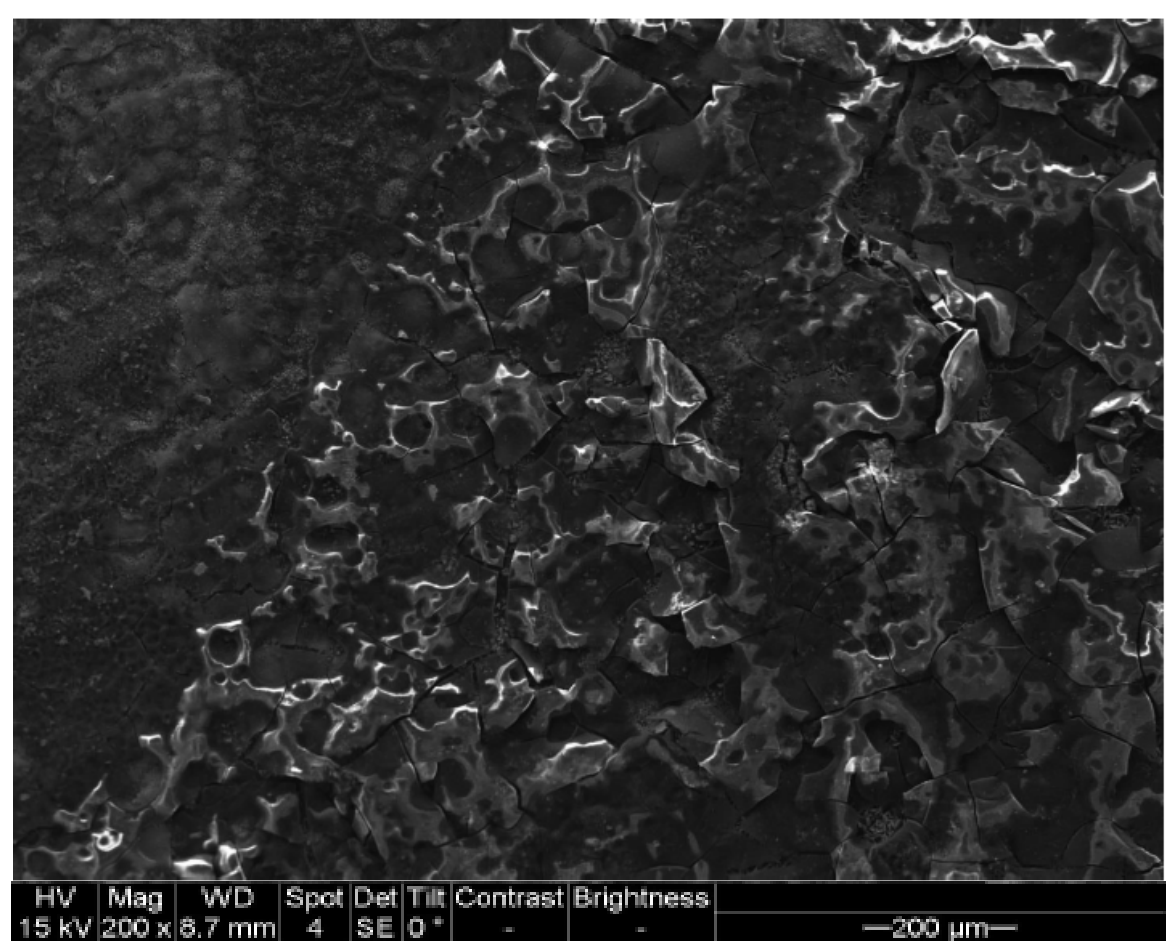

Figure 4.26: Joint 12, L-80 at 372.47 mKB SEM; (Coupon 9) 


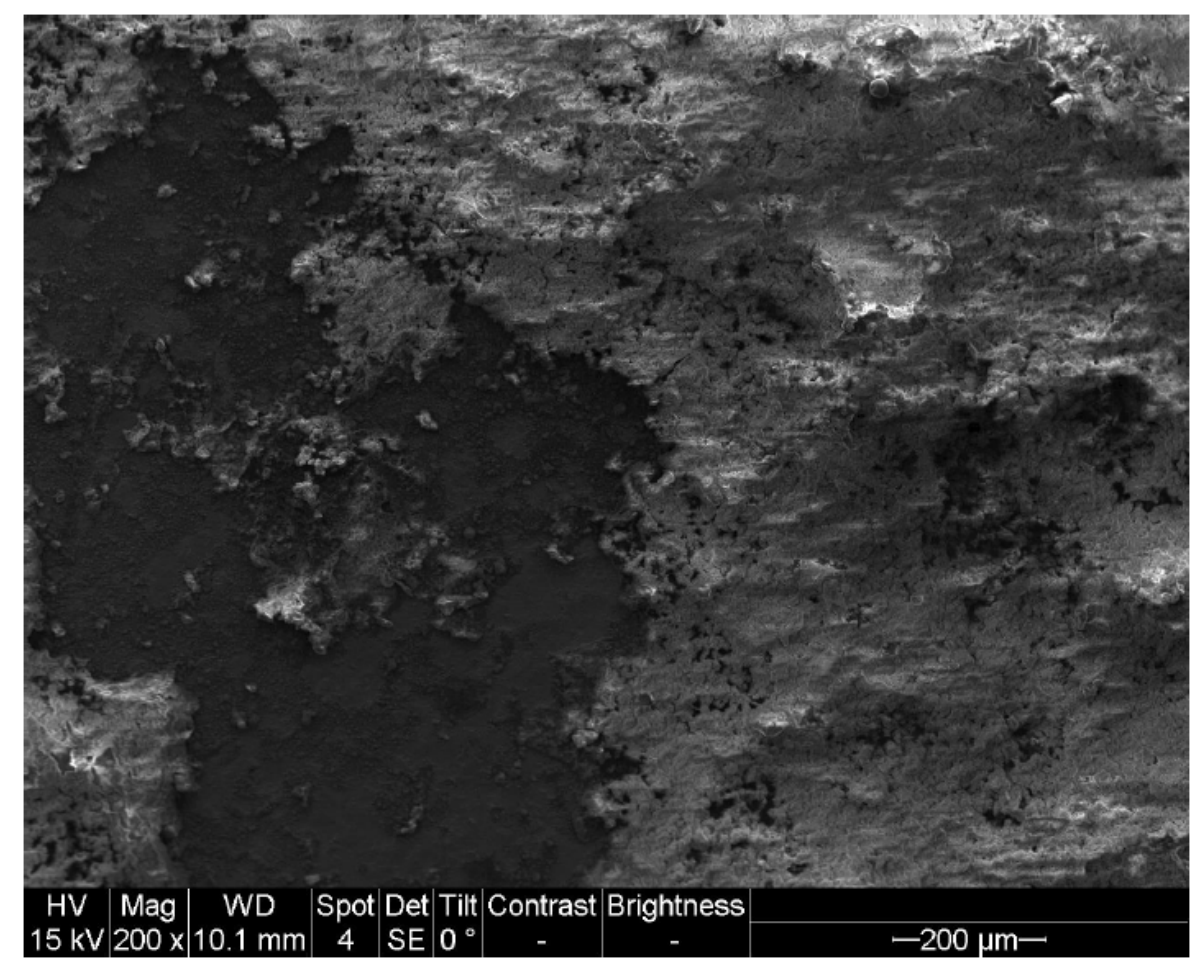

Figure 4.27: Joint 24, L-80 at 209.76 mKB SEM; (Coupon 18)

The second J-55 coupons coupled with the GLV-J55 SEM results in Figure 4.28 and Figure 4.29. These indicate a flakier, less compact, scale buildup over a section of the lower joint 12 coupon sample compared to the joint 24 coupon. The joint 24 coupon shows a dense and compact looking structure. 


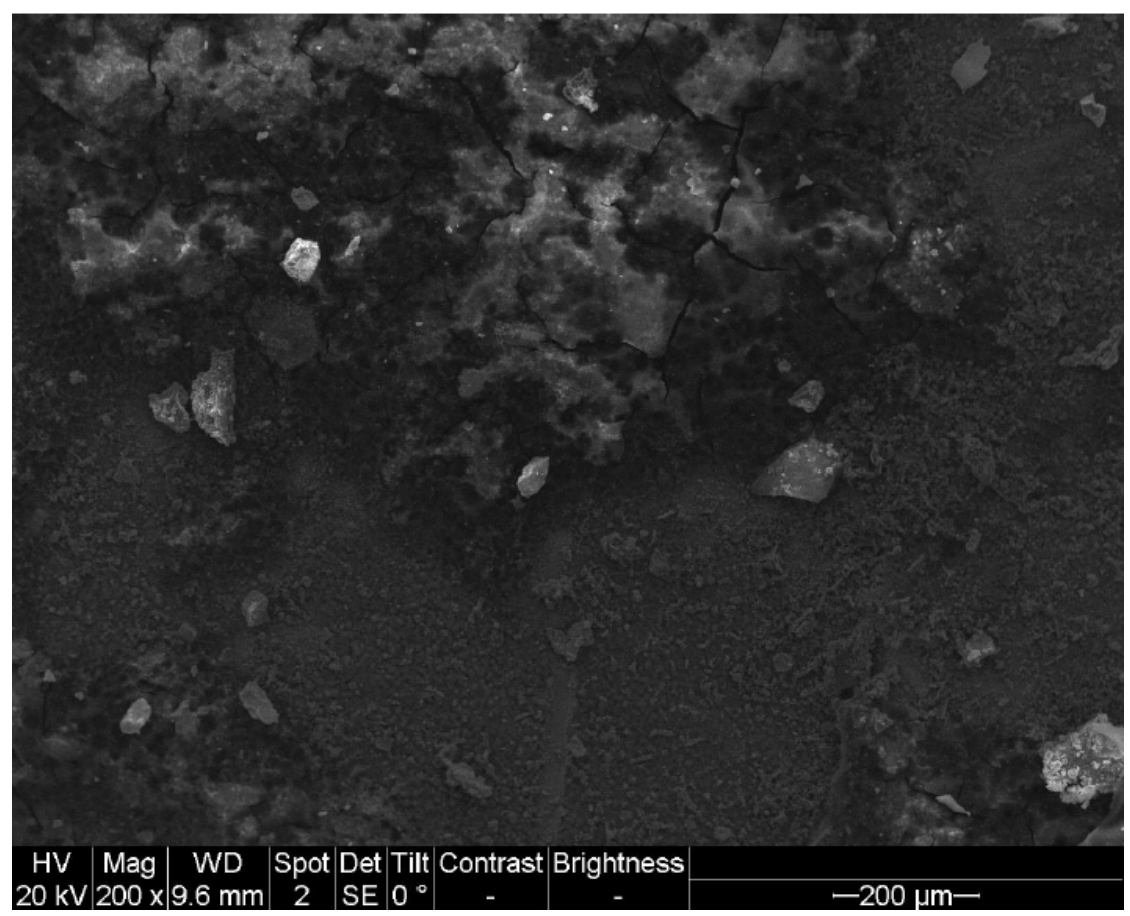

Figure 4.28: Joint 12, J-55 at 372.47 mKB SEM; (Coupon 49)

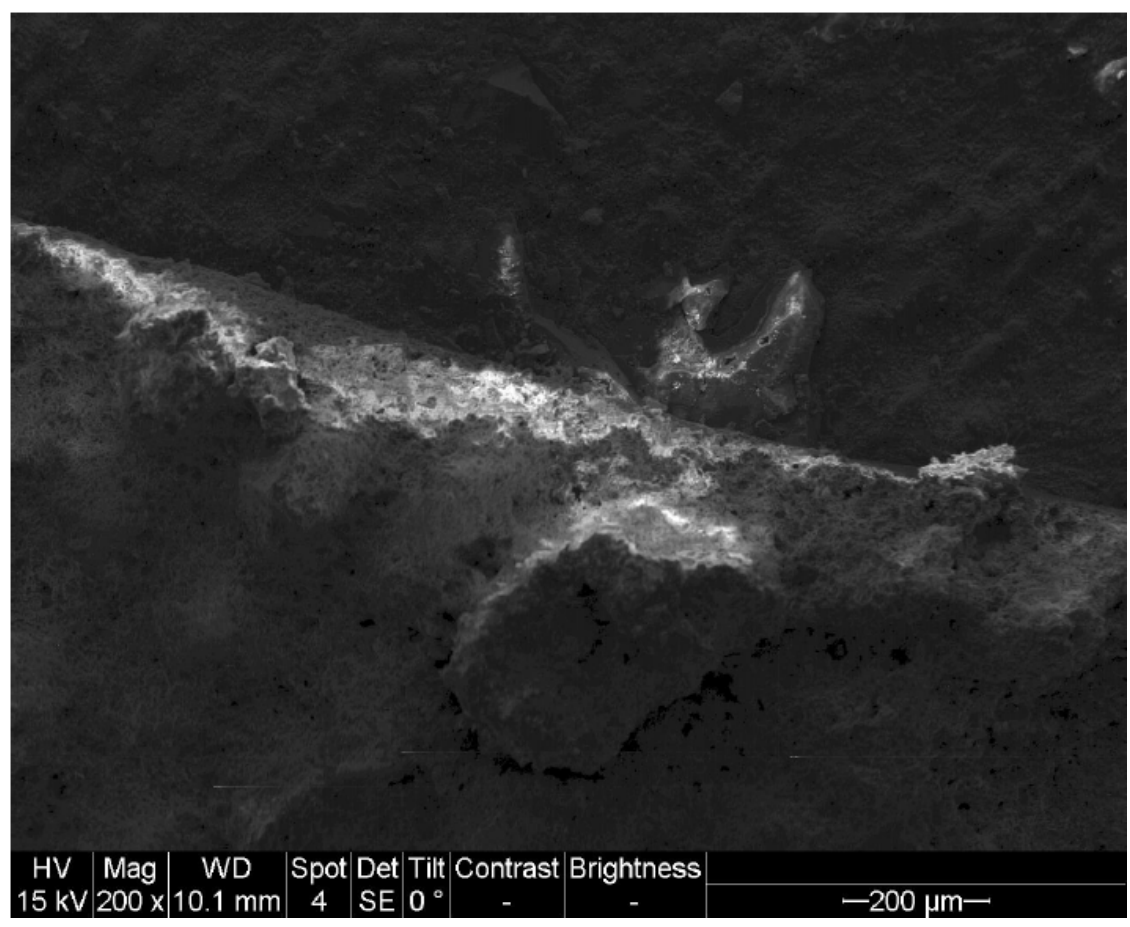

Figure 4.29: Joint 24, J-55 at 209.76 mKB SEM; (Coupon 33) 
Finally the GLV-J55 joint 12 and 24 coupon images in Figure 4.30 and Figure 4.31, show a rougher and more corroded surface on the lower joint 12 coupon as compared to the lighter color and less corroded joint 24 sample.

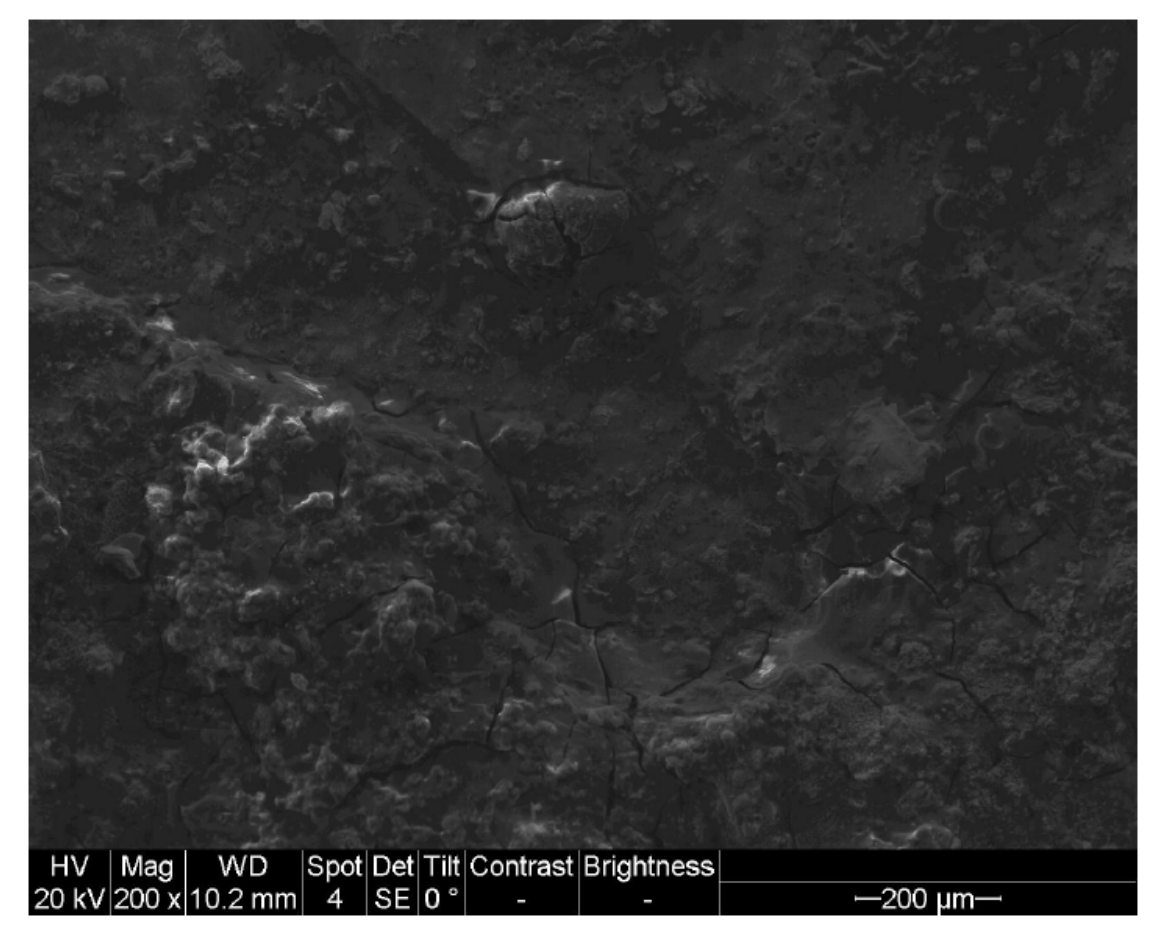

Figure 4.30: Joint 12, GLV-J55 at 372.47 mKB SEM; (Coupon 47) 


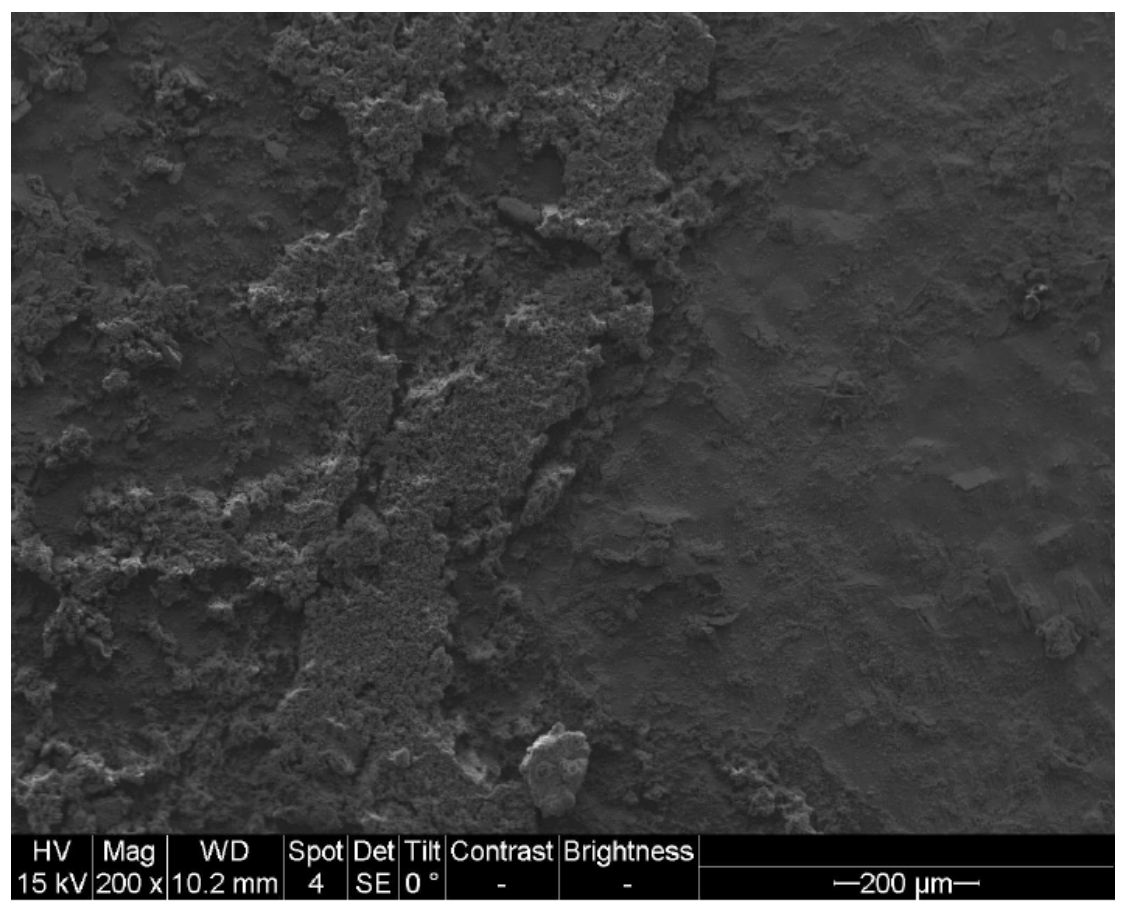

Figure 4.31: Joint 24, GLV-J55 at 209.76 mKB SEM; (Coupon 35)

These results appear to be in line with the corrosion rate testing analysis. The lower coupons all appeared to have less scale product present which would lead to lesser corrosion protection and a higher corrosion rate. A similar trend was noted on corrosion rates as the joint 12 samples appeared to corrode more compared to the higher ones at joint 24 [91]. XRD results are presented from Table 4.11 to Table 4.21. The intensity plots are also presented from Figure 4.32 to Figure 4.39.

Table 4.11: Joint 2, coupon \#8, J-55, position \#1, deposit analysis

\begin{tabular}{|c|c|c|}
\hline Compound & Chemical Formula & Abundance \\
\hline Pyrrhotite & $\mathrm{FeS}$ & $65-75 \%$ \\
\hline Magnetite & $\mathrm{Fe}_{3} \mathrm{O}_{4}$ & $10-20 \%$ \\
\hline Quartz & $\mathrm{SiO}_{2}$ & $5-10 \%$ \\
\hline Unidentified & $\mathrm{N} / \mathrm{A}$ & $1-5 \%$ \\
\hline
\end{tabular}


Table 4.12: Joint 12, coupon \#9, L-80, position \#2 deposit analysis

\begin{tabular}{|c|c|c|}
\hline Compound & Chemical Formula & Abundance \\
\hline Pyrrhotite & $\mathrm{FeS}$ & $75-85 \%$ \\
\hline Cristobalite & $\mathrm{SiO}_{2}$ & $15-25 \%$ \\
\hline
\end{tabular}

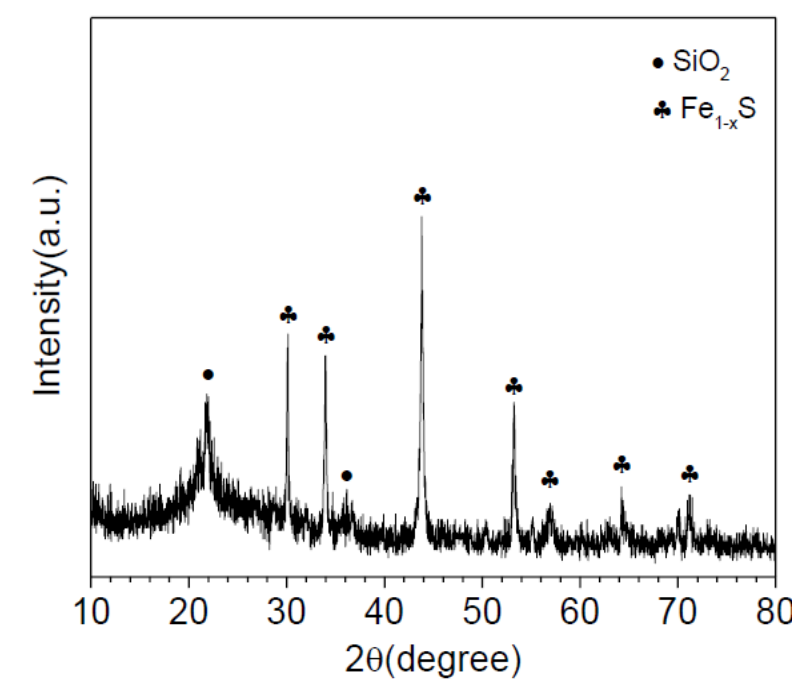

Figure 4.32: Joint 12, coupon \#9, L-80, position \#2 deposit analysis

Table 4.13: Joint 12, coupon \#20, J-55, position \#1 deposit analysis

\begin{tabular}{|c|c|c|}
\hline Compound & Chemical Formula & Abundance \\
\hline Pyrrhotite & $\mathrm{FeS}$ & $70-80 \%$ \\
\hline Cristobalite & $\mathrm{SiO}_{2}$ & $4-10 \%$ \\
\hline Unidentified & $\mathrm{N} / \mathrm{A}$ & $10-20 \%$ \\
\hline
\end{tabular}




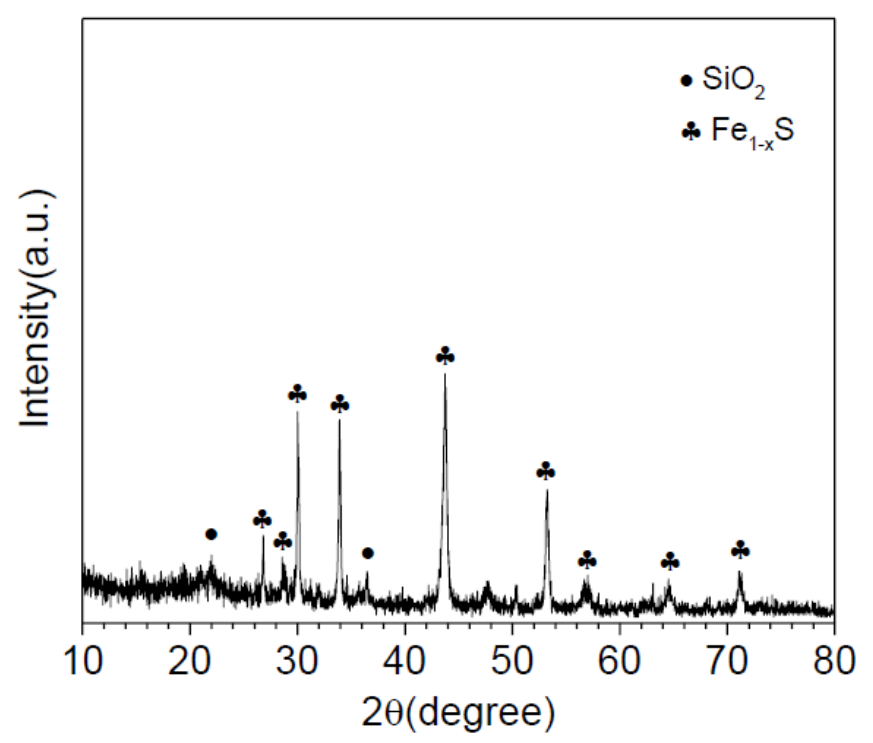

Figure 4.33: Joint 12, coupon \#20, J-55, position \#1 deposit analysis

Table 4.14: Joint 12, coupon \#47, GLV J-55, position \#3 deposit analysis

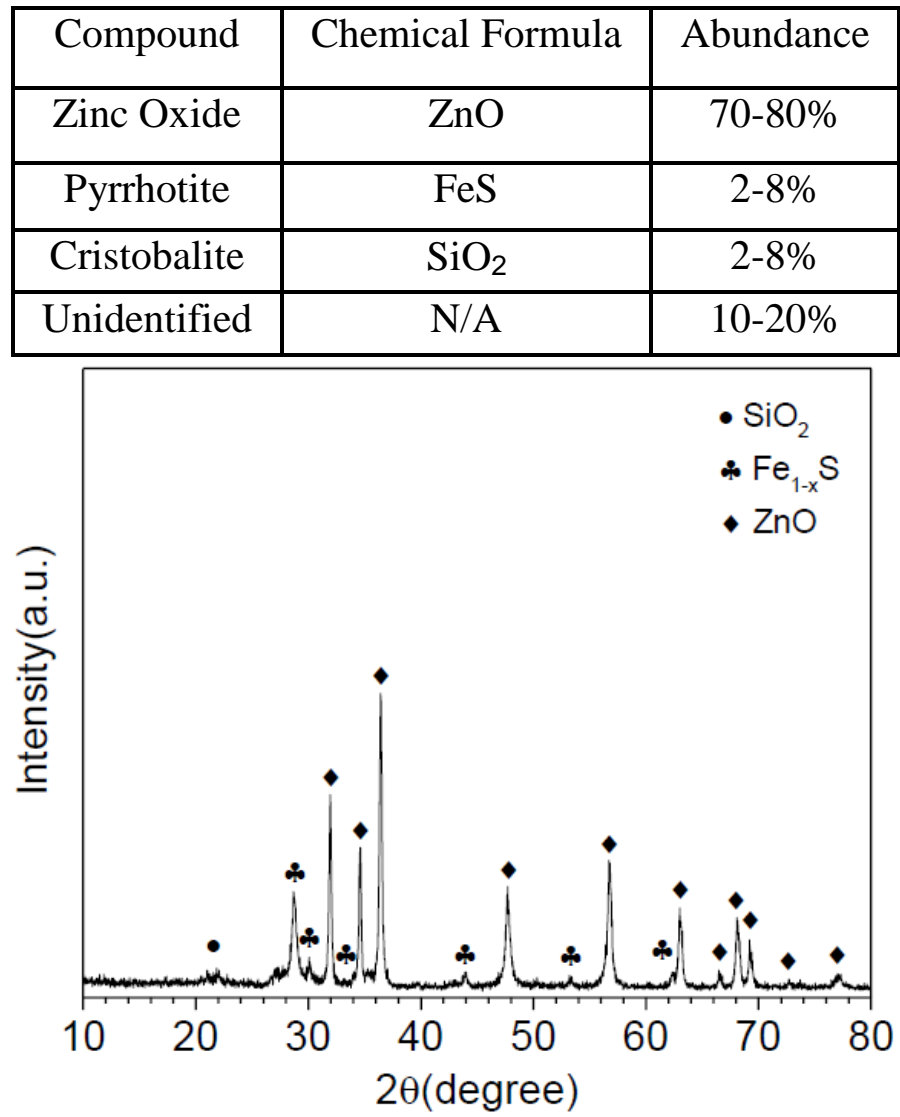

Figure 4.34: Joint 12, coupon \#47, GLV J-55, position \#3 deposit analysis 
Table 4.15: Joint 12, coupon \#49, J-55, position \#3 deposit analysis

\begin{tabular}{|c|c|c|}
\hline Compound & Chemical Formula & Abundance \\
\hline Zinc Oxide & $\mathrm{ZnO}$ & $80-90 \%$ \\
\hline Pyrrhotite & $\mathrm{FeS}$ & $2-8 \%$ \\
\hline Unidentified & $\mathrm{N} / \mathrm{A}$ & $2-8 \%$ \\
\hline
\end{tabular}

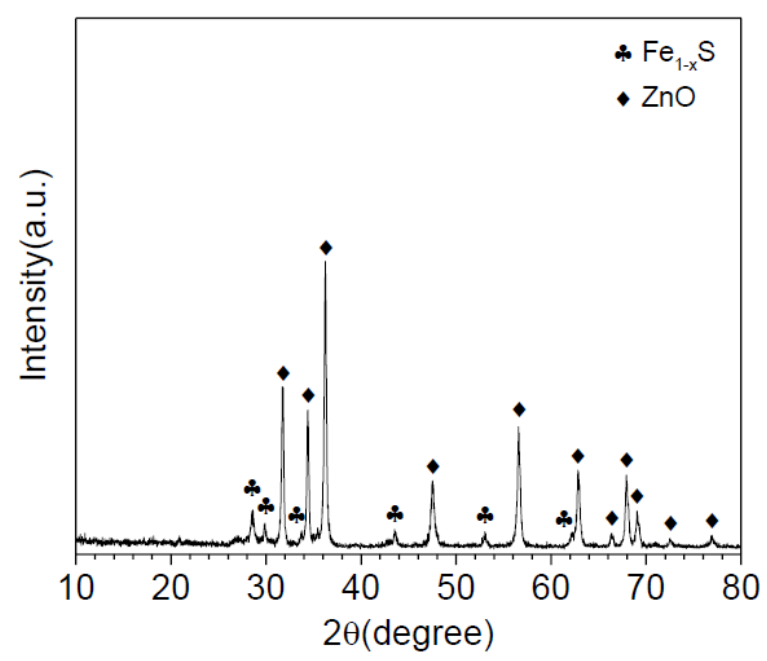

Figure 4.35: Joint 12, coupon \#49, J-55, position \#3 deposit analysis

Table 4.16: Joint 23, coupon \#9, J-55, position \#1 deposit analysis

\begin{tabular}{|c|c|c|}
\hline Compound & Chemical Formula & Abundance \\
\hline Cristobalite & $\mathrm{SiO}_{2}$ & $75-85 \%$ \\
\hline Quartz & $\mathrm{SiO}_{2}$ & $10-20 \%$ \\
\hline Pyrrhotite & $\mathrm{FeS}$ & $5-10 \%$ \\
\hline
\end{tabular}

Table 4.17: Joint 24, coupon \#18, L-80, position \#2 deposit analysis

\begin{tabular}{|c|c|c|}
\hline Compound & Chemical Formula & Abundance \\
\hline Cristobalite & $\mathrm{SiO}_{2}$ & $90-99 \%$ \\
\hline Pyrrhotite & $\mathrm{FeS}$ & $1-10 \%$ \\
\hline
\end{tabular}




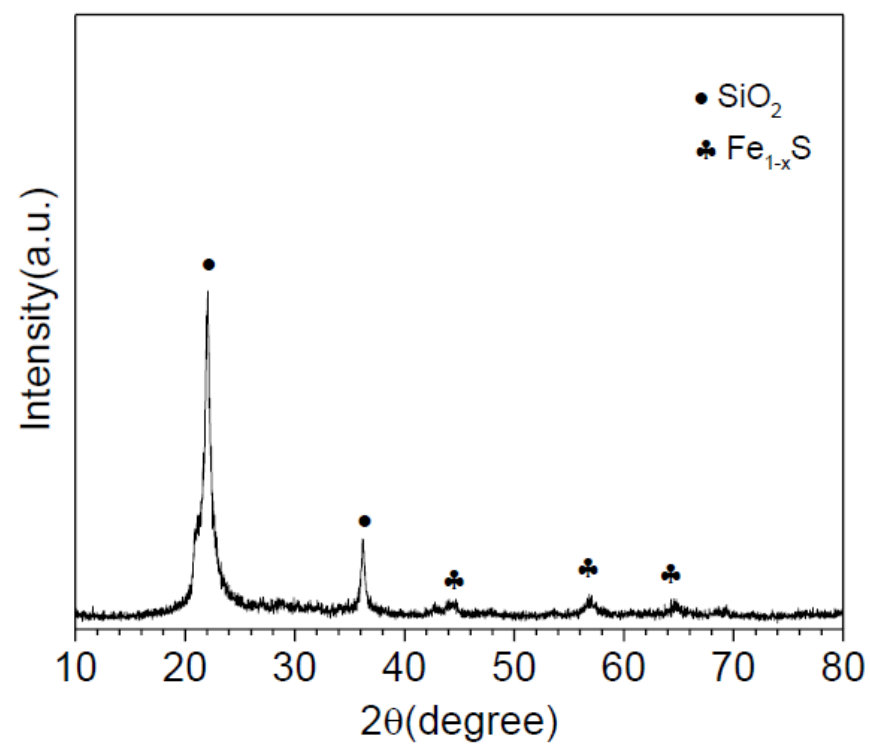

Figure 4.36: Joint 24, coupon \#18, L-80, position \#2 deposit analysis Table 4.18: Joint 24, coupon \#16, J-55, position \#1 deposit analysis

\begin{tabular}{|c|c|c|}
\hline Compound & Chemical Formula & Abundance \\
\hline Cristobalite & $\mathrm{SiO}_{2}$ & $90-99 \%$ \\
\hline Pyrrhotite & $\mathrm{FeS}$ & $1-10 \%$ \\
\hline
\end{tabular}

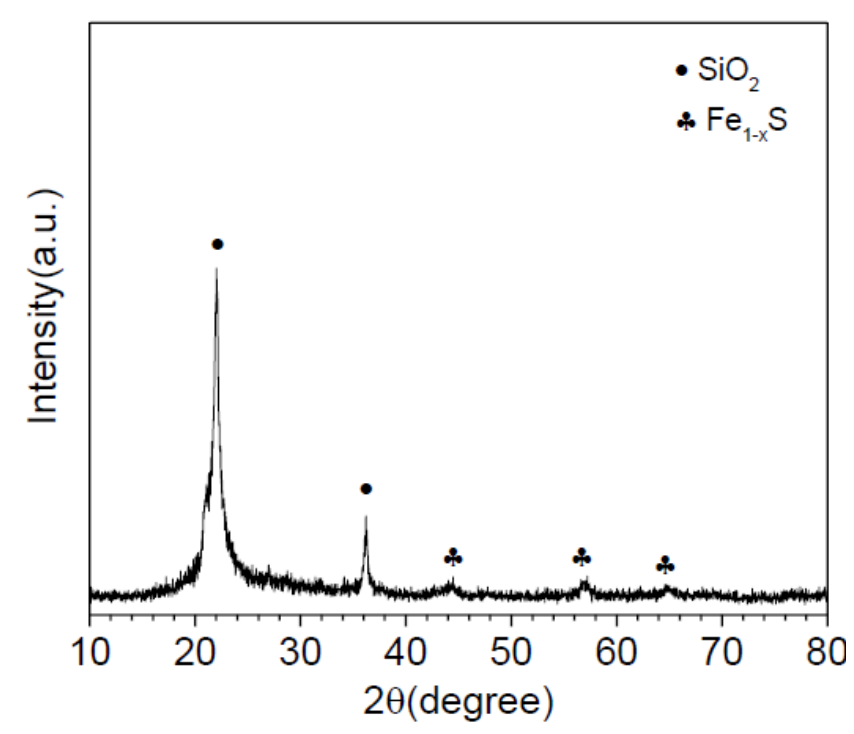

Figure 4.37: Joint 24, coupon \#16, J-55, position \#1 deposit analysis 
Table 4.19: Joint 24, coupon \#35, GLV J-55, position \#3 deposit analysis

\begin{tabular}{|c|c|c|}
\hline Compound & Chemical Formula & Abundance \\
\hline Zinc Oxide & $\mathrm{ZnO}$ & $80-90 \%$ \\
\hline Pyrrhotite & $\mathrm{FeS}$ & $1-5 \%$ \\
\hline Unidentified & N/A & $5-15 \%$ \\
\hline
\end{tabular}

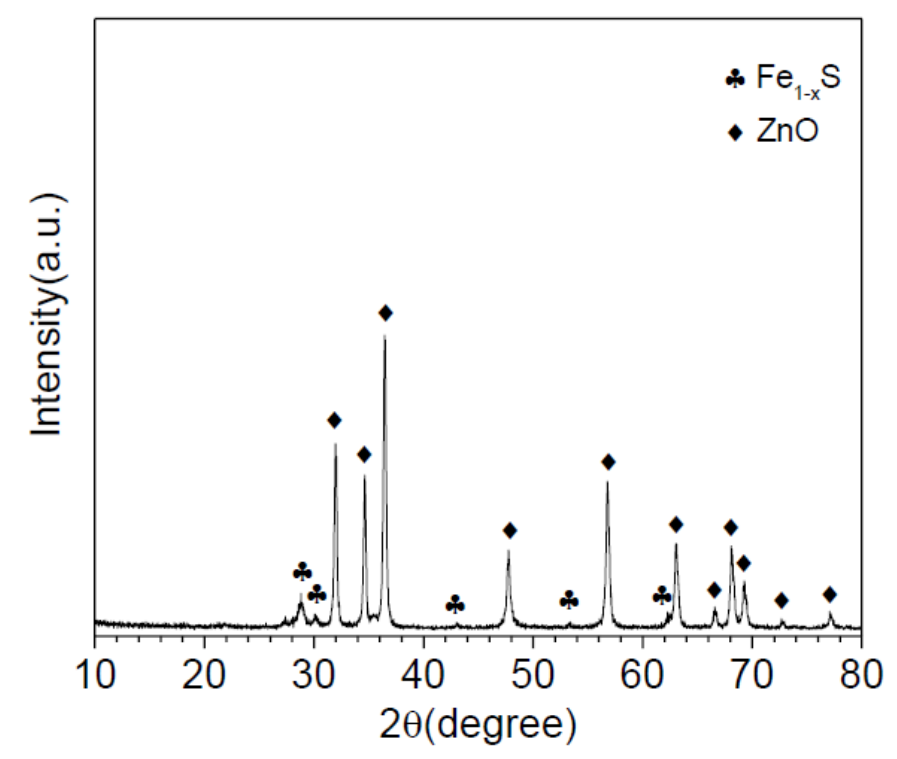

Figure 4.38: Joint 24, coupon \#35, GLV J-55, position \#3 deposit analysis

Table 4.20: Joint 24, coupon \#33, J-55, position \#3 deposit analysis

\begin{tabular}{|c|c|c|}
\hline Compound & Chemical Formula & Abundance \\
\hline Cristobalite & $\mathrm{SiO}_{2}$ & $65-75 \%$ \\
\hline Zinc Oxide & $\mathrm{ZnO}$ & $15-25 \%$ \\
\hline Pyrrhotite & $\mathrm{FeS}$ & $1-5 \%$ \\
\hline Unidentified & $\mathrm{N} / \mathrm{A}$ & $4-10 \%$ \\
\hline
\end{tabular}




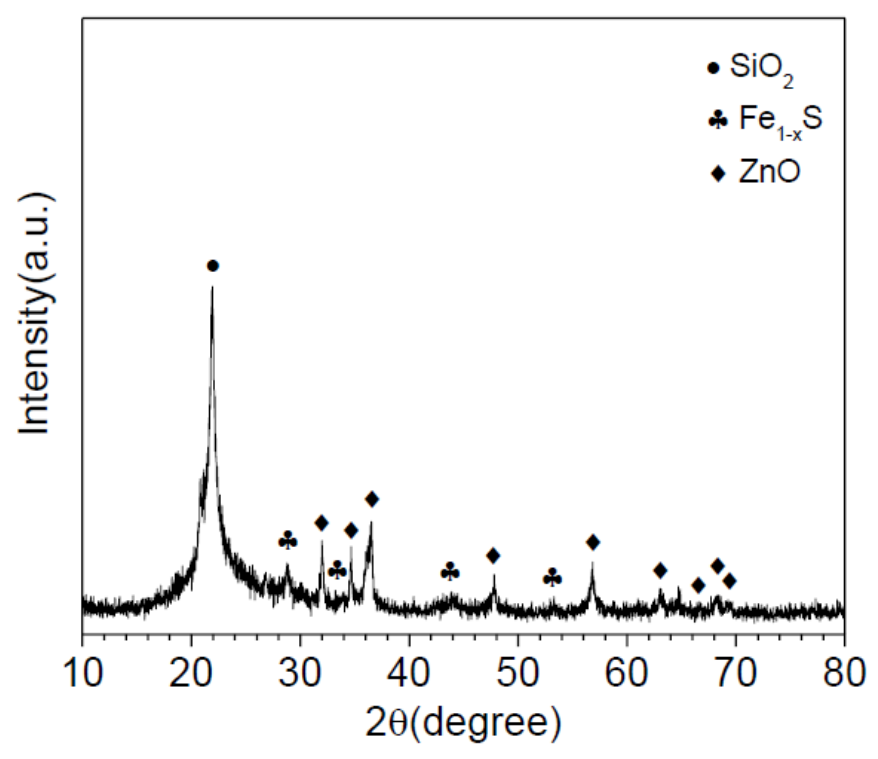

Figure 4.39: Joint 24, coupon \#33, J-55, position \#3 deposit analysis

Table 4.21: Joint 25, coupon \#22, J-55, position \#1 deposit analysis

\begin{tabular}{|c|c|c|}
\hline Compound & Chemical Formula & Abundance \\
\hline Cristobalite & $\mathrm{SiO}_{2}$ & $65-75 \%$ \\
\hline Quartz & $\mathrm{SiO}_{2}$ & $15-25 \%$ \\
\hline Unidentified & $\mathrm{N} / \mathrm{A}$ & $5-15 \%$ \\
\hline
\end{tabular}

These XRD results indicate that on the non-creviced coupons, not the J-55+GLVJ55, that silicate based scales and the iron sulfide compound pyrrhotite make up most the compounds at each depth. The silicate scales present are quartz and cristobalite. The one exception to this is on the joint $25 \mathrm{~J}-55$ coupon in Table 4.21 . Here the only compounds found are silicates and 5-15\% of an unidentified compound. Magnetite was also identified on the lowest joint 2 J-55 coupon, not coupled with the GLV-J55 sample. Silicate scales, including quartz and cristobalite, are commonly found compounds in oil and gas wells, lines, and facilities as they are produced from oil and gas formations. 
Cristobalite is a high-temperature polymorph of silica and has the same chemical formula as quartz, $\mathrm{SiO}_{2}$, but a different crystal structure [90]. Field scale compositional analysis has shown quartz to be present downhole at multiple locations. Including further down the horizontal section of the well in the liner [92], at the ESP as the joint 2 coupon XRD results also show, or above the ESP as is seen on the coupon samples from joints 23 to 25.

$\mathrm{ZnO}$ represents the majority scale compound present on the GLV-J55 coupon as well as the J-55 coupon coupled with it to form a crevice. Galvanized materials are ones that are coated in zinc to reduce corrosion rates by forming a passive $\mathrm{ZnO}$ or $\mathrm{ZnCO}_{3}$ scale. The galvanized coating is zinc based which is anodic to steel and would preferentially corrode when directly exposed to the environment. The rapid initial corrosion of the zinc would lead to local saturation of limits being reached and the formation of the passive scale, which if remaining intact, aids in preventing corrosion. The formation of this scale for protection and reducing corrosion processes appears to be the case here with the zinc reacting with the annular fluids to corrode in preference to the base J-55 and the J-55 coupon it was coupled with. This is also shown in the corrosion rate testing from Figure 4.20 to Figure 4.23. The J-55 coupon coupled with the GLV-J55 material corroded less than all others at each location.

The remaining coupons, with the exception of the joint 25 J-55 coupon, showed pyrrhotite to also be present in varying quantities. Pyrrhotites, or other iron sulfide compounds, are expected to occur as it is the likely corrosion reaction product of steel in the presence of aqueous $\mathrm{H}_{2} \mathrm{~S}$ at elevated temperatures [46, 93]. Field failure analysis has also shown iron sulfide scale products present. It is interesting to note that at lower well 
elevations FeS appears to be the majority scale compound. Whereas at higher elevations it begins to decrease in quantity and at the top joint 25 coupon it is no longer observed as seen in Table 4.21. This compares well to the corrosion rate testing as at higher well elevations corrosion rates, and therefor corrosion product quantities, decreased. An exception is on the joint 25 coupons which showed an increased in corrosion rates but no FeS scale formation, only silicates and unidentified products. This could be due to corrosion occurring where there was no fluid to saturate FeS for scale formation, or that the unidentified portions are pyrrhotite. As discussed above in the literature review section, pyrrhotite is a corrosion product of carbon steel corrosion under sour conditions and is often found at moderate to high $\mathrm{H}_{2} \mathrm{~S}$ concentrations where the corrosion kinetics for FeS scale formation are preferred to $\mathrm{FeCO}_{3}$. Pyrrhotite is an iron sulfide mineral with the formula $F e_{(1-x)} S$ (x $=0$ to 0.2 ). It is a nonstoichiometric variant of FeS, troilite [94]. Magnetite is a carbon steel corrosion product often found in systems where aqueous $\mathrm{CO}_{2}$ is present as is the case in SAGD. The unidentified scale portions refer to one reflection on the diffraction pattern that did not appear to correspond to any of the known compounds $[95,96]$.

\subsection{Testing summary and analysis}

This section summarizes the lab autoclave and field testing using corrosion coupons representative of commonly used wellhead and various downhole completion materials. 


\subsubsection{Autoclave testing}

Table 4.22 again outlines the materials tested in the autoclaves, measurements taken, and the type of corrosion being analyzed.

Table 4.22: Autoclave testing summary

\begin{tabular}{|c|c|c|c|}
\hline & Materials & Measurements & Test Purpose \\
\hline \multirow[t]{3}{*}{ Wellhead Materials } & 1018 Carbon Steel & $\begin{array}{l}\text { - Linear Polarization Resistance } \\
\text { - Weight Loss }\end{array}$ & - General CR \\
\hline & Deloro-40 HF & $\begin{array}{l}\text { - Linear Polarization Resistance } \\
\text { - Weight Loss } \\
\text { - Cyclic Potentiodynamic Potential } \\
\text { - Potentiostatic Potential }\end{array}$ & - General CR \\
\hline & Stellite-6 HF & $\begin{array}{l}\text { - Linear Polarization Resistance } \\
\text { - Weight Loss } \\
\text { - Cyclic Potentiodynamic Potential } \\
\text { - Potentiostatic Potential }\end{array}$ & - General CR \\
\hline \multirow[t]{5}{*}{$\begin{array}{l}\text { Downhole } \\
\text { Materials }\end{array}$} & $J-55$ & - Weight Loss & $\begin{array}{l}\text { - Crevice CR } \\
\text { - Galvanic CR }\end{array}$ \\
\hline & $\mathrm{K}-55$ & $\begin{array}{l}\text { - Linear Polarization Resistance } \\
\text { - Weight Loss } \\
\text { - Zero Resistance Ammeter }\end{array}$ & $\begin{array}{l}\text { - General CR } \\
\text { - Crevice CR } \\
\text { - Galvanic CR }\end{array}$ \\
\hline & TN-55TH & $\begin{array}{l}\text { - Linear Polarization Resistance } \\
\text { - Weight Loss } \\
\text { - Zero Resistance Ammeter }\end{array}$ & $\begin{array}{l}\text { - General CR } \\
\text { - Crevice CR } \\
\text { - Galvanic CR }\end{array}$ \\
\hline & GLV-K55 & $\begin{array}{l}\text { - Linear Polarization Resistance } \\
\text { - Weight Loss } \\
\text { - Zero Resistance Ammeter }\end{array}$ & $\begin{array}{l}\text { - Crevice CR } \\
\text { - Galvanic CR }\end{array}$ \\
\hline & GLV-J55 & - Weight Loss & - Crevice CR \\
\hline
\end{tabular}

\subsubsection{Autoclave wellhead material testing}

Wellhead material autoclave testing verified 1018 carbon steels susceptibility to corrosion in the conditions tested. LPR measurements indicated corrosion rates between $0.38-1.79 \mathrm{~mm} / \mathrm{y}$ with average weight loss corrosion rate of $0.25 \mathrm{~mm} / \mathrm{y}$. These rates are considered high relative to NACE standards. Deloro-40 HF, which is currently being 
used as a gate valve gate face overlay material, experienced LPR corrosion rates between 0-0.024 mm/y with an average weight loss corrosion rate of $0.00076 \mathrm{~mm} / \mathrm{y}$ which can be considered negligible due to instrumentation measurement error and accuracy limits [60]. Similarly, the Stellite-6 HF overlay experienced low LPR corrosion rates between 0.015$0.024 \mathrm{~mm} / \mathrm{y}$, and a negligible weight loss measurement for the same reason as the Deloro-40 HF [97]. To better compare the Deloro-40 HF and Stellite-6 HF materials 4day CPP and potentiostatic polarization testing was completed to determine their susceptibility to pitting and ability to re-passivate should corrosion occur. These tests indicated that the Stellite-6 HF finish would provide superior protection. It had higher apex and pitting potentials found through CPP evaluations. Further, the re-passivation potential indicates if pitting were to occur, the Stellite-6 HF material should more readily re-passivate to reduce the depth and severity of attack. The Stellite-6 HF also showed a negative hysteresis loop indicating a more corrosion resistant material, compared to the positive loop in the Deloro-40 HF hysteresis loop.

\subsubsection{Autoclave downhole completion material testing}

Autoclave testing was then done on downhole completion materials in general, crevice, and galvanic corrosion setups. General 7-day corrosion rate testing was completed on K-55 and TN-55TH materials through LPR and weight loss analysis. The initial and final LPR K-55 coupon measurements showed rates between 0.188-0.243 $\mathrm{mm} / \mathrm{y}$, and a weight loss rate of $0.297 \mathrm{~mm} / \mathrm{y}$. The TN-55TH LPR measurements increased from $0.196 \mathrm{~mm} / \mathrm{y}$ up to $0.243 \mathrm{~mm} / \mathrm{y}$ with an average weight loss rate of 0.319 $\mathrm{mm} / \mathrm{y}$. Both the weight loss and LPR tests showed the TN-55TH material to have slightly 
higher corrosion rates. The slightly higher rates can be considered insignificant as they are within measurement device reading accuracy tolerance limits.

In the autoclave crevice corrosion tests, weight loss measurements were utilized to determine the effects of crevices on corrosion rates in a SAGD environment after 7day exposure. Three crevices setups were made between K-55+TN-55TH, K-55+GLV-J55, and K-55+K-55 coupon couples. The K-55 and TN-55TH materials weight loss corrosion rates were determined to be $0.241 \mathrm{~mm} / \mathrm{y}$ and $0.246 \mathrm{~mm} / \mathrm{y}$ respectively, with moderate surface etching and no localized corrosion noticed at the creviced location. The similar rates are expected as these materials are very similar, they are both carbon steels but the TN-55TH is a patented carbon steel blend with slightly tighter chemistry tolerances compared to standard API K-55 and J-55 materials. The creviced couple of K55+K-55 materials had identical rates of $0.215 \mathrm{~mm} / \mathrm{y}$ each as expected given they are the same material. Finally, the K-55+GLV-J55 pair showed very different corrosion rates of $0.276 \mathrm{~mm} / \mathrm{y}$ and $0.137 \mathrm{~mm} / \mathrm{y}$ respectively with no localised or preferential attack on either coupon. It is likely that the GLV-J55 sample had reduced corrosion rates due to the formation of a passive $\mathrm{ZnO}$ or $\mathrm{ZnCO}_{3}$ scale. The galvanized coating is zinc based which is anodic to steel and would preferentially corrode when directly exposed to the environment. The rapid initial corrosion of the zinc would lead to local saturation of limits being reached and the formation of the passive scale, which if remaining intact, aids in preventing corrosion.

Finally autoclave tests were completed to understand the effects of galvanic couples on corrosion rates. This testing was done on the same materials as in the crevice testing by measuring the potential difference between the two materials using a 
potentiostat in ZRA mode over the 4-day test period. Here two electrode pairs were galvanically coupled and corrosion rates monitored over a 4-day period. Positive current readings represent a net current flow from the K-55 and negative current readings represent a net current flow from the TN-55TH. Weight loss measurements were also taken and corrosion rates were calculated. The electrode pairs evaluated were K-55+TN55TH and K-55+GLV-K55. The galvanic current density between the K-55+TN-55TH pair varied considerably throughout the test from an initial $18.54 \mu \mathrm{A} / \mathrm{cm}^{2}$ to $-6.55 \mu \mathrm{A} / \mathrm{cm}^{2}$ over the first 10 hours. The current flow then reversed indicating the TN-55TH electrode was corroding preferentially. However, the coupled current remained relatively low throughout and would not be considered high enough to indicate significant galvanic corrosion was occurring due to dissimilar metal compositions. This is verified by the corrosion rates found on both the K-55 and TN-55TH materials, with weight loss rates of $0.462 \mathrm{~mm} / \mathrm{y}$ and $0.454 \mathrm{~mm} / \mathrm{y}$ respectively. These are again similar materials and similar rates are expected with no preferential corrosion. It is likely that the weight loss corrosion rates are higher because of the shorter test duration compared to the previous crevice corrosion testing. The K-55+GLV-K55 pair had a very low coupled galvanic current; trending between $-0.76 \mu \mathrm{A} / \mathrm{cm}^{2}$ to $0.58 \mu \mathrm{A} / \mathrm{cm}^{2}$. The low current readings indicate that galvanic corrosion between the two was minimal. The coupled open circuit potential stabilised at $\sim-40 \mathrm{mV}$ versus the Hastelloy reference. This potential is significantly less anodic, corrosive, than the K-55/TN-55TH couple. The weight loss corrosion rates were also lower for the K-55 and GLV-K55 samples at $0.257 \mathrm{~mm} / \mathrm{y}$ and $0.236 \mathrm{~mm} / \mathrm{y}$ respectively. It is likely that the presence of the galvanized coating again quickly formed 
a passive scale very quickly which protected the metals and kept corrosion rates and current densities low throughout the test period.

\subsubsection{Field corrosion coupon testing}

Corrosion rate and scale analysis was completed on the corrosion coupons installed in a producing SAGD well. XRD results showed the presence of pyrrhotite, quartz, cristobalite, zinc oxide, magnetite, and some unidentified compounds. Pyrrhotite, quarts, and cristobalite are present on most samples in varying concentrations. Zinc oxides are identified on the galvanized coupon sample sets as expected. The scales composition varied in a noticeable manner from the well bottom at the ESP to the liquid level. Coupons from the clamps at the bottom of the well on joints 2 and 12 showed the highest concentrations of pyrrhotite scales of between $65-85 \%$, with 5-25\% silicate scales (quartz and cristobalite), and up to $20 \%$ of an unidentified compound. Scales on the higher joint 23, 24, and 25 clamp coupons tended to show reduced pyrrhotite concentrations of between 1-10\% pyrrhotite, and increased silicate scale concentrations 10-99\%. The J-55 coupon in the highest joint 25 clamp showed only the presence of silicate scales, no iron sulfide compounds, with 5-15\% of an unidentified compound. Magnetite was also noted on the bottom joint 2 clamp J-55 coupon. Magnetite is not an uncommon compound based on the presence of $\mathrm{CO}_{2}$ and its ability to corrode carbon steels under the right conditions. It is also possible that it formed after being removed from the well if the pyrrhotite scale was damaged and $\mathrm{CO}_{2}$ remained trapped under the scale. 
The scale composition and concentration results correspond well to the corrosion rate data. On almost all coupon samples and setups corrosion rates decreased from the bottom of the well to the top of the set of coupons. Comparing this to the XRD scale analysis, lesser amounts of iron sulfide corrosion product were noted moving from the bottom to the top of the well. An exception to this was on the top joint 25 coupons. At this location no FeS corrosion products were noted and corrosion rates increased on all materials. It is difficult to determine the corrosion mechanism here given no corrosion products ( $\mathrm{FeS}$ or $\mathrm{FeCO}_{3}$ ) were noted, only silicates. But because of the increase in corrosion rates relative to the joint 24 clamp coupons that they were partially in/out of the fluids and that the solubility limits in the surrounding environment were not reached, therefore no corrosion product scale formed.

Corrosion rates also decreased consistently with the standard J-55 material showing the highest rates, followed by the L-80, the second J-55 coupon coupled with the GLV-J55. In each case the galvanized material experienced much higher rates of corrosion due to its anodic properties, as well as to how it was cleaned for scale analysis.

Visual inspections indicated the presence of pitting on only the L-80 coupons which can likely be attributed to it being a harder and stronger material with higher carbon concentrations compared to the J-55, K-55, and TN-55TH materials. The scales were consistently darker in appearance with shades of black, grey, and brown, along with white compounds. Iron sulfide scale have a darker grey/black and brown appearance, magnetite is also a brownish scale, with silicates having a clear and white appearance. 


\subsubsection{Combined testing analysis and summary}

At a first glance comparing the lab test corrosion rate results to the field coupon corrosion rates they do not appear to match. Lab results show much more aggressive corrosion rates compared to the field weight loss testing, up to 10 times higher. This is likely due to the much shorter test exposure period and is common when comparing field to lab data. The downhole coupons were tested for 330 days, compared to the 4 and 7-day lab testing. Also, the autoclave testing brines did not contain oil, a known corrosion inhibitor, and could have led to increased corrosion rates.

It is interesting to note that when comparing the lab results to past field failure analysis completed, some analysis compares well with this testing while other findings are not as expected. Wellhead material testing showed the Stellite-6 HF material to performing exceptionally well compared to carbon steel and better than the Deloro-40 HF. Select wellhead components used contain a Stellite-6 HF overlay, gate valve gate face seat components, have not shown signs of corrosion, like the testing results here. Whereas the gate faces finished with a Deloro-40 HF overlay have experienced pitting corrosion. For this reason it is recommended that a field trial be completed by replacing the Deloro-40 HF overlay with the Stellite-6 HF overlay on the gate valve gate face to determine its performance in real production conditions. It is also recommended that further autoclave and field testing be completed on a third tungsten carbide HF overlay material. This material has been proposed for use by different wellhead and valve suppliers but has not yet been testes in SAGD like conditions.

Lab and field testing and analysis on downhole completion materials have shown that downhole materials are susceptible to corrosion, specifically aqueous $\mathrm{H}_{2} \mathrm{~S}$ corrosion 
when subject to SAGD operating conditions. In general "low" rates of uniform corrosion were found and corrosion rates decreased at higher well elevations up to and just below the annular liquid level. At and just above the liquid level an increase in corrosion rates was found and can be expected in the form of both general uniform and pitting corrosion. These results compare to past downhole component failure analysis which has led to the belief that the most concerning area for corrosion is closer to the top of the annular liquid level due to the presence of water, not oil, and the highest concentrations of aqueous acidic gases. Testing has confirmed this with the "low" uniform corrosion rates calculated at all well depths, but an increase in uniform corrosion rates and formation of corrosion pits on select materials at the top coupons. Pitting corrosion is of much greater concern due to its more severe and often sudden consequences.

The "low" uniform corrosion rates at all locations are likely due to the formation of passive scales, the presence of oil at lower well elevations, as well as a reduction in aqueous acidic gas concentrations at lower well elevations due to the partitioning of the gases into the oil phase [98].

Galvanic and crevice corrosion do not appear to be of concern due to similar materials being used and proper material couples made between components to ensure that passive films are able to form. It is important that the films on galvanized materials remain intact, not removed chemically or mechanically, due to the anodic properties of $\mathrm{Zn}$ relative to most other metals. If the protective scales are continually removed severe localized corrosion can occur. This has been noted in past failure analysis.

Pitting corrosion at higher well elevations, at and above the liquid level, can be expected on susceptible materials, $\mathrm{L}-80$ in testing, due to higher concentration of aqueous 
$\mathrm{H}_{2} \mathrm{~S}$, changes in fluid exposure and scale solubility, crevices, and a slightly more dynamic fluid environment with the occurrence of vapor flashing and condensation.

Based on this testing the development and injection of SAGD specific corrosion inhibitor is recommended with a focus should be placed on inhibiting the lower and upper portions of the wells annulus. Different inhibitors and application procedures should be used based on the location of injection and conditions present. It is recommended that to inhibit the lower portion of the well that an inhibitor be injected down the bubbletube, and the upper portion through inhibitor or scavenger injection at the wellhead. It is also recommended that a review of materials being used at higher well elevations be completed to avoid materials susceptible to pitting corrosion. 


\section{Chapter Five: Mechanistic aspects of metal corrosion in $\mathrm{H}_{2} \mathrm{~S}$ and $\mathrm{CO}_{2}$ SAGD environments}

The final objective of this research was to determine the corrosion mechanisms present in SAGD given the conditions tested. Literature review has shown that limited to no corrosion mechanistic analysis or research has been completed under SAGD type conditions comparable to Firebag. SAGD temperatures can range between $150^{\circ} \mathrm{C}$ to $240^{\circ} \mathrm{C}$, and relatively high concentrations of $\mathrm{CO}_{2}$ and $\mathrm{H}_{2} \mathrm{~S}$ are present. This research shows that the dominating corrosion mechanism present under these environments is that of aqueous $\mathrm{H}_{2} \mathrm{~S}$ corrosion based on the scale compositions, corrosion morphology, past failure analysis, as well as literature review [17, 35, 50, 99]. Because of the elevated concentrations of $\mathrm{CO}_{2}$, one might expect $\mathrm{CO}_{2}$ corrosion to be a dominating mechanism. This testing showed that due to the low ratio of $\mathrm{CO}_{2} / \mathrm{H}_{2} \mathrm{~S}$ and the fact that iron sulfide is less soluble than iron carbonate under these conditions, aqueous $\mathrm{H}_{2} \mathrm{~S}$ corrosion is the dominating mechanism [31, 36, 41, 53, 54, 98]. It could also be expected that fluid compositional changes alter the dominating mechanism due to electrolyte property and condition changes; this did not appear to be the case.

As found and noted in the literature review section 2.3.2, the mechanism for hydrogen sulfide corrosion is that of a solid-state reaction mechanism [41, 43, 52, 72, 81] leading to the formation of an iron sulfide corrosion product. Mackinawite is often the first scale formed on the surface, but can quickly transform into alternate forms of iron sulfide products including amorphous ferrous sulfide, cubic ferrous sulfide, smythite, greigte, pyrrhotite, troilite and pyrite. Mackinawite often forms at lower temperatures $\left(\mathrm{T}<135^{\circ} \mathrm{C}\right)$, but at the elevated SAGD temperatures can rapidly and iso-chemically transition into alternate amorphous iron sulfide products including pyrrhotite as was 
found in the testing. It is important to differentiate the type of scale formed as it can influence the corrosion kinetics and rate of corrosion. The following section further discusses this mechanism, factors affecting it, and its implications in SAGD.

\subsection{Mechanism of hydrogen sulfide corrosion}

The probable mechanism of $\mathrm{H}_{2} \mathrm{~S}$ corrosion on steel is that of a direct solid state reaction and can be stated as follows [100, 101]:

$$
\begin{aligned}
& \mathrm{H}_{2} \mathrm{~S} \text { dissolution: } H_{2} \mathrm{~S}_{(g)} \leftrightarrow H_{2} \mathrm{~S}_{(a q)} \\
& \mathrm{H}_{2} \mathrm{~S} \text { dissociation: } H_{2} \mathrm{~S}_{(a q)} \leftrightarrow H_{(a q)}^{+}+H S_{(a q)}^{-} \\
& \text {HS'dissociation: } H S_{(a q)}^{-} \leftrightarrow H_{(a q)}^{+}+S_{(a q)}^{2-} \\
& \mathrm{H}_{2} \mathrm{~S} \text { reduction: } 2 \mathrm{H}_{2} \mathrm{~S}_{(a q)}+2 e^{-} \rightarrow \mathrm{H}_{2(g)}+2 \mathrm{HS}_{(a q)}^{-} \\
& \text {FeS formation by precipitation: } \mathrm{Fe}_{(a q)}^{2+}+S_{(a q)}^{2-} \leftrightarrow F e S_{(s)} \\
& \text { FeS formation by solid state reaction: } \mathrm{Fe}_{(s)}+\mathrm{H}_{2} \mathrm{~S}_{(a q)} \rightarrow \mathrm{FeS}_{(s)}+\mathrm{H}_{2(g)}
\end{aligned}
$$

Here the $\mathrm{H}_{2} \mathrm{~S}$ is initially adsorbed onto the steel to quickly form a thin $(<<1 \mu \mathrm{m})$, dense, and adhesive iron sulfide film. At lower temperatures $\left(\sim 135^{\circ} \mathrm{C}\right)$ the film is likely that of mackinawite $[41,100]$. At elevated temperatures between $170^{\circ} \mathrm{C}$ to $200^{\circ} \mathrm{C}$ mackinawite will transition into alternate iron sulfide products including pyrrhotite [41]. Past failure analysis and this research have consistently identified pyrrhotite as being a main corrosion products present.

This initial scale formed acts as a diffusion barrier which quickly reduces corrosion rates, but does not completely stop it. Corrosion and scale formation continues 
and as it precedes internal stresses and variations in the in the molar volume ratio of the film to the iron initiates and progresses film micro cracking. As this film breaks off, it continues to re-form. The outer scale is less dense, porous and adhesive than the base layer and continues the formation, growth, and cracking process.

Because of the rapid formation of a protective, passive, film the rate of corrosion is limited to how quickly corrosive species can diffuse through it. Meaning it is influenced mainly by a mass flux transfer control process. The mass flux is controlled by the inner and outer pyrrhotite film layers as well as the liquid boundary layer as follows [43, 72]:

$$
\begin{aligned}
& {\text { Flux } \mathrm{H}_{2} \mathrm{~S}}=k_{m\left(\mathrm{H}_{\mathrm{S}} \mathrm{S}\right)}\left(C_{\left(\mathrm{H}_{2} \mathrm{~S}\right)}-C_{o\left(\mathrm{H}_{2} \mathrm{~S}\right)}\right) \\
& {\text { Flux } \mathrm{H}_{2} \mathrm{~S}}=\frac{D_{\left(\mathrm{H}_{\mathrm{S}} \mathrm{S}\right)} \varepsilon \varphi}{\delta_{\mathrm{OS}}}\left(C_{o\left(\mathrm{H}_{2} \mathrm{~S}\right)}-C_{i\left(\mathrm{H}_{2} \mathrm{~S}\right)}\right) \\
& {\text { Flux } \mathrm{H}_{2} \mathrm{~S}}=A_{\mathrm{H}_{2} \mathrm{~S}} \ln \left(\frac{C_{i\left(\mathrm{H}_{2} \mathrm{~S}\right)}}{C_{S\left(\mathrm{H}_{2} \mathrm{~S}\right)}}\right)
\end{aligned}
$$

The process of continued film cracking and re-growth is a steady state one. For that reason the corrosion rate can be estimated by equating these equations to give the final expression $[43,72]$ :

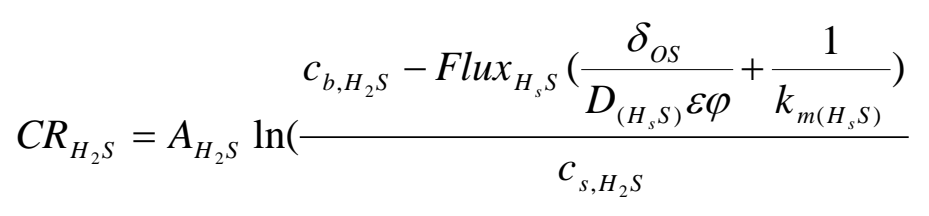

Where:

$C R_{\mathrm{H}_{2} \mathrm{~S}}:$ Corrosion rate as $\mathrm{mol} / \mathrm{m}^{2} \mathrm{~s}$

$k_{m\left(H_{s} S\right)}$ : Mass transfer coefficient of $\mathrm{H}_{2} \mathrm{~S}$ in liquid boundary layer in m/s 
$D_{\left(H_{s} S\right)}$ : Diffusion transfer coefficient of $\mathrm{H}_{2} \mathrm{~S}$ in water

$\varepsilon \varphi$ : Porosity and tortuosity of outer film

$\delta_{O S}:$ Outer film thickness, $\mathrm{m}$

$c_{b, H_{2} S}, c_{s, H_{2} S}: \mathrm{H}_{2} \mathrm{~S}$ concentrations in the bulk solution and locally at the steels surface

respectively, $\mathrm{mol} / \mathrm{m}^{3}$

A difference between the corrosion mechanisms in an $\mathrm{H}_{2} \mathrm{~S}$ containing system which does not have $\mathrm{CO}_{2}$ and the ones found in SAGD which do have $\mathrm{CO}_{2}$ is that additional bulk fluid chemical reactions occur, these include [102]:

The dissociation of dissolved $\mathrm{H}_{2} \mathrm{~S}$ :

$$
\mathrm{H}_{2} \mathrm{~S} \rightarrow \mathrm{H}^{+}+\mathrm{HS}^{-}
$$

With solubility product:

$$
K_{H_{2} S}=\frac{\left[H^{+}\right]\left[H S^{-}\right]}{\left[H_{2} S\right]}
$$

The dissociation of $\mathrm{HS}^{-}$ions:

$$
H S^{-} \rightarrow H^{+}+S^{2-}
$$

With solubility product:

$$
K_{H S^{-}}=\frac{\left[H^{+}\right]\left[S^{2-}\right]}{\left[H S^{-}\right]}
$$

Calculating the solubility products shows that $\mathrm{H}_{2} \mathrm{~S}$ gas is approximately 3 times more soluble than $\mathrm{CO}_{2}$ gas. The acid created by the dissociation of $\mathrm{H}_{2} \mathrm{~S}$ is also about 3 
times weaker than carbonic acid. Therefore the effects of each gas on the solutions $\mathrm{pH}$ are similar.

\subsection{Factors which affect the $\mathrm{H}_{2} \mathrm{~S}$ corrosion mechanism}

The research and literature review completed indicate that several factors can affect the corrosion rate of steels when dominated by aqueous $\mathrm{H}_{2} \mathrm{~S}$ corrosion. These include fluid composition and flow rate, temperature, $\mathrm{H}_{2} \mathrm{~S}$ activity, $\mathrm{pH}$, and $\mathrm{H}_{2} \mathrm{~S}$ concentration.

\subsubsection{The effect of flow rate and fluid composition}

Literature and field studies have shown that flow rate, and therefore fluid composition, can play a role in corrosion rates. The annular space in a production wells is a low flow environment where fluid phase separation takes place whereas inside the production tubing where emulsified fluids continually flow through it. The continual flow fluid and partitioning of aqueous $\mathrm{H}_{2} \mathrm{~S}$ into the oil phase and scale formation all appear to limit and prevent corrosion from occurring [98]. To date no severe corrosion has been found on the internal surfaces of the production tubing. The same tubing lines have experienced corrosion on the external surfaces. Because of the fluid composition variation, different corrosion rates have been found at different well locations. Regardless of material, uniform corrosion rates were highest at the lower well elevations (closer to the ESP) and increased as the fluid transitions from an emulsion, to being water at the top of the well before separating into produced gases released form the liquids. The mechanism of aqueous $\mathrm{H}_{2} \mathrm{~S}$ corrosion does not appear to change as iron sulfide products have been found at all well locations. Research, past failure analysis, and XRD analysis 
have shown the presence of pyrrhotite, troilite, and pyrite, at all well depths. Although pyrrhotite was not present on the top coupons in this research, past failure analysis and XRD results indicated that pyrrhotite and other corrosion products can be expected at all well elevations in the presence of steel.

\subsubsection{The effect of $\mathrm{H}_{2} \mathrm{~S}$ concentration}

$\mathrm{H}_{2} \mathrm{~S}$ concentration plays a significant role in corrosion rates due to the inability for a dense iron sulfide scales to form at high concentrations. Higher $\mathrm{H}_{2} \mathrm{~S}$ content leads to the formation of a loose and easily removed film [103]. Also, the concentration and relative partial pressure of $\mathrm{H}_{2} \mathrm{~S}$ compared to $\mathrm{CO}_{2}$ will dictate the active corrosion mechanism. This research and sampling has shown that concentrations of $\mathrm{H}_{2} \mathrm{~S}$ are high enough to have aqueous $\mathrm{H}_{2} \mathrm{~S}$ corrosion be the dominating mechanism and that often a stable and protective iron sulfide scale is able to form. Past failure analysis where siderite and magnetite have been identified is likely due to the partial pressure ratio $\mathrm{CO}_{2} / \mathrm{H}_{2} \mathrm{~S}$ to be in the transitional mechanistic zone, not a fully dominating $\mathrm{H}_{2} \mathrm{~S}$ zone. Further sampling should be done to confirm this.

\subsubsection{The effect of temperature}

Research has shown that at lower temperatures (less than $\sim 60^{\circ} \mathrm{C}$ ) that temperature can play in important role in increasing and decreasing $\mathrm{H}_{2} \mathrm{~S}$ corrosion rates due to improved hydrogen diffusion rates. But that above $\sim 40-60^{\circ} \mathrm{C}$ the effects of temperature are less pronounced. Temperature also appears to impact the type of FeS scale formed, not whether or not a passive scale will form [41]. Some iron sulfide scales 
have shown to display improved protective properties, but to no great extent. All are dense and adhere to steel [50, 81, 99].

Although the effects of aqueous $\mathrm{H}_{2} \mathrm{~S}$ corrosion does not appear to be affected greatly by temperature under SAGD conditions, should the ratio of $\mathrm{CO}_{2} / \mathrm{H}_{2} \mathrm{~S}$ begin to favor the corrosion kinetics for $\mathrm{CO}_{2}$ corrosion to dominate it is known that $\mathrm{CO}_{2}$ corrosion is highly dependent on temperature. At a temperature greater than $\sim 60^{\circ} \mathrm{C}$ a highly passive iron carbonate scale forms to reduce corrosion rates.

In this research temperatures remained well above $150^{\circ} \mathrm{C}$ for most of the testing period in the well at the liquid level top. Temperatures at the ESP remained above $200^{\circ} \mathrm{C}$ and at times up to $220^{\circ} \mathrm{C}$. This research confirms that at temperatures between $150-220^{\circ} \mathrm{C}$ similar scales will form, likely that of pyrrhotite. As mentioned, past failure analysis has shown iron sulfide scales to be present at higher well elevations and not just silicate scales.

\subsubsection{The effect of $\mathrm{pH}$}

Literature review has shown corrosion rates to be highly dependent on the solutions $\mathrm{pH}$ [102]. At lower $\mathrm{pH}$ values FeS is not as likely to precipitate to form a scale due the high solubility of iron causing continual corrosion to occur at high rates. At slightly higher $\mathrm{pH}$ values, between $\mathrm{pH} \sim 3-5$, the iron sulfide films can form and become stable. $\mathrm{pH}$ and $\mathrm{H}_{2} \mathrm{~S}$ partial pressure are often used when selecting materials for sour service applications [44].

Produced fluid analysis from SAGD wells has indicated $\mathrm{pH}$ values in the 2-5.5 range. Autoclave testing on the $1018 \mathrm{CS}$, J-55, and TN-55TH materials show the likely 
dependence of corrosion rates on $\mathrm{pH}$ based on the LPR trends observed. Testing at $\mathrm{pH}$

4.36 showed an increasing corrosion rate trend before corrosion rates stabilized, compared to the decreasing corrosion rate trend at pH 5.5 levels for the 1018 carbon steel. This indicates a difference in how the iron sulfide scales form in varied conditions before eventually stabilizing at similar rates.

Field test results also confirm this effect based on the "low" rates of corrosion found on all coupons installed and pitting corrosion occurring at higher coupon locations as well as the increase in corrosion rates at the top clamp location. At lower well elevations where an emulsion and oil are present the partitioning of the gases into an oil phase will lead to increased $\mathrm{pH}$ values and aid in the formation of a passive scale, as $\mathrm{XRD}$ results confirm. Moving up the well and with $\mathrm{pH}$ decreasing, as gases are released from the oil phase, less corrosion product was noted. An increase in corrosion rates may be expected due to the reduction in $\mathrm{pH}$, but it is likely that the more dynamic conditions at the lower joint 2 clamp coupons, closer to the ESP, delay the scales rate of formation. At the higher joint 25 clamp the increased acidic gas concentration decreases the $\mathrm{pH}$ to a point where the reduced $\mathrm{pH}$ and high rate of iron solubility prevent a passive FeS scale from forming.

\subsection{Implications of mechanistic research}

The implication of this mechanistic research and finding aqueous $\mathrm{H}_{2} \mathrm{~S}$ corrosion to be the dominating mechanism are as follows:

- Promoting the initial solid state reaction and formation of the initial iron sulfide scale can help to protect the base metal during longer term operation. Ensuring 
that this scale is dense and non-porous will limit the inwards flux of fluids or other impurities which can promote further corrosion, although still reduced.

- When both $\mathrm{CO}_{2}$ and $\mathrm{H}_{2} \mathrm{~S}$ are present, ensuring that the partial pressure ratio of $\mathrm{CO}_{2} / \mathrm{H}_{2} \mathrm{~S}$ is higher enough for only iron carbonate scales to form, or low enough that only iron sulfide scales form is important. Avoiding the transitional area where both iron carbonate and iron sulfide scales are present is important as impurities can prevent either scale from proper adhesion and protection.

- Material selection considerations should also be made as some materials are more susceptible to aqueous $\mathrm{H}_{2} \mathrm{~S}$ corrosion than others. Although all materials tested were affected by corrosion, L-80 proved to be susceptible to pitting corrosion while others did not. This is concerning due to the difficulty in detecting pitting corrosion and how it often leads to sudden failures. Reviewing and selecting materials being used at the liquid level in the well should be considered. Evaluate and select materials which are less susceptible to pitting corrosion caused by aqueous $\mathrm{H}_{2} \mathrm{~S}$.

- Also, given the dependence of aqueous $\mathrm{H}_{2} \mathrm{~S}$ corrosion on $\mathrm{pH}$, inhibition or scavenging should be considered to ensure the systems $\mathrm{pH}$ remains in a range of 3-5. Evaluating other methods to control the systems $\mathrm{pH}$ should also be considered.

- Literature review and failure analysis have shown that aqueous acidic gas corrosion can be prevented/reduced in the conditions present inside the production tubing lines where a continually flowing emulsion is present. This being due to the formation of a protective scale, oil wetting surfaces, as well as the partitioning 
of the gases from the aqueous phase into the oil phase. Although difficult in operation, considerations should be made to either promote the formation and flow of an emulsion from the annular space, or to re-designing well as to not have stagnant fluids present in separated phases. 


\section{Chapter Six: Conclusions and recommendations}

\subsection{Conclusions}

The laboratory evidence and field testing results have led to the following conclusions:

- Aqueous $\mathrm{H}_{2} \mathrm{~S}$ corrosion is the dominating corrosion mechanism

- "Low" corrosion rates can be expected due to the formation of pyrrhotite, possibly other FeS scales, which prevent increasing corrosion rates

- Stellite-6 HF material should replace the Deloro-40 HF overlay

- The standard tubular materials J-55, K-55, and TN-55TH coupons consistently showed the highest corrosion rates in both the lab and field testing, up to 0.46 $\mathrm{mm} / \mathrm{y}$ and $0.0282 \mathrm{~mm} / \mathrm{y}$ respectively

- Galvanic testing in both the field and lab showed only a slight increase in corrosion rates

- Uniform corrosion rates generally decreased from the bottom coupons in the well to the top on all materials tested

o At and above the fluid level general and pitting corrosion rates can be expected to increase and is likely due to the combination of increased acidic gas concentrations, water and vapor condensates, and the presence of galvanic/creviced conditions

- Corrosion product compounds and their relative concentrations changed clearly with well depth 


\subsection{Recommendations for industry and future work}

Based on the findings of this research the following recommendations are made.

- Design further laboratory tests to include oil for 3-phase fluid testing, oil + water + gas, with silicate scales present to coat the sample surfaces.

- Designing test loops and autoclave setups for testing at higher temperatures ( $200^{\circ} \mathrm{C}$ ), and testing for longer durations of 14 to 21 days.

- Complete further autoclave testing on a third material, tungsten carbide HF overlay. This material has been proposed for use by different wellhead and valve suppliers but has not yet been tried in SAGD like conditions.

- Complete CPP and PP tests on L-80 materials to better understand their pitting characteristics and tendencies in the SAGD environments.

- Further research on how aqueous gas concentrations and pH change when partitioning into the oil phase occurs and evaluate changes at different well elevations.

- Comparing solubility of FeS and silicate scales to better understand which scale will preferentially form in SAGD conditions and what can control it.

- Further review and testing of the corrosion inhibiting effects of silicate scales compared to iron sulfide scales. 


\section{References}

1. Mining versus in-situ: How energy companies are shifting their priorities. July 18, 2017 [cited 2017 Jan 10, 2017]; Oil Sands Description]. Available from: http://www.oilsandsmagazine.com/news/2016/7/18/mining-versus-in-situ-howenergy-companies-are-shifting-their-priorities.

2. In Situ Production Information. 2017 [cited 2017 Feb 12, 2016]; In-Situ Oil and Gas Description]. Available from: http://www.suncor.com/about-us/oil-sands/insitu.

3. Hoffmann, G.G. and T. David, Aquathermolysis of Organic Compounds in the Presence of Hydrogen Sulfate. German Petroleum Institute: Walther-NmSt-Str. 7, Clausthal-Zellerfeld, G-38678, Germany.

4. Thimm, H.F., Aquathermolysis and Sources of Produced Gases in SAGD in SPE Heavy Oil Conference. 2014, SPE International: Calgary Alberta, Canada.

5. Tenaris Steel Grades, Tenaris, Editor. 2017, Tenaris.

6. $\quad$ Stellite-6-Datasheet, Excor, Editor. 2017, Excor.

7. Pehlke, T., Field Installed Corrosion Coupon Data Sheet. 2016: Calgary Alberta.

8. Laser Cladding with Stellite Alloys Technical Detail, Kennametal, Editor. 2012, Kennametal: Goshen, Indiana.

9. Suncor FIREBAG 2014-02-17 4P1 Gas Sample. 2014, MAXXAM Analytics.

10. Suncor Firebag SAGD 3P1 Produced Water Sample. 2013, MAXXAM Analytics.

11. Koch, G., et al., NACE IMPACT: International Measures of Prevention, Application, and Economics of Corrosion Technologies Study. 2016, NACE International: Houston, Texas, USA.

12. Well Integrity in Drilling and Well Operations, in NORSOK Standards. 2004, NORSOK Standards: Strandveien, Norway.

13. Daviesa, R.J., et al., Oil and gas wells and their integrity: Implications for shale and unconventional resource exploitation. ScienceDirect, 2014. 56(September 2014): p. 239-254.

14. Jackson, R.B. The integrity of oil and gas wells. Proc Natl Acad Sci U S A 2014 [cited 2016 March 18]; Available from:

https://www.ncbi.nlm.nih.gov/pmc/articles/PMC4121783/.

15. Brondel, D., et al., Corrosion in the Oil Industry. 1994, Schlumberger.

16. Droffelaar, H.V. and J.T.N. Atkinson, Corrosion and its Control: An Introduction to the subject. Vol. 2. 1995, Houston Texas: NACE International.

17. Hornsby, F., Suncor Firebag P7P13 ESP Cannon Clamp Failure Report. 2013.

18. Why is the ocean salty. 2014 [cited 2017 April 3]; Available from: http://oceanservice.noaa.gov/facts/whysalty.html.

19. Eight Forms of Corrosion. [cited 2016 Nov 2016]; 1:[Accepted forms of corrosion]. Available from: http://corrosion-doctors.org/CorrosionHistory/Eight.htm.

20. Dealloying (selective leaching). 2017 [cited 2016 Nov 13]; Available from: https://www.nace.org/Dealloying/.

21. Anodic protection, in Wikimedia. 2016, Wikimedia Foundation, Inc.

22. Corrosion Glossary - A. [cited 2016 Nov 15]; Available from: http://corrosiondoctors.org/GlossaryLetters/Glossary-A.htm. 
23. Anodic Protection. [cited 2016 Nov 18]; Definition of AP]. Available from: https://www.corrosionpedia.com/definition/97/anodic-protection.

24. Kermani, M.B. and A. Morshed, Carbon Dioxide Corrosion in Oil and Gas Production-A Compendium. NACE CORROSION 2003, 2003. 59(8): p. 659683.

25. Ansarizadeh, M., et al., Carbon Dioxide - Challenges and Opportunities. Oilfield Review, 2015. 27(2).

26. Choi, Y.-S., et al., Wellbore integrity and corrosion of carbon steel in CO2 geologic storage environments: A literature review. International Journal of Greenhouse Gas Control, 2012(16): p. 70-77.

27. Nyborg, R. and A. Dugstad, Understanding and Prediction of Mesa Corrosion Attack, in NACE CORROSION 2003. 2003, NACE International: San Diego, California.

28. C. De Waard, D.E.M., Carbonic Acid Corrosion of Steel. CORROSION, 1974. 31(5): p. 177-181.

29. Nyborg, R., NACE 10371: CO2 Corrosion Models for Oil and Gas Production Systems, in NACE CORROSION 2010. 2010, NACE International: Houston, Texas.

30. Cheng, F., Modeling and Prediction of Corrosion of Steel Tubulars in SAGD/CO2 Co-injection and Production Systems. 2014: Calgary, Alberta Canada.

31. Allen, T. and A. Roberts, Production Operations: Well Completions, Workover and Stimulation. PetroSkills, 2012. 2(5).

32. Tanupabrungsun, T., et al., Construction and Verification of Pourbaix Diagrams for CO2 Corrosion of Mild Steel Valid up to 250C, in NACE CORROSION 2012. 2012, NACE International: Houston, TX.

33. Bonab, M.A.M., Mechanism of Failure by Hydrogen-Induced Cracking, in Department of Mechanical Engineering. 2015, University of Saskatchewan: Saskatoon.

34. Ahmad, Z., Principles of Corrosion Engineering and Corrosion Control. 2006: Elsevier Ltd. 672.

35. Kvarekval, J., Morphology of Localized Corrosion Attacks in Sour Environments, in NACE CORROSION 2007. 2007, NACE International: Nashville, Tennessee.

36. Bonis, M., et al., Weight loss corrosion with H2S Using past operations for designing future facilities, in NACE CORROSION 2006. 2006, NACE International: San Diego, California.

37. Smith, S.N. and M.W. Joosten, Corrosion of Carbon Steel by H2S in CO2 Containing Oilfield Environments - 10 Year Update, in NACE CORROSION 2015, N. International, Editor. 2015, NACE International: Houston, Texas.

38. Eden, B., P.J. Laycock, and M. Fielder, Oilfield Reservoir Souring. 1993.

39. Tuttle, R.N. and R.D. Kane, H2S Corrosion in Oil and Gas Production - A Compilation of Classic Papers. 1981: NACE International.

40. Hausler, R.H., Contribution to the Understanding of H2S Corrosion, in NACE CORROSION 2004. 2004, NACE International: New Orleans, Louisiana.

41. Smith, S., B. Brown, and W. Sun, Corrosion at Higher H2S Concentrations and Moderate Temperatures, in NACE CORROSION 2011. 2011, NACE International: Houston, Texas. 
42. Smith, S.N. and J.L. Pacheco, Prediction of Corrosion in Slightly Sour Environments, in NACE CORROSION 2002. 2002, NACE International: Denver, Colorado.

43. Nešić, S., et al., A New Updated Model of CO2/H2S Corrosion in Multiphase Flow, in NACE CORROSION 2008. 2008, NACE International: New Orleans, Louisiana.

44. Society, N.I.C., NACE MR0175/ISO 15156-1: Petroleum and Natural Gas Industries - Materials for use in H2S Containing Environments in Oil and Gas Production, in General principles for selection of cracking-resistant materials. 2001, NACE International: Houston, Texas, USA.

45. Ashworth, V., et al. A Short Introduction to Corrosion and its Control Corrosion of Metals and its Prevention.

46. Qi, Y., et al., Effect of Temperature on the Corrosion Behavior of Carbon Steel in Hydrogen Sulphide Environments International Journal of Electrochemical Science, 2014. 6.

47. Smith, S.N. and M.W. Joosten, Corrosion of Carbon Steel by H2S in $\mathrm{CO} 2$ Containing Oilfield Environments, in NACE CORROSION 2006. 2006, NACE International: San Diego, California.

48. Brown, B. and S. Nesic, Aspects of Localized Corrosion in an H2S/CO2 Environment, in NACE CORROSION 2012. 2012, NACE International: Salt Lake City, Utah.

49. Lee, K.-L. and S. Nesic, EIS Investigation on the Electrochemistry of CO2/H2S Corrosion, in NACE CORROSION 2004. 2004: New Orleans, Louisiana.

50. Sun, W., S. Nesic, and S. Papavinasam, Kinetics of Iron Sulfide and Mixed Iron Sulfide/Carbonate Scale Precipitation in CO2/H2S Corrosion, in NACE CORROSION 2006. 2006, NACE International: San Diego, California.

51. Choi, Y.-S., S. Nesic, and S. Ling, Effect of H2S on the CO2 Corrosion of Carbon Steel in Acidic Solutions. Electrochimica Acta, 2011. 56(4): p. 1752-1760.

52. Svenningsen, G., A. Palencsár, and J. Kvarekvå, Investigation of Iron Sulfide Surface Layer Growth in Aqueous H2S/CO2 Environments, in NACE CORROSION 2009. 2009, NACE International: Atlanta, Georgia.

53. Dunlop, A.K., H.L. Hassel, and P.R. Rhodes, Fundamental Considerations in Sweet Gas Well Corrosion, in NACE CORROSION 1983. 1983, NACE International.

54. Smith, S.N., Discussion of the History and Relevance of the CO2/H2S Ratio, in NACE CORROSION 2011. 2011, NACE International: Houston, Texas.

55. ASTM Specifications. 2014 [cited 2017 April 10]; Available from: https://www.galvanizeit.org/specification-and-inspection/hdg-specifications/astmspecs.

56. L80 - Chemical Composition. 2017 [cited 2017; Available from: http://www.contalloy.com/products/grade/l80

57. Oven Industries Model 5C6-355 Temperature Controller Tech Sheet, O.I. Inc, Editor., Oven Industries Inc: Mechanicsburg, PA , USA.

58. Oven Industries Temp Controller TS80-237 Drawing. 2015, Oven Industries Inc.

59. PC-410D Digital Stirrer Data Sheet. 2014, Corning Incorporated 
60. Gamry Instruments Interface 1000 Potentiostat/Galvanostat/ZRA Operator's Manual 2012, Gamry Instruments, Inc.

61. ECM8 Electrochemical Multiplexer Operator's Manual I. Gamry Instruments, Editor. 2011, Gamry Instruments, Inc.

62. Properties of Polymers. 2013 [cited 2017 April 2]; PEEK Material Description]. Available from: https://www.vici-jour.com/support/mat_poly.php\#peek.

63. International, N., Preparation Installation Analysis and Interpretation of Corrosion Coupons in Oilfield Operation, in Standard Practive. 2013, NACE International: Houston, Texas.

64. Koldijk, M., Gate Valve Hard Facing Material Corrosion Performance Evaluation 2015, Cormetrics Ltd: \#4 - 2280 - 39th Avenue NE, Calgary, AB. T2E 6P7

65. Koldijk, M., Well Annulus Autoclave Corrosion Testing. 2016, Cormetrics: \#4 2280 - 39th Avenue NE, Calgary, AB.

66. Koldijk, M., Cormetrics Suncor Firebag Corrosion Testing Preliminary Report. 2016, Cormetrics Ltd: \#4 - 2280 - 39th Avenue NE, Calgary, AB Canada.

67. Krishnan, R., Analysing Corrosion Resistance of HF Alloys using EIS, in School of Engineering and Information Technology 2015, Charles Darwin University

68. Marimuthu, V., I. Dulac, and K. Kannoorpatti, Significance of Pourbaix Diagrams to Study the Corrosion Behaviour of HF Alloys based on Cr Carbides at 25C. J Bio Tribo Corros, 2016.

69. Polarisation Curves of Passivating Metals. 2016 [cited 2017 March 20]; Available from: http://www.corrosionclinic.com/corrosion_online_lectures/ME303L11.HTM.

70. Lecture 11: Electrochemical Techniques. Lecture 11: Electrochemical Techniques [cited 2017; Available from: http://www.corrosionclinic.com/corrosion_online_lectures/ME303L11.HTM.

71. Beavers, J.A., N.G. Thompson, and C.L. Durr, Unique Interpretations of Potentiodynamic Polarization Technique, in NACE CORROSION 1998. 1998, NACE International: San Diego, California.

72. Nesic, S., et al., A Free Open Source Mechanistic Model for CO2\&H2S Corrosion of Carbon Steel, in CORROSION 2009. 2009, NACE International: Atlanta Georgia.

73. Performance of Hot-Dip Galvanized Steel Products. 2010, American Galvanizers Association.

74. Yurevich, S.A. Hydrogen Sulfide Reaction with Zinc. 2017 [cited 2017 March 2]; Available from: http://chemiday.com/en/reaction/3-1-0-11310.

75. Roberge, P.R. Galvanic Series. 2017 [cited 2017 August]; Available from: http://corrosion-doctors.org/Definitions/galvanic-series.htm.

76. Zeng, K., Corrosion Coupon Holder Installation Removal Procedures - Rev 3, T.P. Alan Watt, Mark Rhodenizer Editor. 2016.

77. Thermal properties for water. 2017; Available from: http://www.engineeringtoolbox.com/water-thermal-properties-d_162.html.

78. Sutherland, K. and M. M. Density Of Steel. 2004; Available from: http://hypertextbook.com/facts/2004/KarenSutherland.shtml. 
79. Different Types of Corrosion - Recognition, Mechanisms \& Prevention: Pitting Corrosion. 1995 [cited 2016 November 12]; Available from:

http://www.corrosionclinic.com/types_of_corrosion/pitting_corrosion.htm.

80. Pitting Corrosion. [cited 2016 Nov 13]; Available from:

https://www.nace.org/Pitting-Corrosion/.

81. Brown, B. and S. Nesic, CO2 \& H2S Corrosion under Scale Forming Conditions, in NACE CORROSION 2005. 2005, NACE International: Houston, Texas.

82. Pugh, D.V., et al., Top-Of-Line Corrosion Mechanism For Sour Wet Gas Pipelines, in NACE CORROSION 2009. 2009, NACE International: Atlanta, Georgia.

83. Magnetite, in Wikimedia. 2017.

84. Blaney, L., Magnetite (Fe3O4): Properties, Synthesis, and Applications Lehigh Review, 2007. 15.

85. Hall, A.J., Pyrite-pyrrhotine redox reactions in nature to Magnetite, in MINERALOGICAL MAGAZINE. 1986, Department of Applied Geology, University of Strathclyde, Glasgow

86. Hornsby, F., 12-043 Suncor Firebag ESP Cable Failure Nov12. 2012. p. 21.

87. Quartz, in Wikimedia. 2017, Wikimedia Foundation, Inc.

88. Anthony, J.W., et al., Quartz Mineral Data Publishing, in Handbook of Mineralogy, M.S.o. America, Editor. 2001, Mineralogical Society of America: Chantilly, VA 20151-1110, USA.

89. Anthony, J.W., et al., Cristobalite Mineral Data Publishing, in Handbook of Mineralogy. Mineralogical Society of America: Chantilly, VA 20151-1110, USA.

90. Cristobalite, in Wikimedia. 2017, Wikimedia Foundation, Inc.

91. Smith, S.N. and J.L. Pacheco, Current Understanding of Corrosion Mechanisms Due to H2S in Oil and Gas Production Environments, in NACE CORROSION 2015. 2015, NACE International: Dallas, Texas.

92. XRD, SEM, and Elemental Analysis of Nine Firebag McMurray Samples for Suncor Energy. 2015, GR Petrology Consultants Inc: Calgary, Alberta, Canada.

93. Kvarekval, J., R. Nyborg, and H. Choi, Formation of Multilayer Iron Sulfide Films During High Temperature CO2/H2S Corrosion of Carbon Steel, in NACE CORROSION 2003. 2003, NACE International: San Diego, California.

94. Pyrrhotite, in Wikimedia. 2017, Wikimedia Foundation, Inc.

95. Nahnybida, C., Report on X-Ray Diffraction Patterns-Downhole Coupons, F. Hornsby, Editor. 2017, Cormetrics Ltd: Calgary, Alberta Canada.

96. Hornsby, F., FIREBAG P7P9 (14-35-094-06W4) DOWNHOLE CORROSION COUPONS 2017, Cormetrics LTD: Calgary, Alberta Canada.

97. OHAUS EP114C Electronic Balance Data Sheet. OHAUS Corperation.

98. Case, R., et al., Evaluation of Corrosivity of Produced Fluids during SAGD Operations, in NACE CORROSION 2014. 2014, NACE International: Antonio, Texas, USA.

99. Sun, W., Kinetics of FeCO3 and FeC Scale Formation in H2S/CO2 Corrosion, in Chemical and Biomolecular Engineering 2006, Ohio University. p. 226.

100. Singer, M., et al., Combined Effect of CO2, H2S and Acetic Acid on Bottom of the Line Corrosion, in CORROSION 2011. 2011, NACE International: Nashville, Tennessee. 
101. Sun, W., A.I. Marquez, and G.G. Botte, Theoretical Investigation of H2S Corrosion of Mild Steel. Ohio University Institute for Corrosion and Multiphase Technology West State Street, Athens.

102. Mythili Koteeswaran, CO2 and H2S Corrosion in Oil Pipelines, in Mathematics and Natural Science. 2010, University of Stavanger: Norway.

103. Shoesmith, D.W., et al., The Formation of Ferrous Monosulfide Polymorphs during the Corrosion of Iron by Aqueous Hydrogen Sulfide at $21^{\circ} \mathrm{C}$. Journal of The Electrochemical Society, 1980. 127(5): p. 1007-1015. 


\section{Appendix}

Sample material mechanical properties

\begin{tabular}{|l|l|l|}
\hline Material & Yield Strength (MPa) & Tensile Strength (MPa-min) \\
\hline J55 & $379-552$ & 517 \\
\hline K55 & $379-552$ & 655 \\
\hline TN55TH & $379-552$ & 655 \\
\hline L80 & $552-655$ & 655 \\
\hline
\end{tabular}

TN-55TH chemistry

\begin{tabular}{|l|c|c|c|c|c|c|c|c|c|c|c|c|c|}
\hline & $\mathrm{C}$ & $\mathrm{Mn}$ & $\mathrm{P}$ & $\mathrm{S}$ & $\mathrm{Mo}$ & $\mathrm{Cr}$ & $\mathrm{Ni}$ & $\mathrm{B}$ & $\mathrm{Nb}$ & $\mathrm{Ti}$ & $\mathrm{Al}$ & $\mathrm{Si}$ & $\mathrm{Cu}$ \\
\hline Min & - & - & - & - & - & - & - & - & - & - & 0.010 & - & - \\
\hline Max & 0.35 & 1.35 & 0.02 & 0.015 & 0.20 & 0.25 & 0.20 & 0.001 & 0.005 & 0.025 & - & 0.50 & 0.25 \\
\hline
\end{tabular}

API L-80 Type 1 chemistry

\begin{tabular}{|l|c|c|c|c|c|c|c|}
\hline & C & Mn & P & S & NI & Cu & Si \\
\hline Min & - & - & - & - & - & - & - \\
\hline Max & 0.43 & 1.90 & 0.030 & 0.030 & 0.25 & 0.35 & 0.45 \\
\hline
\end{tabular}

Stellite-6 HF chemical composition

\begin{tabular}{|l|l|l|l|l|l|}
\hline & Co & Cr & W & C & Other \\
\hline \multirow{2}{*}{ Min } & \multirow{2}{*}{ Base } & 27 & 4 & 0.9 & $\mathrm{Ni}, \mathrm{Fe}, \mathrm{Si}, \mathrm{Mn}, \mathrm{Mo}$ \\
\cline { 3 - 6 } & & 32 & 6 & 1.4 & \\
\hline
\end{tabular}

Stellite-6 HF mechanical properties

\begin{tabular}{|l|c|l|c|}
\hline & Hardness & Density & Melting Range \\
\hline Imperial & $36-45 \mathrm{HRC}$ & $0.305 \mathrm{ib} / \mathrm{in}^{3}$ & $2340-2570^{\circ} \mathrm{F}$ \\
\hline Metric & $380-490 \mathrm{HV}$ & $8.44 \mathrm{~g} / \mathrm{cm}^{3}$ & $1285-1410^{\circ} \mathrm{C}$ \\
\hline
\end{tabular}

